\title{
The effect of tert-butylhydroquinone, an Nrf2-ARE signaling pathway inducer, on oxidative stress-related neurodegeneration
}

Jiahong Sun

Follow this and additional works at: https://researchrepository.wvu.edu/etd

\section{Recommended Citation}

Sun, Jiahong, "The effect of tert-butylhydroquinone, an Nrf2-ARE signaling pathway inducer, on oxidative stress-related neurodegeneration" (2015). Graduate Theses, Dissertations, and Problem Reports. 6742. https://researchrepository.wvu.edu/etd/6742

This Dissertation is protected by copyright and/or related rights. It has been brought to you by the The Research Repository @ WVU with permission from the rights-holder(s). You are free to use this Dissertation in any way that is permitted by the copyright and related rights legislation that applies to your use. For other uses you must obtain permission from the rights-holder(s) directly, unless additional rights are indicated by a Creative Commons license in the record and/ or on the work itself. This Dissertation has been accepted for inclusion in WVU Graduate Theses, Dissertations, and Problem Reports collection by an authorized administrator of The Research Repository @ WVU.

For more information, please contact researchrepository@mail.wvu.edu. 


\title{
The effect of tert-butylhydroquinone, an Nrf2-ARE signaling pathway inducer, on oxidative stress-related neurodegeneration
}

\author{
Jiahong Sun \\ Dissertation submitted to the West Virginia University Health Science Center Neuroscience \\ Program in partial fulfillment of the requirements for the degree of
}

Doctor of Philosophy in Neuroscience

\author{
Committee: \\ James W. Simpkins, Ph.D., Chair \\ Candice Brown, Ph.D \\ Jason Huber, Ph.D \\ Rosana Schafer, Ph.D \\ Taura Barr, Ph.D
}

WVU Neuroscience Program

Morgantown, West Virginia

2015

Keywords: Stroke, oxidative stress, mitochondria, Nrf2-ARE signaling pathway

Copyright 2015 Jiahong Sun 


\begin{abstract}
The effect of tert-Butylhydroquinone, an Nrf2-ARE signaling pathway inducer, on oxidative stress-related neurodegeneration
\end{abstract}

\title{
Jiahong Sun
}

Oxidative stress is actively involved in stroke pathogenesis; however, almost all the antioxidants that have been applied into the clinical trials fail to improve ischemic stroke outcomes. We note that most drug candidates have very limited diversity of antioxidative activities. tBHQ is a food additive, which is considered to be safe for human consumption. As both an antioxidant and an Nrf2-ARE signaling pathway inducer, tBHQ can directly eliminate ROS and activates the expression of all the antioxidative genes under Nrf2-ARE regulation. My dissertation investigated the potential clinical application of tBHQ for ischemic stroke treatment by using both in vitro glutamate-induced oxidative stress models and an in vivo murine permanent middle cerebral artery occlusion model. Our study mechanistically demonstrated the protection of tBHQ against oxidative stress-induced cytotoxicity in neurons though increasing mitochondrial antioxidative capacity and preserving mitochondrial function. However, we observed paradoxical results from our in vivo study in that tBHQ increased the mortality and worsened stroke outcomes in a pMCAO model. Further, we found that tBHQ significantly suppressed mitochondrial respiration in the cerebrovascular endothelial cells, which might results in the disruption of the BBB. Overall, my research raises safety concerns related to the use of tBHQ for human consumption or a potential therapeutic treatment for stroke. 


\section{Dedication}

This effort is dedicated to the three people who have taught me the most important lessons in my life. To the memory of my father who inspires me to grow and who will always be a continual source of support; to my mother, whose unconditional love paved the path for this accomplishment; to my aunt, who gave me the thirst for new knowledge and the potential to seek it. 


\section{Acknowledgments}

I would like to thank my mentor and advisor Dr. James W. Simpkins. He gave me the freedom to do whatever I wanted, at the same time continuing to contribute valuable feedback, advice, and encouragement. His guidance, patience, and strong belief in me through the years have helped shape me into a well-prepared, independent scientist.

I would also like to thank my committee members, Dr. Taura Barr, Dr. Candice Brown, Dr. Jason Huber, Dr. Rosana Schafer for their insight and enlightenment.

Lastly, I would like to thank current and past members of the Simpkins labs for their support. 


\section{Table of Contents}

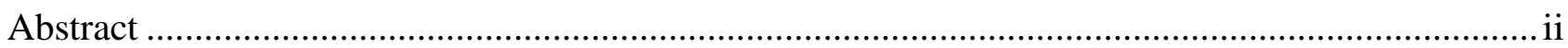

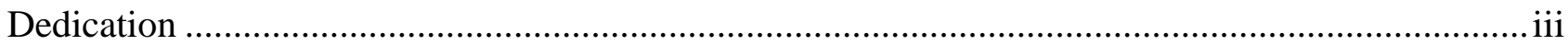

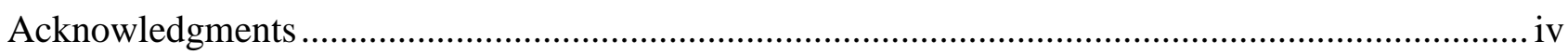

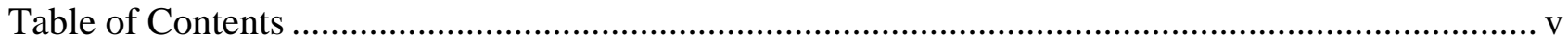

Figures and Tables ............................................................................................................ vii

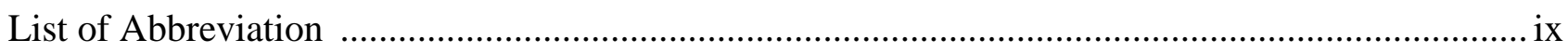

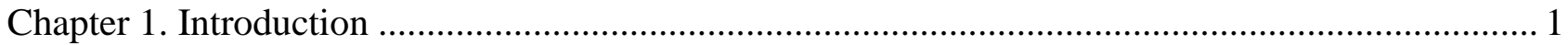

1.1. Stroke

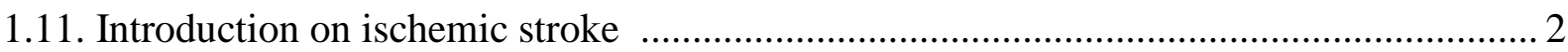

1.12. Mechanism of ischemic stroke damage …………...................................................... 2

1.2. Oxidative stress, mitochondria and neurodegenration ..................................................... 4

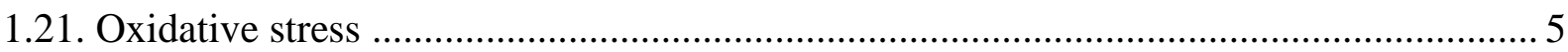

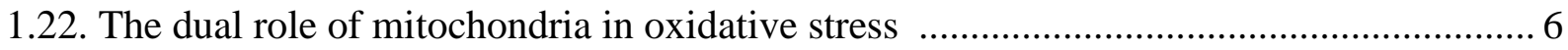

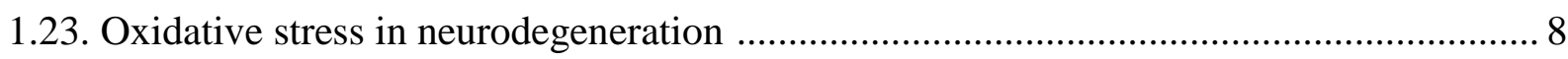

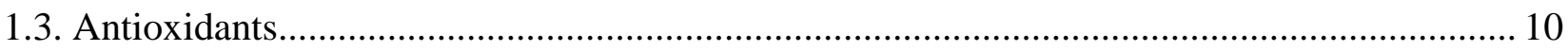

1.31. Current clinical trials of antioxidants on stroke .......................................................... 10

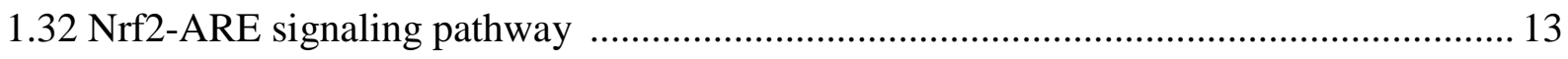

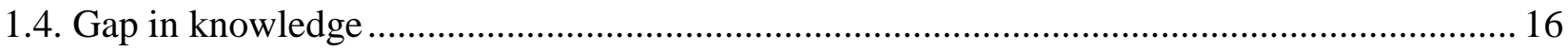

Chapter 2. tBHQ prevents mitochondrial dysfunction and neuronal cell death under glutamate-

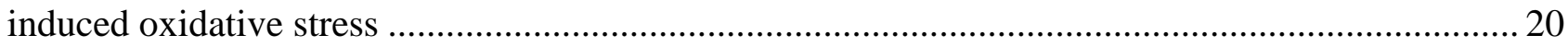

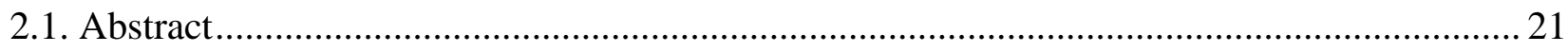

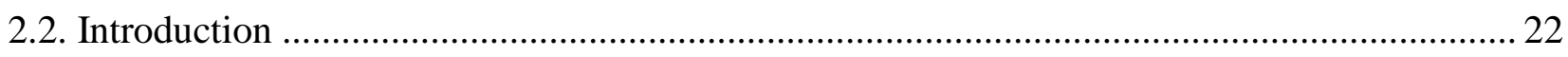

2.3. Materials and Methods …………………………......................................................... 24

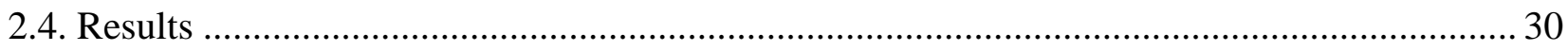

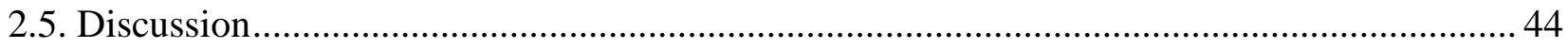

Chapter 3. tBHQ compromises survival in murine experimental stroke …………..........................52 


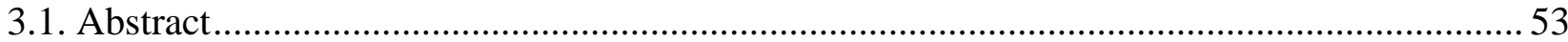

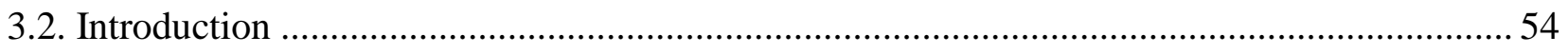

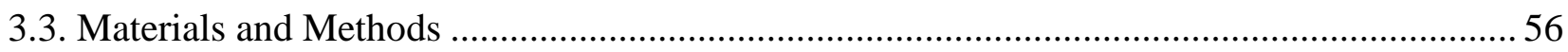

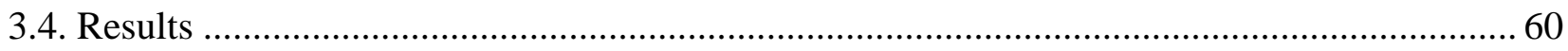

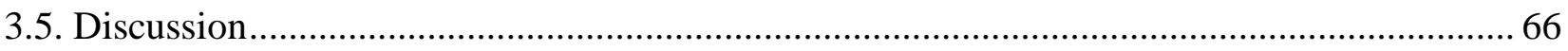

Chapter 4. Discussions and conclusions ......................................................................................... 70

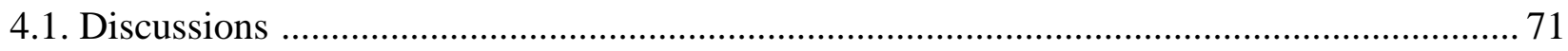

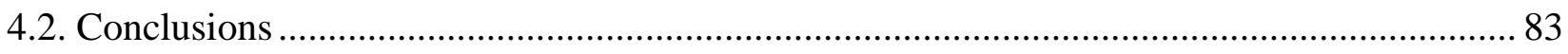

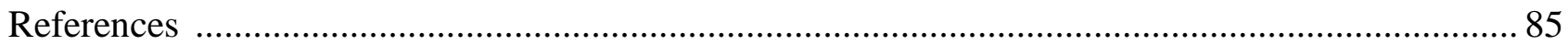




\section{Figures and Tables}

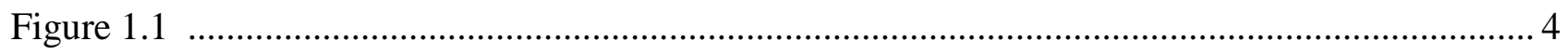

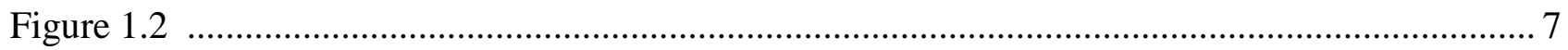

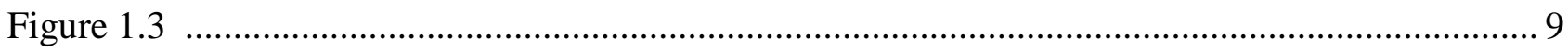

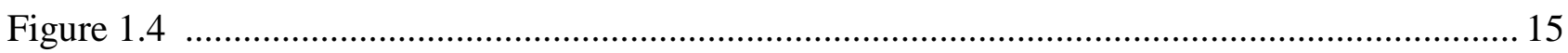

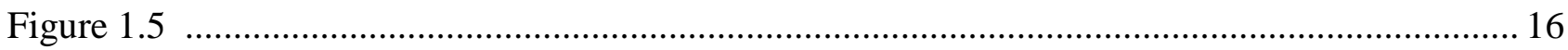

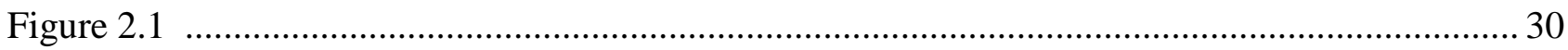

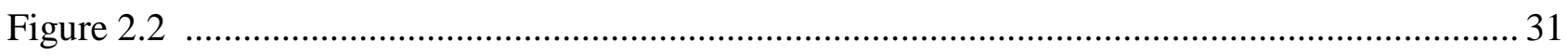

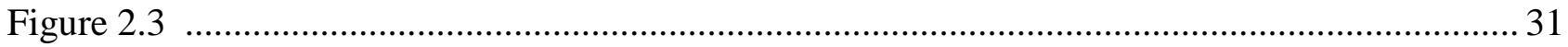

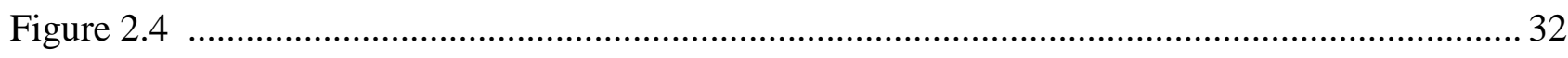

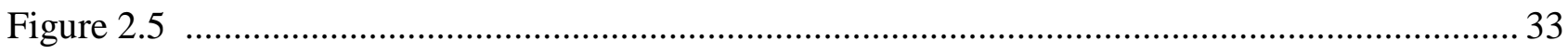

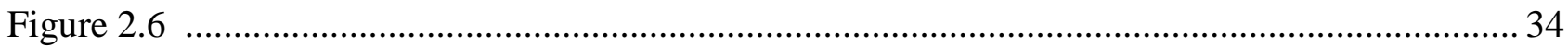

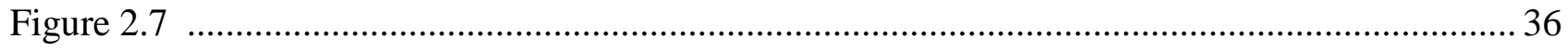

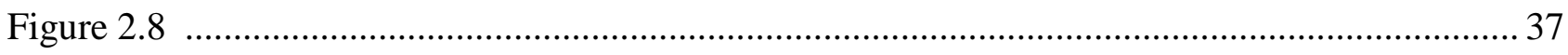

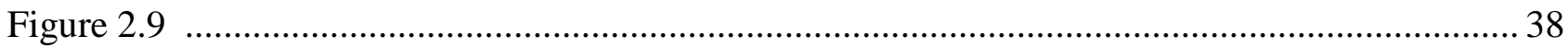

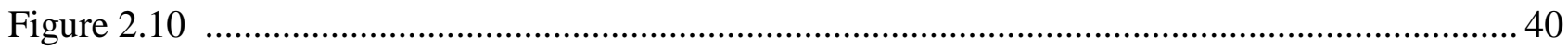

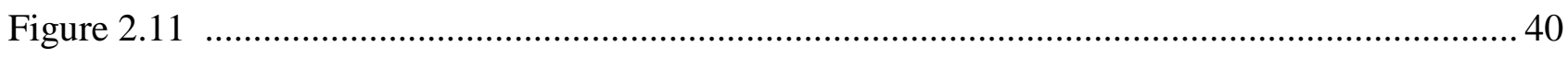

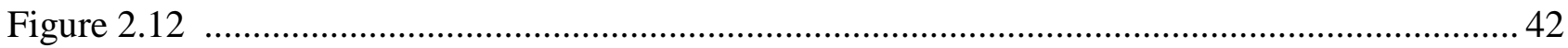

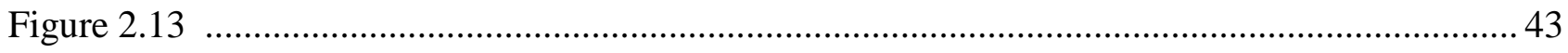

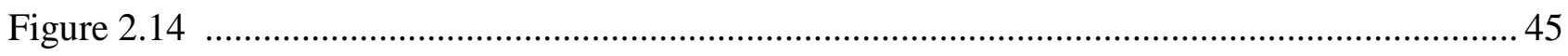

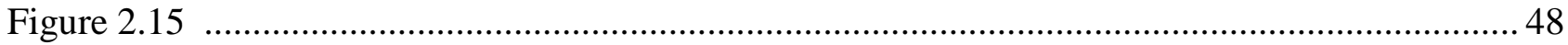

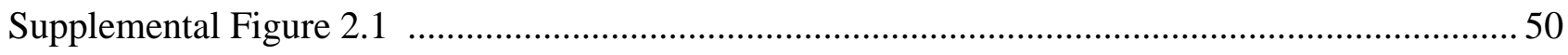

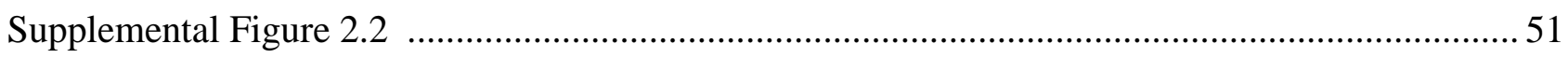

Figure 3.1 .

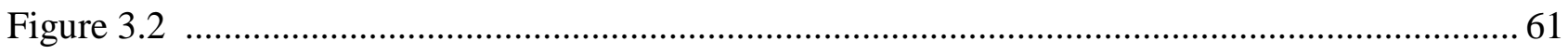

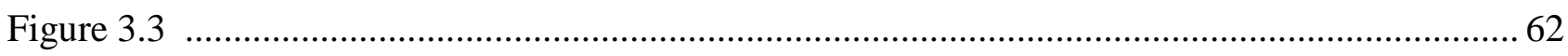

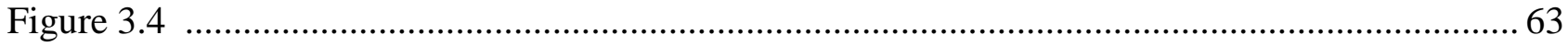

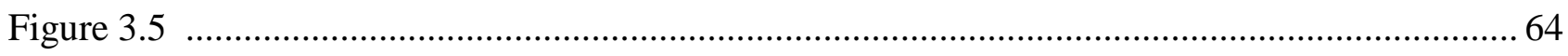




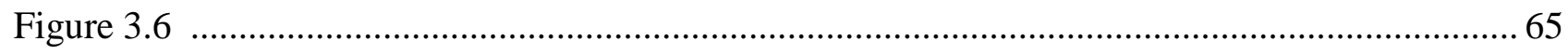

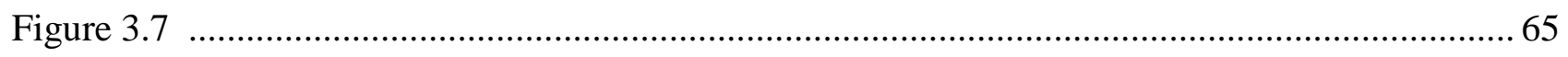

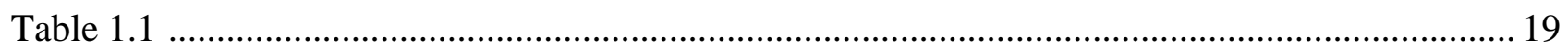

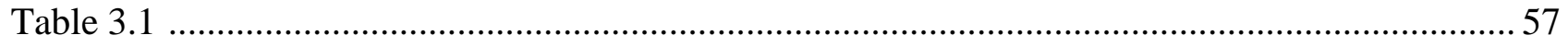




\section{List of Abbreviation}

AIF, apoptosis-inducing factor

ARE, antioxidant response element

ATP, adenosine 5'-triphosphate

BBB, blood-brain barrier

BSO, buthionine sulfoximine

CNS, central nervous system

DAPI, 4',6-diamidino-2-phenylindole

DMEM, glucose Dulbecco modified Eagle medium

ETC, electron transport chain

FACS, fluorescence-activated cell sorting

FCCP, carbonilcyanide $p$-triflouromethoxyphenylhydrazone

FRET, fluorescence resonance energy transfer

GSH, glutathione

H2DCFDA, 2',7'-dichlorodihydrofluorescein diacetate

$\mathrm{H}_{2} \mathrm{O}_{2}$, hydrogen peroxide

HBSS, Hank's Balanced Salt Solution

HDAC1, histone deacetylase 1

HO-1, heme oxygenase 1

Keap1, Kelch-like ECH-associated protein 1

LPS, lipopolysaccharide 
MFI, mean fluorescence intensity

mPTP, mitochondrial permeability transition pore

$\mathrm{NAO}$, nonylacridine orange

Nrf2, nuclear factor E2-related factor 2

$\mathrm{O}_{2} \cdot{ }^{-}$, superoxide

OCR, oxygen consumption rate

PBS, phosphate buffered saline

pMCAO, permanent middle cerebral artery occlusion

RIPA, radio-immunoprecipitation assay

ROS, reactive oxygen species

SAINT, Stroke-Acute Ischemic NXY Treatment

$\mathrm{SOD}_{2}$, superoxide dismutase 2

tBHQ, tert-butylhydroquinone

TBI, traumatic brain injury

tMCAO, transient middle cerebral artery occlusion

TMRE, tetramethylrhodamine, ethyl ester

tPA, tissue plasminogen activator

TTC, 2,3,5-triphenyltetrazolium chloride

$\Delta \Psi \mathrm{m}$, mitochondrial membrane potential 


\section{Chapter 1}

\section{Introduction and Background}




\subsection{Stroke}

\subsection{Introduction on ischemic stroke}

According to the World Health Organization, over 15 million people a year, equating to one in every 400 people, suffer from stroke worldwide (Weir \& Dennis, 1997). In the United States, approximately 800,000 people have stroke and more than 137,000 people die from a stroke each

year. These facts lead to stroke being the fifth leading cause of death and the leading cause of adult disability. The American Heart Association predicts a 5.1\% increase in stroke cases for people between 45-64 years of age by 2030 (American heart Association, 2012). Ischemic stroke accounts for approximately $80-85 \%$ of all cases, which is caused by the disruption of cerebral blood flow and lack of oxygen to the affected area due to a clot (Roger et al., 2012). Currently, the only Food and Drug Administration approved treatment for ischemic stroke is tissue plasminogen activator (tPA), which is a thrombolytic therapy to break up the clot. Properly titrated use of tPA improves clinical outcomes. However, less than $5 \%$ of patients receive tPA (Miller et al., 2011). The majority of patients are unable to receive tPA for acute ischemic stroke because they do no not reach the hospital soon enough. In addition, there is an associated risk of hemorrhagic transformation after tPA therapy, which further restricts tPA treatment (Wang et al., 2004). Of those patients presenting within the limited time window of 4.5 hours, $29-43 \%$ of patients might be excluded from tPA treatment because their symptoms are either considered too mild or are rapidly improving (Barber et al., 2001). A substantial minority of patients deemed too good for intravenous tPA are unable to be discharged home (Smith et al., 2005). Overall, the current therapeutic strategy for ischemic stroke is not optimal.

\subsection{Mechanism of ischemic damage}


Ischemic stroke due to occlusion of the cerebral artery leads to an immediate decrease of regional cerebral blood flow to the brain area supplied by that artery. The flow reduction is not homogenous throughout the ischemic territory but is maximal at its center, and this region is called the ischemic core. The region surrounding the ischemic core, in which the decrease in cerebral blood flow is less severe, is called the ischemic penumbra (Bandera et al., 2006). The term "brain ischemia" comprises both infarct core and penumbra. The penumbra includes ischemic areas that recover spontaneously as well as areas that develop to irreversible damage without effective treatment. The penumbra is the major focus of scientific research and the most clinically relevant target. The current goal of ischemic stroke therapy is to protect brain before development of irreversible damage. Rate of progression to infarction is determined by various factors, including the circulation of collateral arteries, duration of occlusion, and metabolic cellular state (Kaufmann et al., 1999). Therefore, ischemic conditions and outcomes vary from person to person, which is a substantial challenge for stroke treatment.

Energy failure is the predominant mechanism of cell death in the ischemic core; however, more complicate mechanisms are involved with ischemic damage in the ischemic penumbra (Janardhan \& Qureshi, 2004). When the cerebral blood supplement is reduced, neurons in the penumbra lose ionic balance and become depolarization due to the dysfunction of ATPasedependent ionic pumps, which further induce the synaptic release of neurotransmitter, glutamate. The accumulation of extracellular glutamate leads to over-activation of ionotropic glutamate receptors, following with an uncontrolled influx of calcium and sodium ions through the channels gated by these receptors (Lee et al., 1999). The whole progress further exacerbates intracellular ionic imbalance. An increase in calcium signaling, the universal second messenger, initiates a series of intracellular harmful events, such as activation of apoptotic enzymes, 
excessive production of oxygen radicals and impairment of mitochondrial function (Dirnagl et al., 1999). Cells compromised by energy deficits and subcellular structure damage died through necrosis or apoptosis (Fig 1.1).

Therapeutic strategies for neuroprotection are targeted at increasing the resistance of neurons to ischemia by counteracting with the mediators initiating ischemic brain damage (Graham \& Chen, 2001). Among the intracellular events induced by ischemia, over-generation of oxidative free radicals play a vital role in programmed cell death (Andersen, 2004). The elevation in lipid peroxidation levels in the circulation and the debilitated cellular antioxidant defense system are considered the direct pathological symptoms from stroke (Manzanero et al., 2013).

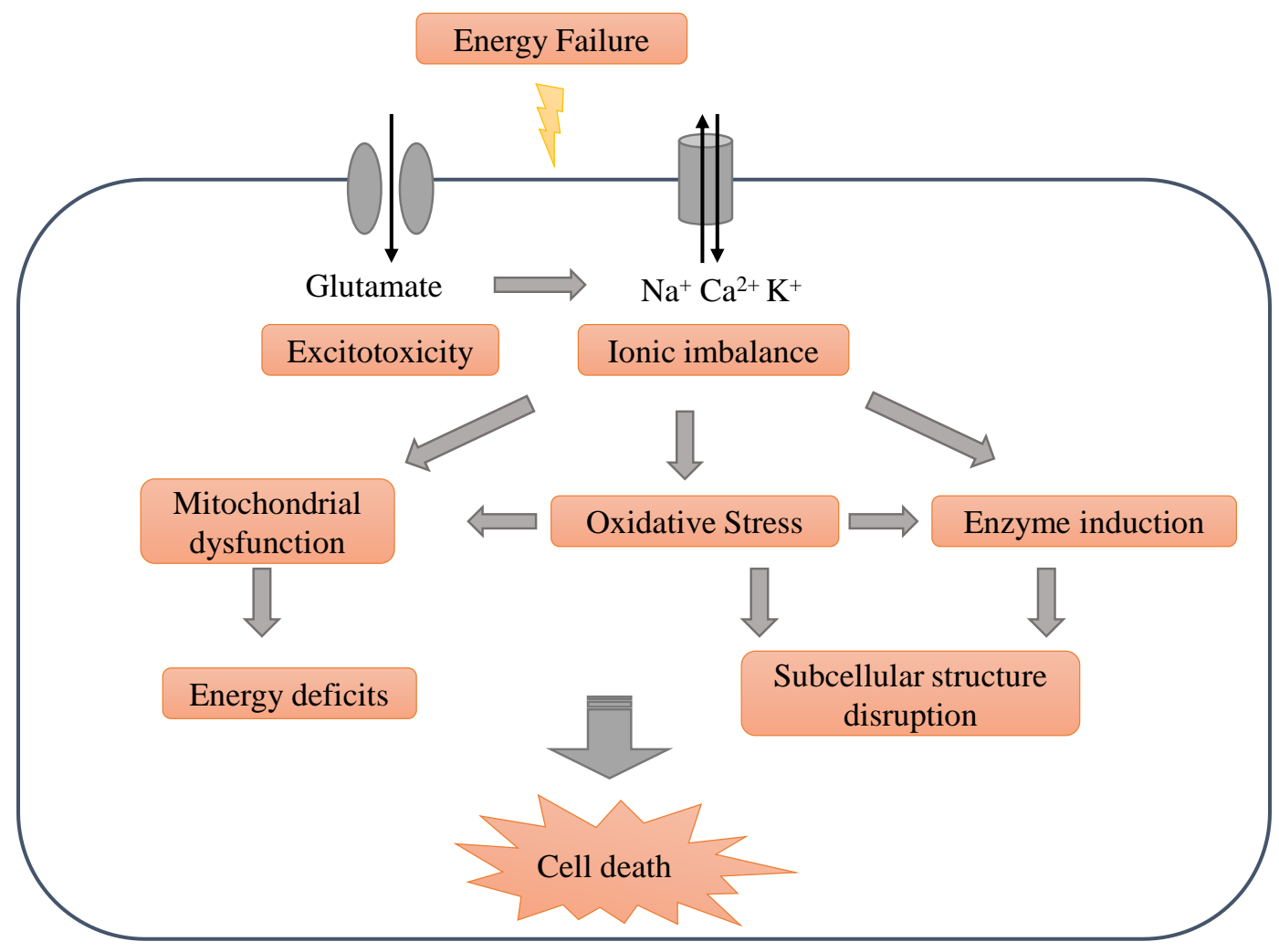

Figure 1.1 ischemic brain injury mechanisms. Abbreviations : Glutamate (Glu)

\subsection{Oxidative stress, mitochondria and neurodegeneration}




\subsection{Oxidative stress}

Humans consistently consume oxygen to supply ATP through mitochondrial oxidative phosphorylation. Reactive oxygen species (ROS) are generated as byproducts during oxygen metabolism (McCord, 2000). ROS are defined as molecular entities containing highly reactive unpaired electrons, such as superoxide, nitric oxide, hydroxyl radical and other molecular species. ROS can react with cellular components which results in detrimental effects on the physiological functions (Devasagayam et al., 2004). Most cellular ROS are generated during incomplete metabolic reduction of oxygen to water. Therefore, intracellular redox status is tightly associated with oxygen metabolism (Finkel, 2003). In-built antioxidant system of cells plays a decisive role in prevention of damage due to free radicals. In the healthy condition, there is a balance between the production of ROS and antioxidative defenses. A basal level of ROS are not immediately removed, which play an important biological role in signaling processes. However, imbalanced defense mechanism of antioxidants or overproduction of free radicals leads to oxidative stress, which induces dysfunction of subcellular organelles and even triggers cell death (Valko et al., 2007).

Even though ROS are short-living compounds, they can initiate complex chain reactions. ROS directly react with a multitude of biological target molecules, such as proteins, lipids and DNA, to produce a wide range of intracellular damage (Imlay, 2003). Oxidation of proteins can change the active sites of enzymes or the configuration of protein (Du \& Gebicki, 2004). Oxidative modification of unsaturated fatty acids lead to the production of lipid peroxides, which can disrupt membranes that are the components of all cellular organelles, such as mitochondria (Gutteridge, 1995). Oxidative damage to DNA produces strand breaks as well as many oxidized bases (Dumont \& Monari, 2015). All of oxidative modified intracellular molecules exert a 
fundamental impairment of biological function. Not only might ROS induce accidental damage to molecules, but they might also actively modulate critical subcellular organelle functions, such as endoplasmic reticulum stress and mitochondrial dysfunction (Jacobson, 1996).

1.22 The dual role of mitochondria in oxidative stress

Mitochondria are the main subcellular organelles to supply energy needed for normal physiological function. However, ROS are unavoidably generated in the electron transport chain (ETC) during normal mitochondrial respiration (Liu et al., 2002; Turrens, 2003). 2-5\% of the total oxygen consumed during mitochondrial respiration yields ROS (Cadenas \& Davies, 2000). Mitochondria contain numerous redox enzymes capable of transferring single electrons to oxygen, generating superoxide. Manganese superoxide dismutase (SOD2), the primary defense against mitochondrial superoxide, converts superoxide to hydrogen peroxide, which can further react to form the hydroxyl radical (Starkov, 2008). It is widely considered that the major portion (about $95-98 \%$ ) of the total ROS is produced during aerobic metabolism in neurons (Floyd \& Hensley, 2002). The steady state concentration of superoxide in the mitochondrial matrix is about 5- to 10-fold higher than that in the cytosolic and nuclear spaces (Kudin et al., 2004). When the amount of ROS exceeds the detoxification capacity of cells, oxidative stress is induced. As the primary site for ROS generation, mitochondria are vulnerable target of oxidative stressinduced damage (Ott et al., 2007). Other than a direct oxidative damage to mitochondrial components, ROS can also induce a detrimental effect on mitochondrial function (Figure 1.2). It is well known that mitochondrial $\mathrm{Ca}^{2+}$ uptake is important to maintain intracellular $\mathrm{Ca}^{2+}$ homeostasis (Rizzuto et al., 2012). Mitochondrial $\mathrm{Ca}^{2+}$ overload can be induced by oxidative stress (Orrenius et al., 2003; Richter \& Kass, 1991). In response to mitochondrial $\mathrm{Ca}^{2+}$ deregulation, activation of mitochondrial permeability transition pore (mPTP) occurs, which 
creates an open channel across the mitochondrial inner and outer membranes and allows a free diffusion of molecules (Mattson \& Chan, 2003). The mitochondrial membrane potential ( $\Delta \Psi \mathrm{m})$ is the result of asymmetric distribution of protons and other ions on both sides of the inner mitochondrial membrane to give an electrical gradient, which is essential for ATP production (Nicholls, 2004). Opening of the mPTP disrupts $\Delta \Psi \mathrm{m}$, which further suppresses mitochondrial respiration and causes an energy crisis (Halestrap et al., 2002). Besides metabolism, mitochondria also participate in many other intracellular events including apoptosis (Lemasters et al., 2009). When the mPTP is open, apoptotic proteins can escape from mitochondria and further execute programmed cell death (Lemasters et al., 1998). Therefore, normal mitochondria function is vital for optimal cell function and survival.

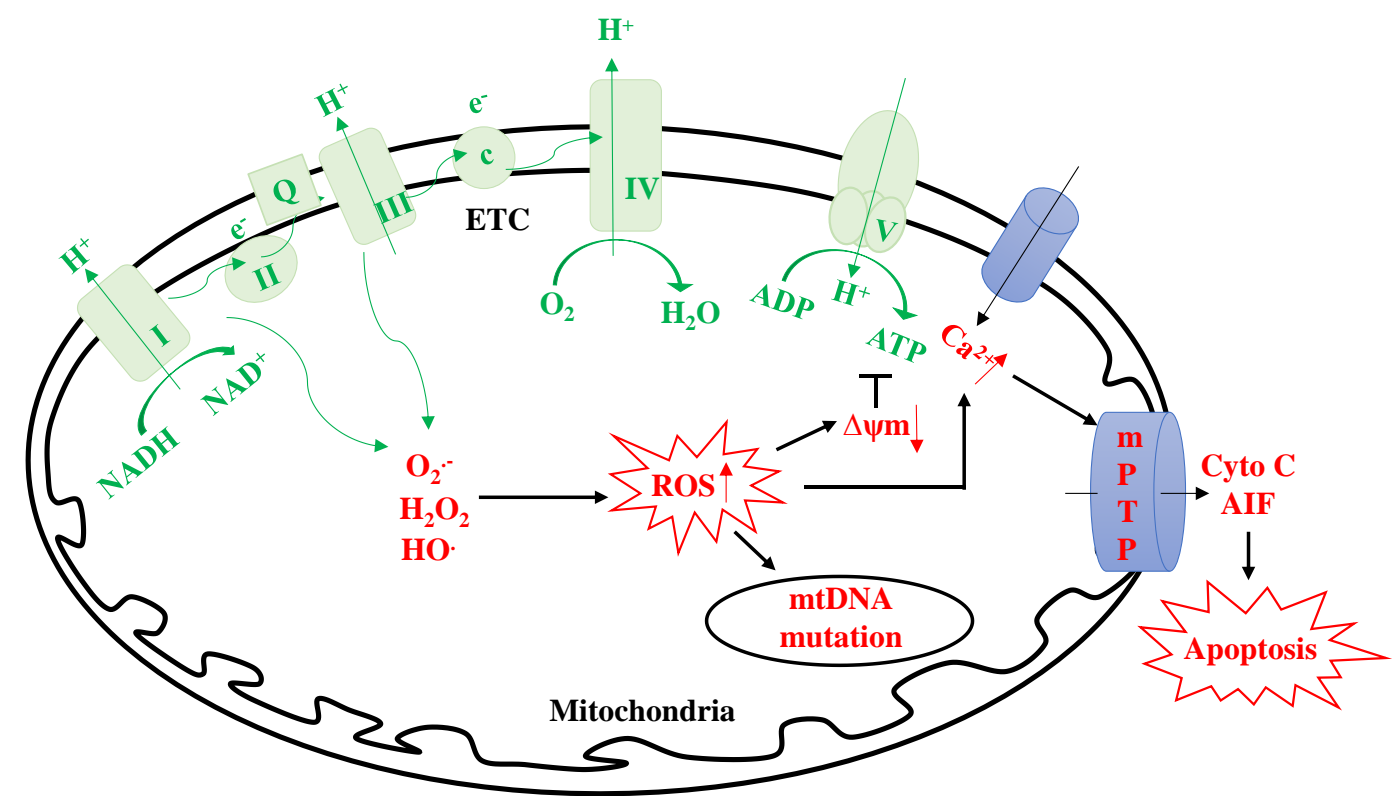

Figure 1.2 Oxidative stress-induced mitochondrial dysfunction. Abbreviations : apoptosis inducing factor (AIF), cytochrome $\mathrm{C}$ (Cyto C), electron transport chain (ETC), hydrogen peroxide $\left(\mathrm{H}_{2} \mathrm{O}_{2}\right)$, hydroxyl radical (HO), mitochondrial membrane potential $(\Delta \psi \mathrm{m})$, mitochondrial permeability transition pore (mPTP), reactive oxygen species $(\mathrm{ROS})$, superoxide $\left(\mathrm{O}_{2} \cdot^{-*}\right)$

Much evidence present in the literature demonstrates that oxidative stress-induced mitochondrial dysfunction plays a crucial role in neurodegeneration (Lin \& Beal, 2006). Neurons within the 
brain are highly vulnerable to metabolic disturbances; therefore, impairment of mitochondrial function clearly threatens the viability of neurons and further damages the function of neuronal networks. Focusing on mitochondrial function during neurodegeneration is useful for defining the pathology of neurodegenerative diseases and opening new perspectives for therapy.

\subsection{Oxidative stress is an important factor in neurodegeneration}

Several areas of study demonstrate that brain is a vulnerable target for oxidative stress. Although brain represents only $2 \%$ of body weight, it receives $20 \%$ of total oxygen consumption of the body (Raichle, 2010). The fact that energy source for normal brain function almost exclusively relied on glucose for its energy source explains why brain consumes such high level of oxygen. Since the major portion of intracellular ROS are produced during aerobic metabolism, ROS are unavoidably generated in the brain due to the high oxygen consumption in the brain (Adam-Vizi \& Chinopoulos, 2006). In addition, the brain has a high content of peroxidizable unsaturated fatty acids, which easily react with oxygen-derived free radicals, but the antioxidative protective defenses are not vigorous in the brain (Floyd \& Hensley, 2002). This makes brain sensitive to oxidative stress-induced damage. As post-mitotic cells, neurons can not be replaced after an irreversible damage. The general inability of neurons to divide explains why aging and neurodegenerative disease results in loss of brain function (Yang \& Herrup, 2007). Neurodegeneration is the umbrella term for the progressive loss of structure or function of neurons, including death of neurons and breakage or severing of axons (Su et al., 2013). Oxidative stress has become an area of intense research since extensive evidence has demonstrated that oxidative stress is responsible for the dysfunction or death of neuronal cells and contributes to disease pathogenesis. 


\section{Clinical Trials of Neuroprotectants in Acute Ischemic Stroke}

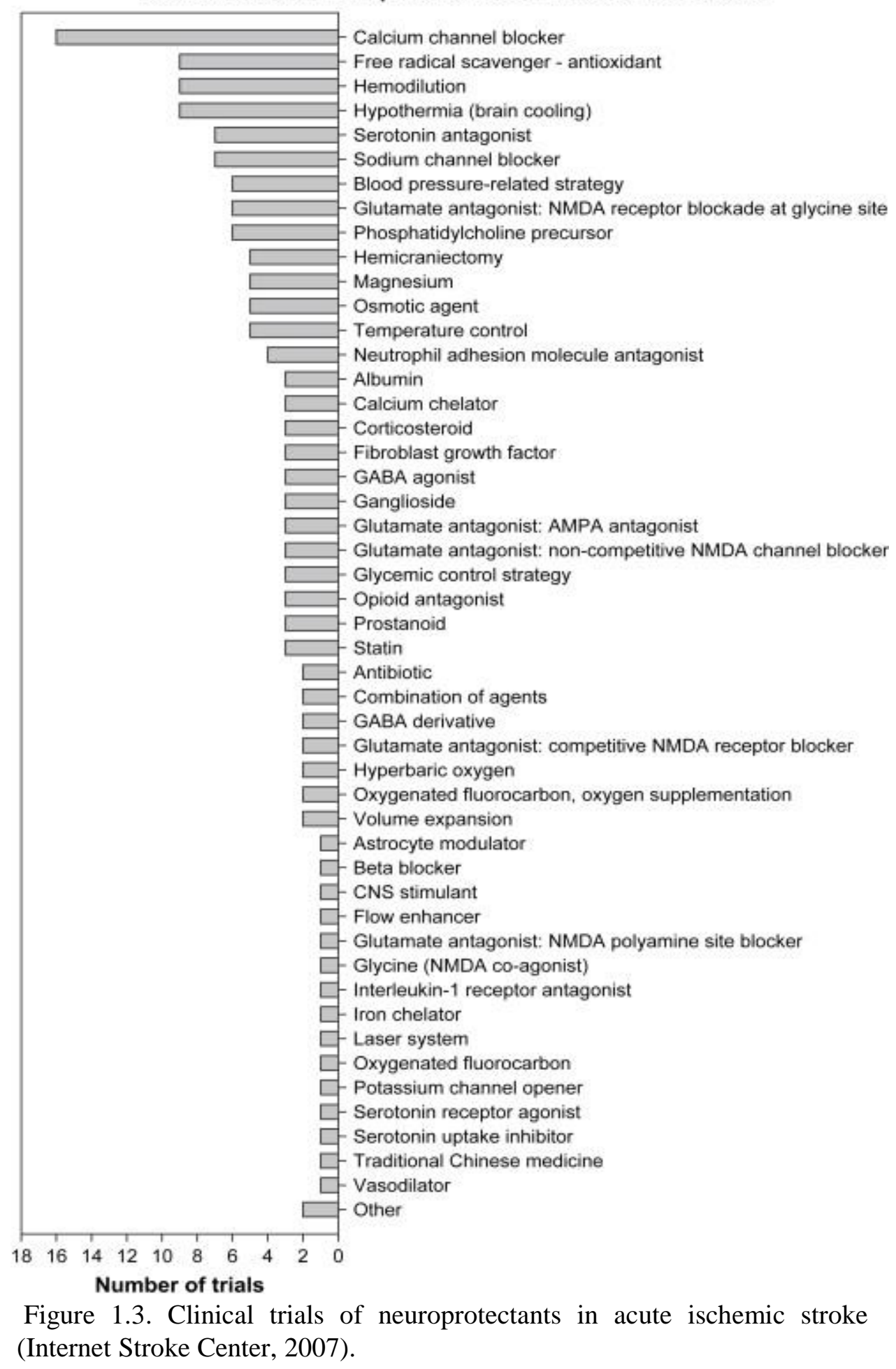

Different neurodegenerative diseases have different pathological causes and symptoms. However, oxidative stress has been shown to be a common pathogenic mechanism in aging and most 
neurodegenerative disease, including stroke (Barnham et al., 2004; Emerit et al., 2004; Manzanero et al., 2013). Oxidative stress has a profound contribution to stroke pathogenesis since neurons have a high susceptibility of neurons to ROS-induced damage. The cerebral vasculature, which is involved in the pathogenesis of ischemic brain injury after cerebrovascular attack, is also a major target of oxidative stress (Allen \& Bayraktutan, 2009). The endothelium of the small blood vessels in the brain is less permeable to molecules than other vascular endothelia, although essential molecules such as glucose, and most lipid soluble molecules can still penetrate. This cerebrovascular structure is called blood-brain barrier (BBB) (Pardridge et al., 1975). BBB excludes many toxins and peripheral molecules and cells, such as circulating phagocytes, from the healthy brain (Banks \& Erickson, 2010). In ischemic stroke, ROS-induced oxidative damage causes breakdown of BBB and further formation of brain edema (Al Ahmad et al., 2012; Freeman \& Keller, 2012; Kahles et al., 2007). Overall, oxidative stress induces a broad detrimental effect on brains during stroke.

\subsection{Antioxidants}

\subsection{Current clinical trials of antioxidants on stroke}

When oxidative stress occurs, cells function to combat the resulting oxidative effects and to restore the redox homeostasis. All organisms have adaptive responses to oxidative stress, such as increasing the expression of defensive enzymes and antioxidants. Antioxidants are widely discussed in both the clinical and scientific literature as health-promoting agents that may protect against various central nervous system (CNS) diseases (Levi \& Brimble, 2004; Moosmann \& Behl, 2002; Olanow, 1993). Numerous research studies have demonstrated that antioxidants 
protect neuron from degeneration in experimental animal models. Currently, there are a number of such drug candidates that have been applied into human clinical trials for neurodegenerative diseases, including stroke. Human data from controlled trials can be divided into two categories, nutritional supplement studies and therapeutic drug trials. Such studies, if successful, could validate and vindicate decades of free radical research (Kamat et al., 2008). The Internet Stroke Center website provides a comprehensive clinical stroke-trial database and reports that free radical scavengers are the second large category of neuroprotectants in clinical trials of acute ischemic stroke (Figure 1.3) (Internet Stroke Center, 2007). Even though the protection of these antioxidants has been observed in bench studies, unfortunately, the outcomes of clinical trials are disappointing as exemplified by a remarkable failure of antioxidant-based stroke therapies (Ginsberg, 2008). As described below, human clinical experience with antioxidative strategy is generally negative.

Tirilazad is a 21 -aminosteroid free radical scavenger and a potent inhibitor of iron-dependent lipid peroxidation. Extensive pre-clinical studies have been published that tirilazad improves infarct volume and neurological score in animal models of focal ischemia (Sena et al., 2007). Several randomized clinical trials of tirilazad were conducted in patients with acute stroke treated within $6 \mathrm{~h}$ of onset. Clinical trials revealed that tirilazad had no effect on infarct volume and did not improve overall functional outcome (A randomized trial of tirilazad mesylate in patients with acute stroke (RANTTAS). the RANTTAS investigators.1996; van der Worp et al., 2002). Some trials were prematurely terminated based on independent interim analysis showing lack of efficacy or safety problem (Tirilazad mesylate in acute ischemic stroke: A systematic review. tirilazad international steering committee.2000; Haley, 1998). 
NXY-059 is a nitrone-based free radical spin trapping agent that was proposed to protect against stroke damage caused by oxygen-derived free radicals. Despite abundant pre-clinical efficacy in rodent and primate models (Kuroda et al., 1999; Marshall et al., 2001), and modestly significant benefit in the initial "Stroke-Acute Ischemic NXY Treatment (SAINT)-I" human clinical trial (Lees et al., 2006), the definitive "SAINT-II" trial for NXY-059 completely failed to achieve pre-set endpoints (Shuaib et al., 2007). In addition, an excess of hypokalemia was observed as a safety problem in NXY-059-treated patients (Serebruany, 2006).

Ebselen is a selenium compound with glutathione peroxidase-like activity that potentially inhibits free radical-induced damage. In rodent models of middle cerebral artery-distribution ischemia, ebselen reduced ischemic damage and improved neurological deficits (Imai et al., 2001; Takasago et al., 1997). Clinical studies of ebselen in ischemic stroke were performed in Japan. In a clinical trial of 302 acute ischemic stroke patients, ebselen was reported to improve stroke outcomes (Yamaguchi et al., 1998). A secondary analysis also suggested the beneficial effects of ebselen treatment (Ogawa et al., 1999). A phase III study of 394 patients incorporating a 24-h window was slated to begin in 2001 (Internet Stroke Center, 2007), but no report has appeared. Based on the lack of publication of the results of this Phase III trials, it is assumed that ebselen either fail to show efficacy or exhibit toxicity.

Edaravone is an oxygen radical scavenger and blocker of lipid peroxidation. Early pre-clinical reports described salutary effects in both global and focal cerebral ischemia even when administered at 6 hours after onset of ischemia (Amemiya et al., 2005; Watanabe et al., 1994; Zhang et al., 2005). Only a single phase II clinical trial of edaravone has been published. There was a significant improvement in functional outcome in edaravone treatment group compared to placebo within 3 months (Edaravone Acute Infarction Study Group, 2003). Edaravone was 
introduced to the Japan market for clinical use in the management of acute ischemic stroke in 2001. In a recent clinical study of patients with internal carotid artery occlusion, edaravone has been shown to delay infarcts and edema evolution and decrease mortality in the acute stage. However, it did not significantly improve functional outcome among the surviving patients (Toyoda et al., 2004).

Lubeluzole is shown to inhibit nitric oxide production (Lesage et al., 1996). Lubeluzole was studied extensively in both global and focal cerebral ischemia experimental models. Lubeluzole has been shown to protect brains from infarction and improve functional outcomes (Aronowski et al., 1996; Haseldonckx et al., 1997). A series of phase I to III trials were conducted to examine its therapeutic efficacy for ischemic stroke. However, a Phase III trial failed to show any benefit of lubeluzole in acute ischemic stroke (Diener et al., 2000). In addition, a review of all the trials found no effect on mortality but noted a significant increase of heart-conduction disorders in lubeluzole-treated subjects (Gandolfo et al., 2002).

Oxidative damage is widely known as an important contributor of acute ischemic stroke pathogenesis. Much bench research demonstrated that targeting oxidative stress is protective against ischemic brain injury. To date, no antioxidative approaches have been approved in the United States despite the success of these compounds in stroke animal models. We should note that most of drug candidates tested in the clinical trials are free radical scavengers, which directly react with ROS. This strategy can rapidly eliminate ROS, but it fails to improve endogenous antioxidative status. A more comprehensive of antioxidant-based strategies might lead to encouraging results in stroke treatment.

1.32 Nrf2-ARE signaling pathway 
A major mechanism in the cellular defense against oxidative stress is activation of the nuclear factor E2-related factor 2 (Nrf2)-antioxidant response element (ARE) signaling pathway, which controls the expression of genes whose protein products are involved in the detoxification and elimination of reactive oxidants and electrophilic agents through conjugative reactions. Therefore, activation of Nrf2-ARE signaling pathway broadly enhances intracellular antioxidant capacity (Itoh et al., 2004). Under normal conditions, Nrf2, as a transcription factor, remains inactivated by binding to Kelch-like ECH-associated protein 1 (Keap1), which serves as a sensor of intracellular redox status (Itoh et al., 1999). Upon sensing of oxidative stress, phosphorylated Nrf2 dissociates with Keap1, translocates into the nucleus and activates the transcription of ARE-driven genes (Figure 1.4) (Apopa et al., 2008; Huang et al., 2002). ARE-driven genes are involved in encoding a battery of antioxidant and phase II enzyme production (Johnson et al., 2008). Activation of Nrf2-ARE signaling pathway is a potent strategy to repress oxidative stress, which has been shown to be protective in many neurodegenerative disease models (Calkins et al., 2009).

Among Nrf2 regulated phase II enzymes, heme oxygenase 1 (HO-1), the rate-limiting enzyme in catalysis of heme, has been reported to be critical for the protective effect of Nrf2-ARE signaling pathway in neurodegenerative diseases (Alfieri et al., 2013; Satoh et al., 2006). SOD2, the primary antioxidative enzyme against mitochondrial ROS, is also regulated by the Nrf2-ARE signaling pathway (Piantadosi et al., 2008). As shown in Figure 1.5, SOD2 coordinates with HO1 to regulate mitochondrial antioxidative capacity. When mitochondrial superoxide is generated during mitochondrial respiration, SOD2 catalyzes superoxide $\left(\mathrm{O}_{2^{-}}^{--}\right)$to hydrogen peroxide $\left(\mathrm{H}_{2} \mathrm{O}_{2}\right)$. To further convert $\mathrm{H}_{2} \mathrm{O}_{2}$ to non-toxic water, it requires the involvement of biliverdin/bilirubin, 
which is under the catalysis of HO-1. Therefore, both HO-1 and SOD2 are critical for intracellular redox homeostasis.

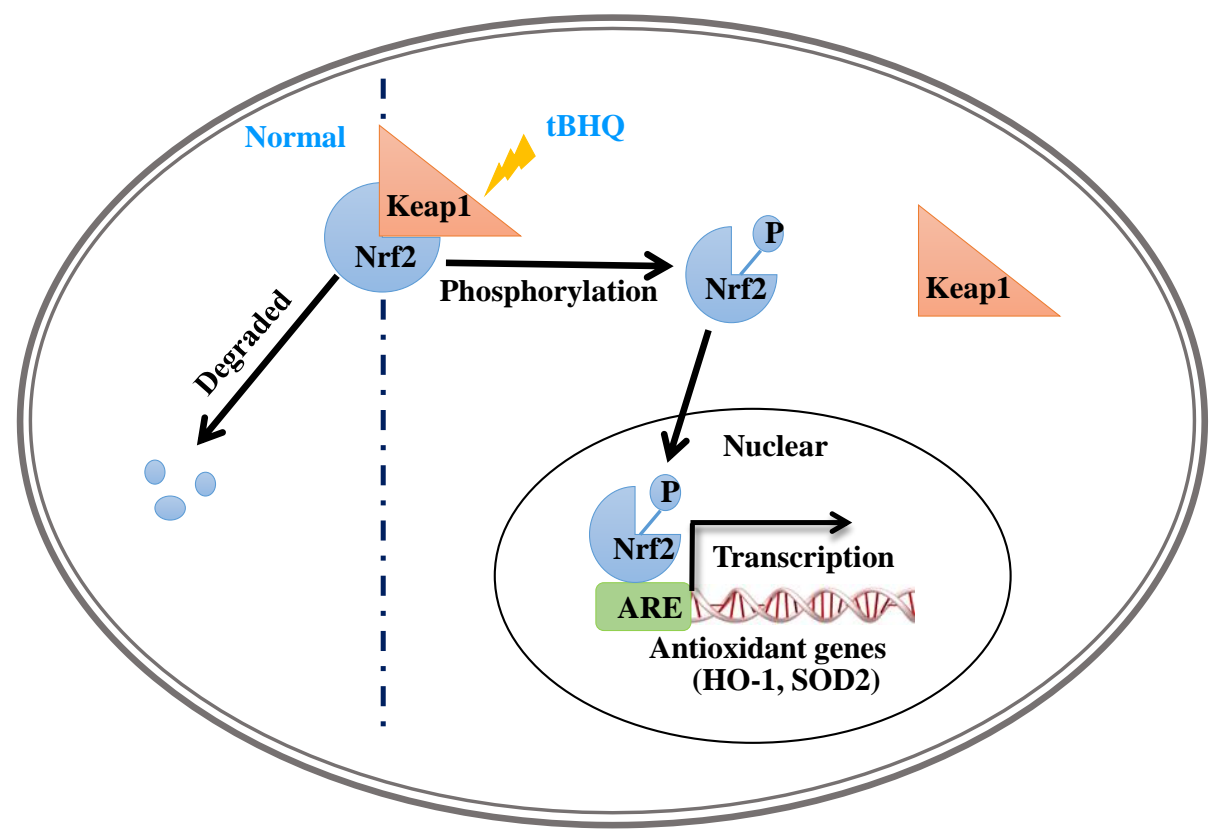

Figure 1.4 Activation of Nrf2-ARE signaling pathway. Abbreviations : antioxidant response element (ARE), heme oxygenase 1 (HO-1), Kelch-like ECH-associated protein 1 (Keap1), nuclear factor E2-related factor 2 (Nrf2), superoxide dismutase 2 $\left(\mathrm{SOD}_{2}\right)$ Tert-butylhydroquinone (tBHQ)

Tert-Butylhydroquinone (tBHQ) is an antioxidant, which is used as food additive for unsaturated vegetable oils as well as many other edible animal fats (National Toxicology Program, 1997). Other than directly scavenging free radicals, tBHQ is also a well-known Nrf2-ARE signaling pathway inducer by increasing phosphorylated Nrf2 translocation to the nucleus. Since Nrf2ARE signaling pathway regulates a wide spectrum of antioxidative protein expression, activation of this signaling pathway profoundly improves intracellular antioxidative capacity. These characteristics make tBHQ a promising candidate for oxidative stress-induced neurodegeneration treatment. Indeed, tBHQ has been reported to confer neuroprotection in various neurodegenerative conditions (Table 1.1). 


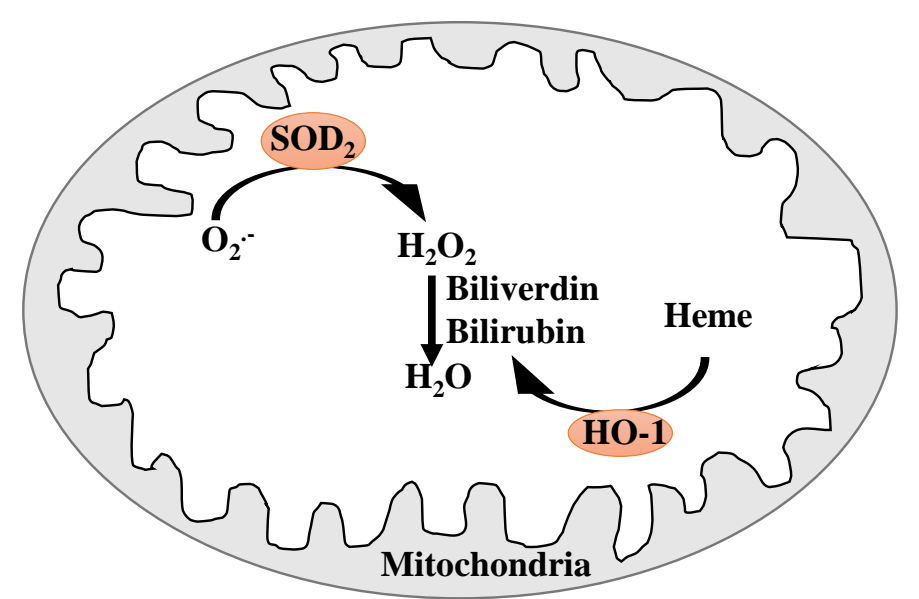

Figure 1.5 Physiologic function of SOD2 and HO-1. Abbreviations : heme oxygenase 1 (HO-1), hydrogen peroxide $\left(\mathrm{H}_{2} \mathrm{O}_{2}\right)$, hydroxyl radical (HO-), superoxide $\left(\mathrm{O}_{2}{ }^{-*}\right)$, superoxide dismutase $2\left(\mathrm{SOD}_{2}\right)$

\subsection{Gaps in knowledge}

As shown in Table 1.1, four published pre-clinical studies reported the protective effect of tBHQ in traumatic brain injury (TBI). tBHQ prevented brain edema and improved neurological deficits through suppressing inflammation and oxidative stress (Jin et al., 2010; Jin et al., 2011; Lu et al., 2014; Saykally et al., 2012). Several studies reported that tBHQ exert the beneficial effects on Alzheimer's disease and Parkinson disease. For Alzheimer's disease, tBHQ has been shown to reduce amyloid beta load in rodent (Akhter et al., 2011; Nouhi et al., 2011). By increasing antioxidative capacity, tBHQ also prevented dopaminergic cell death and improves behavioral performance in experimental model of Parkinson disease (Abdel-Wahab, 2005; Li et al., 2012). Currently, only one study has investigated the protective effect of tBHQ in ischemic stroke (Shih et al., 2005). In addition, the underlying protective mechanism of tBHQ in neurodegenerative conditions is not fully studied.

Oxidative stress is actively involved in stroke pathogenesis; however, almost all the antioxidants that have been applied into the clinical trials fail to improve ischemic stroke outcomes (Margaill 
et al., 2005). We should note that all these drug candidates have very limited diversity of antioxidative activities. Instead of being discouraged, it is necessary to explore a novel and diversified strategy against oxidative stress-induced neurodegeneration. tBHQ is a food additive, which is considered to be safe for human consumption (Evaluation of certain food additives and contaminants. forty-ninth report of the joint FAO/WHO expert committee on food additives.1999; van Esch, 1986). As both an antioxidant and an Nrf2-ARE signaling pathway inducer, tBHQ can directly eliminate ROS and also activate the expression of all the antioxidative genes under Nrf2-ARE regulation. Therefore, it is valuable to investigate the clinical application of tBHQ in ischemic stroke. tBHQ not only might provide a potential therapeutic drug for stroke treatment, but it might also help us to understand why the outcomes of previous clinical trials are disappointing.

Although few studies have assessed the expression of Nrf2-ARE regulated downstream gene after tBHQ exposure during oxidative stress-induced neurodegeneration, there is a substantial lack of understanding of the protective mechanism of Nrf2-ARE signaling pathway. An important confounding factor in oxidative stress-induced neurodegeneration is mitochondrial dysfunction. The regulation of Nrf2-ARE signaling pathway and its downstream genes on mitochondrial function is still unknown. Understanding this relationship is crucial for defining potential therapeutic targets and may also provide a better understanding of how oxidative stress lead to programmed cell death.

My dissertation uses both in vitro glutamate-induced oxidative stress models and a in vivo murine permanent middle cerebral artery occlusion model to understand 1) if tBHQ preserves mitochondrial function and further prevent neuronal cell death during oxidative challenge and 2) if tBHQ prevents brain damage and improve neurological function in ischemic stroke. Overall, 
the study will advance to our understanding on how to approach antioxidative strategy to prevent neurodegeneration. 


\begin{tabular}{|c|c|c|c|}
\hline Articles & Model & Administration & Conclusion \\
\hline $\begin{array}{l}\text { Mediators } \\
\text { Inflamm. } 20 \\
10 ; 502564\end{array}$ & TBI & $\begin{array}{l}\text { tBHQ }(1 \% \mathrm{w} / \mathrm{w}) \text { supplemented diet } \\
\text { for one week prior to injury }\end{array}$ & $\begin{array}{l}\text { tBHQ suppress the intestinal } \\
\text { inflammation and reduce the } \\
\text { mucosal damage following TBI. }\end{array}$ \\
\hline $\begin{array}{l}\text { Injury. } \\
2011 ; \\
42: 714-718\end{array}$ & TBI & $\begin{array}{l}\text { tBHQ }(1 \% \mathrm{w} / \mathrm{w}) \text { supplemented diet } \\
\text { for one week prior to injury }\end{array}$ & $\begin{array}{l}\text { tBHQ attenuates the cerebral } \\
\text { inflammatory response after TBI }\end{array}$ \\
\hline $\begin{array}{l}\text { Neuroscien } \\
\text { ce. } \\
2012 ; \\
223: 305- \\
314\end{array}$ & TBI & $\begin{array}{l}\text { I.P. injection of tBHQ (at } 33.4 \text { or } \\
16.7 \mathrm{mg} / \mathrm{kg} \text { ) post TBI and involved } \\
\text { either a single injection or six } \\
\text { additional daily injections }\end{array}$ & $\begin{array}{l}\text { tBHQ improves cognitive } \\
\text { performance in mice after mild } \\
\text { TBI. }\end{array}$ \\
\hline $\begin{array}{l}\text { J. } \quad \text { Surg. } \\
\text { Res. 2014; } \\
188: 206- \\
212\end{array}$ & TBI & $\begin{array}{l}\text { A total of } 50 \mathrm{mg} / \mathrm{kg} \text { of tBHQ } \\
\text { divided into three injections at } \\
\text { intervals of } 8 \mathrm{~h} \text { before TBI }\end{array}$ & $\begin{array}{l}\text { tBHQ attenuates markers of } \\
\text { cerebral oxidative stress after } \\
\text { TBI and also decreased TBI- } \\
\text { induced brain edema and } \\
\text { neurologic deficits. }\end{array}$ \\
\hline $\begin{array}{l}\text { Arch. } \\
\text { Toxicol. } \\
2012 \\
86: 1729- \\
1740\end{array}$ & $\begin{array}{l}\text { Parkinson's } \\
\text { disease }\end{array}$ & $\begin{array}{l}\text { tBHQ }(1 \% \mathrm{w} / \mathrm{w}) \text { supplemented diet } \\
\text { for } 3 \text { days prior to injury }\end{array}$ & $\begin{array}{l}\text { tBHQ attenuates paraquat- } \\
\text { induced impairments in } \\
\text { behavioral performance and } \\
\text { decreased apoptosis } \\
\text { dopaminergic cell. }\end{array}$ \\
\hline $\begin{array}{l}\text { J. } \\
\text { Biochem. } \\
\text { Mol. } \\
\text { Toxicol. } \\
\text { 3005; } \\
\text { 19:32-41 }\end{array}$ & $\begin{array}{l}\text { Parkinson's } \\
\text { disease }\end{array}$ & $\begin{array}{l}\text { Oral administration of tBHQ (100 } \\
\mathrm{mg} / \mathrm{kg} \text { ) for } 1 \text { week prior to injury }\end{array}$ & $\begin{array}{l}\text { tBHQ has the ability to reverse } \\
\text { the oxidative stress in mice, } \\
\text { while failed to challenge the } \\
\text { histopathological and } \\
\text { histochemical changes induced } \\
\text { by that toxicant. }\end{array}$ \\
\hline $\begin{array}{l}J . \\
\text { Alzheimers } \\
\text { Dis. 2011; } \\
\text { 26:767-778 }\end{array}$ & $\begin{array}{l}\text { Alzheimer's } \\
\text { disease }\end{array}$ & $\begin{array}{l}\text { tBHQ }(1 \% \mathrm{w} / \mathrm{w}) \text { supplemented diet } \\
\text { for } 6 \text { weeks }\end{array}$ & $\begin{array}{l}\text { APP/PS1 mice with tBHQ } \\
\text { containing diet reduce brain A } \beta \\
\text { load and increase brain } \\
\text { antioxidant capacity. }\end{array}$ \\
\hline $\begin{array}{l}\text { Neurochem } \\
\text { 2011; } \\
36: 870-878\end{array}$ & $\begin{array}{l}\text { Alzheimer's } \\
\text { disease }\end{array}$ & $\begin{array}{l}\text { tBHQ }(1 \% \mathrm{w} / \mathrm{w}) \text { supplemented diet } \\
\text { for } 1 \text { week prior to } A \beta \text { injection }\end{array}$ & $\begin{array}{l}\text { tBHQ protected against the } \\
\text { oxidative damage, apoptosis and } \\
\mathrm{A} \beta \text { accumulation in rats. }\end{array}$ \\
\hline $\begin{array}{l}\text { PLoS One. } \\
\text { 2014; } \\
9: \mathrm{e} 97685\end{array}$ & hemorrhage & $\begin{array}{l}\text { tBHQ }(12.5 \mathrm{mg} / \mathrm{kg}) \text { via oral gavage } \\
\text { at } 2 \mathrm{~h}, 12 \mathrm{~h}, 24 \mathrm{~h} \text {, and } 36 \mathrm{~h} \text { after } \\
\text { subarachnoid hemorrhage. }\end{array}$ & $\begin{array}{l}\text { tBHQ abated the development of } \\
\text { early brain injury and cognitive } \\
\text { dysfunction in subarachnoid } \\
\text { hemorrhage model }\end{array}$ \\
\hline $\begin{array}{l}J . \\
\text { Neurosci. } \\
2005 ; \\
25: 10321- \\
10335\end{array}$ & $\begin{array}{l}\text { ischemia- } \\
\text { reperfusion } \\
\text { stroke }\end{array}$ & $\begin{array}{l}\text { I.P. injection of tBHQ }(3.33 \text { or } 16.7 \\
\mathrm{mg} / \mathrm{kg}) \text { or Intracerebroventricular } \\
\text { delivery of tBHQ }(1 \mathrm{mM}) \text { before } \\
\text { ischemia }\end{array}$ & $\begin{array}{l}\text { tBHQ reduces cortical damage } \\
\text { and sensorimotor deficit after } \\
\text { ischemia-reperfusion. }\end{array}$ \\
\hline
\end{tabular}

Table 1.1 Summary of tBHQ in experimental animal study. Abbreviations: Amyloid beta (A $\beta$ ), intraperitoneal (i.p.), Tert-Butylhydroquinone (tBHQ), traumatic brain injury (TBI), 


\title{
Chapter 2
}

\section{tBHQ prevents mitochondrial dysfunction and}

\author{
neuronal cell death under glutamate-induced
}

\author{
oxidative stress
}

Jiahong Sun, Xuefang Ren and James W. Simpkins

Sun J, Ren X, Simpkins JW. Sequential Upregulation of Superoxide Dismutase 2 and Heme Oxygenase 1 by tert-Butylhydroquinone Protects Mitochondria during Oxidative Stress. Mol Pharmacol . 2015;88:437-449. 


\subsection{Abstract}

Oxidative stress is linked to mitochondrial dysfunction in aging and neurodegenerative conditions. The transcription factor, nuclear factor E2-related factor 2 (Nrf2)-antioxidant response element (ARE), regulates intracellular anti-oxidative capacity to combat oxidative stress. We examined the effect of tert-butylhydroquinone (tBHQ), an Nrf2-ARE signaling pathway inducer, on mitochondrial function during oxidative challenge in neurons. tBHQ prevented glutamate-induced cytotoxicity in HT-22 neuronal cell line even with an $8 \mathrm{hr}$ exposure delay. tBHQ blocked glutamate-induced intracellular reactive oxygen species (ROS) and mitochondrial superoxide accumulation. It also protected mitochondrial function under glutamate toxicity, including maintaining mitochondrial membrane potential, mitochondrial $\mathrm{Ca}^{2+}$ hemostasis and mitochondrial respiration. Glutamate activated mitochondria-mediated apoptosis was inhibited by tBHQ as well. In rat primary cortical neurons, tBHQ protected cells from both glutamate and buthionine sulfoximine (BSO) toxicity. We found that tBHQ scavenged ROS, induced a rapid up-regulation of superoxide dismutase $2\left(\mathrm{SOD}_{2}\right)$ expression and a delayed upregulation of heme oxygenase 1 (HO-1) expression. In HT-22 cells with a knockdown of $\mathrm{SOD}_{2}$ expression, delayed treatment of tBHQ failed to prevent glutamate-induced cell death. Briefly, tBHQ rescues mitochondrial function by sequentially increasing $\mathrm{SOD}_{2}$ and HO-1 expression during glutamate-mediated oxidative stress. This study is the first to demonstrate the role of tBHQ in preserving mitochondrial function during oxidative challenge and provides a clinicallyrelevant argument for using tBHQ against acute neuron-compromising conditions. 


\subsection{Introduction}

Intracellular energy supply is highly dependent on oxidative phosphorylation in mitochondria. During ATP production, reactive oxygen species (ROS) are unavoidably generated as intermediates of oxygen reduction (Cadenas \& Davies, 2000). Oxidative stress, caused by the failure of anti-oxidative defense against excessive ROS, leads to dysfunction of mitochondria and other subcellular organelles, and further triggers cell death. Thus, oxidative stress has been linked to mitochondrial dysfunction in aging and neurodegenerative conditions (Barnham et al., 2004).

Glutamate-induced oxidative stress is a known cause of pathological cell death in neurons. This process is initiated by the depletion of antioxidant glutathione (GSH) synthesis by blocking cysteine uptake, and is followed by an accumulation of ROS (Choi, 1994; Coyle \& Puttfarcken, 1993). The ROS accumulation causes mitochondrial dysfunction and the release of apoptosisinducing factor (AIF) from the mitochondria to the cytosol and nucleus and further leads to cell death (Fukui et al., 2009; Landshamer et al., 2008). In contrast, superoxide dismutase 2 ( $\left.\mathrm{SOD}_{2}\right)$ acts as a primary mitochondrial anti-oxidative enzyme and protects glutamate-induced oxidative damage (Fukui \& Zhu, 2010).

The transcription factor, nuclear factor E2-related factor 2 (Nrf2)-antioxidant response element (ARE), regulates intracellular anti-oxidative capacity to combat oxidative stress (Jaiswal, 2004). Under normal conditions, Nrf2 remains inactivated by binding to Kelch-like ECH-associated protein 1 (Keap1), which serves as a sensor of intracellular redox status (Itoh et al., 1999). Upon sensing of oxidative stress, phosphorylated Nrf2 dissociates with Keap1, translocates into the nucleus and activates the transcription of ARE-driven genes (Apopa et al., 2008; Huang et al., 
2002). ARE-driven genes are involved in a battery of antioxidant and phase 2 enzyme production, which is a potent strategy to repress oxidative damage (Calkins et al., 2009). Among Nrf2 regulated phase 2 enzymes, heme oxygenase 1 (HO-1), the rate-limiting enzyme in catalysis of heme, has been reported to be critical for the protective effect of Nrf2-ARE signaling pathway in neurodegenerative diseases (Alfieri et al., 2013; Li et al., 2012; Satoh et al., 2006).

Tert-butylhydroquinone (tBHQ), an Nrf2 inducer, is a widely used food antioxidant (Yu et al., 1997). Previous studies have shown that tBHQ exerts protective effects in multiple neurodegenerative conditions, including stroke (Shih et al., 2005), traumatic brain injury (Jin et al., 2011; Lu et al., 2014), Parkinson's disease (Hara et al., 2003) and Alzheimer's disease (Akhter et al., 2011; Eftekharzadeh et al., 2010). However, the underlying mechanisms of tBHQ's protective role have not been elucidated. Using a glutamate-induced oxidative toxicity model in a mouse hippocampal neuronal cell line (HT-22 cells), we here demonstrate that tBHQ prevents glutamate-induced cell death even with an $8 \mathrm{hr}$ treatment delay. tBHQ exerts protection against glutamate-induced mitochondrial dysfunction and inhibits mitochondrial-mediated apoptosis. In addition, tBHQ protected primary cortical neurons from both glutamate and buthionine sulfoximine (BSO) toxicity. Interestingly, tBHQ, not only scavenges free radicals, but quickly activates the Nrf2-ARE signaling pathway. tBHQ rapidly up-regulates $\mathrm{SOD}_{2}$ level followed by a delayed increase in $\mathrm{HO}-1$ expression. By knocking down $\mathrm{SOD}_{2}$, we demonstrate that $\mathrm{SOD}_{2}$ is necessary for the early phase protection of $\mathrm{tBHQ}$ and that $\mathrm{SOD}_{2}$ coordinates with HO-1 to defense glutamate-induced oxidative damage. Our study clarifies the effect of tBHQ on mitochondrial function under conditions of oxidative challenge, and provides a potential new therapeutic target for neurodegenerative disease. 


\subsection{Materials and Methods}

\section{Cell culture}

HT-22 cells were the generous gift of Dr. David Schubert (Salk Institute, San Diego, CA). Cells were maintained in high glucose Dulbecco's Modified Eagle Medium (HyClone, South Logan, UT) media supplemented with $10 \%$ fetal bovine serum (Altanta Biologicals, Flowery Branch, GA) in 75mm tissue culture flasks (Corning, Tewksbury, MA) at standard cell culture conditions (5\% $\mathrm{CO}_{2}, 95 \%$ air). HT-22 cells used were between passages 8-28.

Primary cortical neurons were prepared from embryonic day 17 Sprague-Dawley rats. The cortices were dissected and placed in Hank's Balanced Salt Solution (HBSS) (HyClone, South Logan, UT). Cells were mechanically dissociated by titration and filtered through $70 \mu \mathrm{m}$ cell strainers (BD Biosciences, San Jose, CA). Cells were maintained in minimal essential medium (ATCC, Manassas, VA) supplemented with $4.4 \mathrm{~g} / \mathrm{L}$ glucose and $10 \%$ heat-inactivated horse serum (Life Technologies, Carlsbad, CA). Cells $\left(8 \times 10^{4}\right.$ cells per well) were plated in poly-Llysine (Sigma, St. Louis, MO) coated 48 well plates (Corning, Tewksbury, MA). After 1 day in vitro culture, cells were treated for $24 \mathrm{hr}$ and morphological changes were observed microscopically (EVOS® FL Auto Imaging System).

\section{Cell viability assay}

HT-22 cells were seeded in 96-well or 6-well plates (Corning, Tewksbury, MA) and were incubated overnight. After respective treatments, medium was removed and cells were incubated with $1 \mu \mathrm{M}$ Calcein AM (Molecular Probes, Grand Island, NY) in phosphate buffered saline (PBS)

for 15 minutes at $37^{\circ} \mathrm{C}$. Calcein AM, a nonfluorescent dye, is converted to a green-fluorescent calcein by intracellular esterases. Fluorescence was measured using a Biotek Synergy H1 Hybrid 
plate reader (excitation 485 emission 530). Calcein AM led to the detachment of cells from the bottom of the wells after siRNA transfection, an effect that compromises the assay. As such, to measure cell viability of siRNA transfected cells, we used morphological changes of cells after respective exposures as observed microscopically. For each well, pictures were randomly taken in three different fields. Based on the morphology, cells in each photomicrograph were counted and categorized into live cells and dead cells by UVP imaging software. The average cell number from three different pictures was calculated to represent cell viability. For the primary cortical neurons, viability of the cells was assessed using Calcein AM, and imaged using fluorescent microscopy.

\section{Reactive oxygen species detection}

Changes in intracellular ROS were measured by the ROS reactive fluorescent indicator $2^{\prime}, 7^{\prime}-$ dichlorodihydrofluorescein diacetate ( $\mathrm{H}_{2}$ DCFDA) (Molecular Probes, Grand Island, NY). The non-fluorescent $\mathrm{H}_{2}$ DCFDA is converted to the highly fluorescent DCF by ROS (Fukui et al., 2010; Kang et al., 2014; Tobaben et al., 2011). Briefly, HT-22 cells were plated overnight at a density of 5,000 cells/ well in a 96-well plate. After respective exposures, the medium was removed, the cells were washed once with PBS, and then incubated with $10 \mu \mathrm{M} \mathrm{H}_{2} \mathrm{DCFDA}$ for $30 \mathrm{~min}$ at $37^{\circ} \mathrm{C}$. Mean fluorescence intensity (MFI) of DCF was measured using a Biotek Synergy H1 Hybrid plate reader (excitation 485, emission 530). DCF fluorescence was standardized based on cell viability.

\section{Mitochondrial superoxide measurement}

MitoSOX Red (Molecular Probes, Grand Island, NY) is a fluorogenic dye targeted to mitochondria and generates red fluorescence after oxidation by superoxide (Fukui \& Zhu, 2010; Mukhopadhyay et al., 2007; Pfeiffer et al., 2014). The fluorescence signal was measured by 
fluorescence-activated cell sorting (FACS) analysis. Cells were harvested, washed once with icecold PBS and stained with $5 \mu \mathrm{M}$ MitoSOX Red in HBSS for 10 min at $37{ }^{\circ} \mathrm{C}$. Cells were then washed twice with PBS before the red fluorescence intensity was analyzed using a flow cytometer (BD Calibur). In each analysis, 10000 events were recorded.

\section{Mitochondria membrane potential analysis}

HT-22 cells were plated at a density of 5,000 cells/ well, and expose to glutamate alone or in combination with tBHQ. The medium was then removed and cells were incubated in PBS containing $1 \mu \mathrm{M}$ nonylacridine orange (NAO) (Molecular Probes, Grand Island, NY) and $1 \mu \mathrm{M}$ tetramethylrhodamine, ethyl ester (TMRE) (Sigma, St. Louis, MO) for 20 min at $37^{\circ} \mathrm{C}$. Under normal mitochondria intermembrane potential, TMRE enters into mitochondria and quenches NAO. Collapse of mitochondrial membrane potential promotes NAO fluorescence. NAO fluorescence was measured using a Biotek Synergy H1 Hybrid plate reader (excitation 485, emission 530), and standardized based on cell viability.

\section{Mitochondrial $\mathrm{Ca}^{2+}$ detection}

Mitochondrial $\mathrm{Ca}^{2+}$ was measured using Rhod2-AM, a fluorogenic dye specifically targeted to mitochondria Rhod-2 AM (Molecular Probes, Grand Island, NY) which exhibits fluorescence upon binding $\mathrm{Ca}^{2+}$. Cells were incubated with $2 \mu \mathrm{M}$ Rhod-2 $\mathrm{AM}$ for 15 min at $37^{\circ} \mathrm{C}$, washed with PBS twice and analyzed immediately by flow cytometry (BD Calibur). In each analysis, 10000 events were recorded.

\section{Mitochondrial respiration measurement}

HT-22 cells were plated at a density of 15000/ well in an $\mathrm{XF}^{\mathrm{e}} 96$ plate (Seahorse Bioscience, North Billerica, MA). After respective exposures, the medium was exchanged $1 \mathrm{hr}$ prior to the 
assay with XF assay medium (Seahorse Bioscience, North Billerica, MA). $1 \mu \mathrm{M}$ oligomycin, 0.5 $\mu \mathrm{M}$ carbonilcyanide $p$-triflouromethoxyphenylhydrazone (FCCP) and $1 \mu \mathrm{M}$ antimycin and rotenone (Sigma, St. Louis, MO) were diluted into $\mathrm{XF}^{\mathrm{e}} 96$ medium and loaded into the accompanying cartridge. Injections of the components into the wells occurred at the time points specified. Oxygen consumption rate (OCR) was monitored using a Seahorse Bioscience XF 96 Extracellular Flux Analyzer.

\section{Caspase 3/7 activity}

Caspase-3 and -7 activities were measured using a luminescence-based assay, Caspase-Glo 3/7 Assay (Promega, Madison, WI). According to the manufacturer's protocol, cells were incubated with proluminescent caspase-3/7 substrate for $1 \mathrm{hr}$ at room temperature. Following caspase cleavage, a substrate for luciferase is released, resulting in the luciferase reaction and the production of light. Luminescence was measured with Biotek Synergy H1 Hybrid plate reader.

\section{Immunocytochemistry}

HT-22 cells were fixed with 4\% paraformaldehyde (Sigma, St. Louis, MO) in PBS for 15 min after respective exposures. The cells were permeabilized with $0.25 \%$ Triton $\mathrm{X}-100$ for $10 \mathrm{~min}$, and were hen incubated in 10\% serum (Sigma, St. Louis, MO) blocking solution containing 0.3 M glycine for $30 \mathrm{~min}$. Cells were exposed to anti-AIF antibody or anti-Nrf2 antibody (1: 100 in block solution, Santa Cruz Biotechnology, Dallas, Texas) overnight at $4^{\circ} \mathrm{C}$, followed by incubation with appropriate fluorescence-conjugated secondary antibodies (Molecular Probes, Grand Island, NY) for $1 \mathrm{hr}$. Nuclei were counterstained with 4',6-diamidino-2-phenylindole (DAPI) (Molecular Probes, Grand Island, NY). Images were acquired using a fluorescence confocal microscope (Zeiss Violet Confocal) with a 40X objective. 


\section{Nuclear isolation}

Cells were collected and resuspended in lysis buffer A (10 mM HEPES, $1.5 \mathrm{mM} \mathrm{MgCl} 2,10 \mathrm{mM}$ $\mathrm{KCl}, 0.5 \mathrm{mM}$ DTT, $0.05 \% \mathrm{NP}-40, \mathrm{pH} 7.9)$. Samples were left on ice for $10 \mathrm{~min}$ and centrifuged (Beckman Allegra ${ }^{\mathrm{TM}}$ 64R centrifuge) at $4^{\circ} \mathrm{C}$ at $3000 \mathrm{rpm}$ for $10 \mathrm{~min}$. Supernatant was removed, cell pellets were resuspended in lysis buffer B ( $5 \mathrm{mM}$ HEPES, $1.5 \mathrm{mM} \mathrm{MgCl} 2,0.2 \mathrm{mM}$ EDTA, $0.5 \mathrm{mM}$ DTT, $26 \%$ glycerol, $300 \mathrm{mM} \mathrm{NaCl}, \mathrm{pH}$ 7.9) and homogenized with 20 full strokes in a glass homogenizer on ice. All the chemicals were ordered from Sigma. After the 30 min incubation on ice, samples were centrifuged at $24,000 \mathrm{~g}$ for $20 \mathrm{~min}$ at $4{ }^{\circ} \mathrm{C}$. Supernatants were collect as the nuclear fraction.

\section{Western blot}

For whole cell lysis, cells were lysed in radio-immunoprecipitation assay (RIPA) buffer with cocktail protease inhibitors (EMD Millipore, Billerica, MA). Briefly, blots were probed with anti-AIF antibody (1: 1000 dilution, Santa Cruz Biotechnology, Dallas, Texas), $\mathrm{SOD}_{2}$ antibody (1: 1000 dilution, Santa Cruz Biotechnology, Dallas, Texas), or Anti-HO-1 antibody (1: 1000 dilution, Abcam, Cambridge, MA) at $4{ }^{\circ} \mathrm{C}$ overnight. Membranes were then exposed to the appropriate HRP-conjugated secondary antibodies (Santa Cruz Biotechnology Dallas, Texas), followed by chemiluminescence detection (Fisher, Waltham, MA) of antibody binding. Equal protein loading was controlled by re-probing the membrane with anti- $\beta$-actin antibody or an antihistone deacetylase 1 (HDAC1) antibody (1:1000 dilution, Santa Cruz Biotechnology, Dallas, Texas). Chemiluminescence was detected using the UVP ChemiDoc-It TS2 Imager, and UVP software was used for quantification of western blot signals.

\section{GSH measurement}


GSH level was measured using a luminescence-based assay, GSH-Glo ${ }^{\text {TM }}$ Glutathione Assay (Promega, Madison, WI). The assay was based on the conversion of a luciferin derivative into luciferin in the presence of glutathione, catalyzed by glutathione S-transferase. According to the manufacturer's protocol, cells were incubated with Glo-GSH ${ }^{\mathrm{TM}}$ reagent for $30 \mathrm{~min}$ at room temperature, followed by a 15 min incubation with luciferin detection reagent and luminescence was measured with Biotek Synergy H1 Hybrid plate reader.

\section{Transfection}

HT-22 cells were seeded at $4 \times 10^{4}$ cells/well in six-well plates at the time of transfection. siRNA selectively targeting mouse $\mathrm{SOD}_{2}$ ( Santa Cruz Biotechnology, Dallas, Texas) was used for transfection and a scrambled non-targeting siRNA was used as the control. Transfections of the siRNA targeting $\mathrm{SOD}_{2}(50 \mathrm{pmol})$ or the scrambled control siRNA was performed using a siRNA transfection reagent (Santa Cruz Biotechnology, Dallas, Texas) based on the protocol provided by the manufacturer. Transfection efficiency was observed microscopically, and $\mathrm{SOD}_{2}$ protein expression was determined by Western blot analysis after 24- or 36-hr transfection.

\section{Statistical analysis}

The data were shown as means \pm SEM. Statistical analyses were performed using one-way ANOVA with Tukey's post hoc test or two-way ANOVA with Bonferroni's post hoc test for multiple comparisons. GraphPad PRISM 5.0 was used for statistical analyses. *p $<0.05, * * p<$ 0.01 , and $* * * \mathrm{p}<0.001$ 


\subsection{Results}

\section{tBHQ protects HT-22 cells against glutamate-induced cytotoxicity.}

To evaluate tBHQ protection against glutamate-induced cytotoxicity, we first measured cytotoxicity of glutamate in HT-22 cells by performing a Calcein AM cell viability assay. Glutamate $(5-20 \mathrm{mM})$ reduced cell viability to $20 \%$ of control after a $24-\mathrm{hr}$ exposure (Figure 2.1A). We selected an exposure of $5 \mathrm{mM}$ glutamate for the following studies. We also timedependently monitored glutamate induced cell death and found that cells start to die at $11 \mathrm{~h}$ after glutamate $(5 \mathrm{mM})$ exposure (Figure 2.1B).

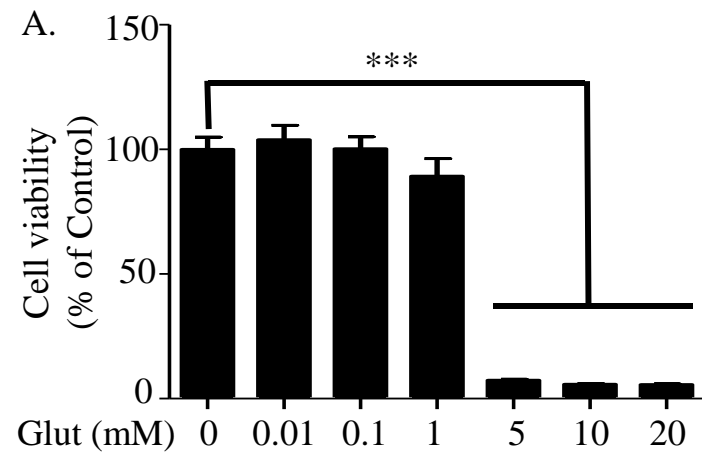

B.

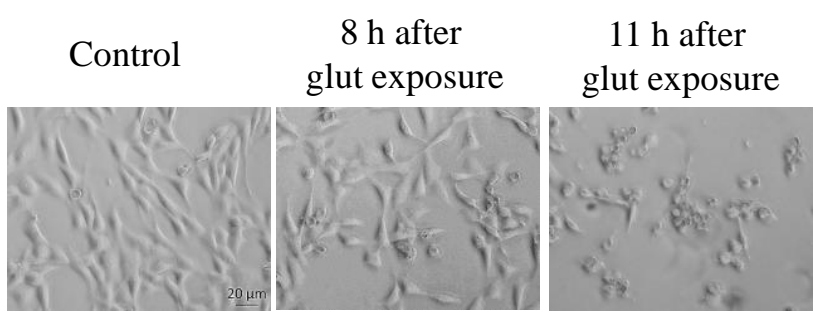

Figure 2.1. Cytotoxicity of glutamate. (A) HT-22 cells were exposed with glutamate $(0.01-20 \mathrm{mM})$ for 24 hr. Cell viability was detected by Calcein AM assay (n=8). (B) HT-22 cells were exposed with glutamate (5 $\mathrm{mM})$. Morphological changes of cells were observed microscopically at 8 and $11 \mathrm{hr}$ after glutamate exposure. Representative experiments were independently repeated three times. Results are reported as mean \pm SEM. $* * * \mathrm{P}<0.001$ compared with glutamate-treated cells (one-way ANOVA, Tukey's test).

With simultaneous exposure to tBHQ (1-25 $\mu \mathrm{M})$, glutamate-induced cell death was significantly ameliorated (Figure 2.2A). At a concentration of $10 \mu \mathrm{M}$, tBHQ reached the maximal protective effect without inducing cytotoxicity (Figure 2.2B). Therefore, we selected an exposure of $10 \mu \mathrm{M}$ tBHQ for the following studies. To determine the duration of treatment delay with $\mathrm{tBHQ}$, we exposed cells to $5 \mathrm{mM}$ glutamate and applied tBHQ at $0-14 \mathrm{hr}$ after the $5 \mathrm{mM}$ glutamate treatment. Cell viability was measured $24 \mathrm{hr}$ after glutamate exposure. Surprisingly, with up to 
an $8 \mathrm{hr}$ delay in exposure, tBHQ rescued more than $75 \%$ of the cells from glutamate-induced cell death. This protection was attenuated when the exposure delay was prolonged to $10 \mathrm{hr}$. tBHQ also failed to protect cells against glutamate toxicity with $12 \mathrm{hr}$ and $14 \mathrm{hr}$ delay exposure (Figure 2.3A). Morphological changes after glutamate and delayed exposure to tBHQ were observed microscopically (Figure 2.3B).
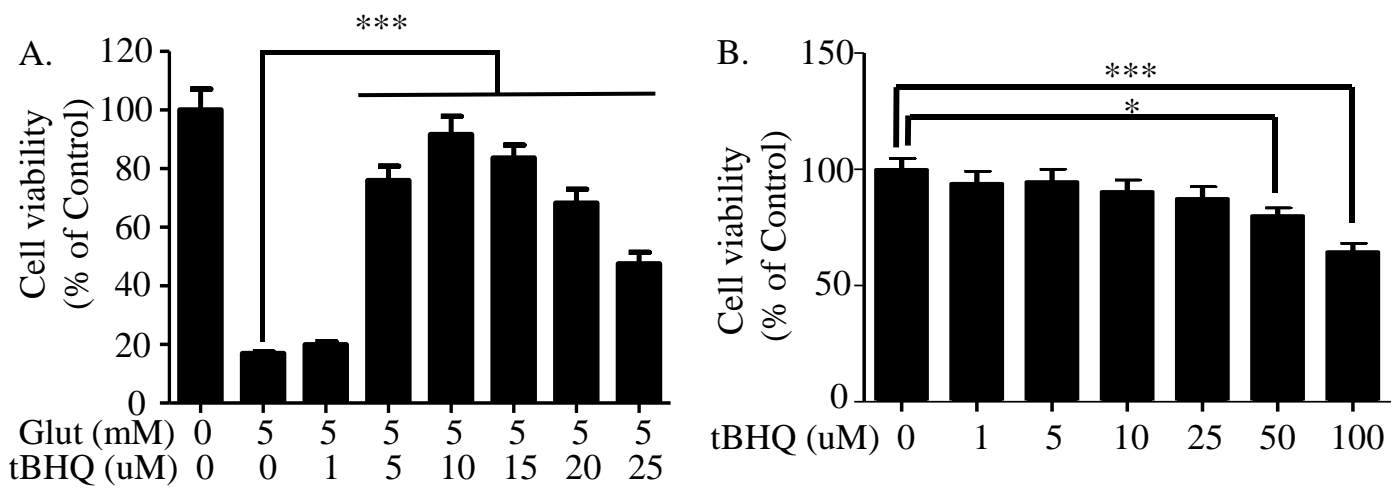

Figure 2.2. tBHQ exerts neuroprotective effect against glutamate toxicity in HT-22 cells. (A) HT-22 cells were exposed with glutamate $5 \mathrm{mM}$ and tBHQ $(1-25 \mu \mathrm{M})$ for $24 \mathrm{hr}$. (B) HT-22 cells were exposed with tBHQ $(1-25 \mu \mathrm{M})$ for $24 \mathrm{hr}$. Cell viability was detected by Calcein AM assay $(n=8)$. Representative experiments were independently repeated three times. Results are reported as mean $\pm \mathrm{SEM}$. $* \mathrm{P}<0.05$, *** $\mathrm{P}<0.001$ compared with glutamate-treated cells (one-way ANOVA, Tukey's test).

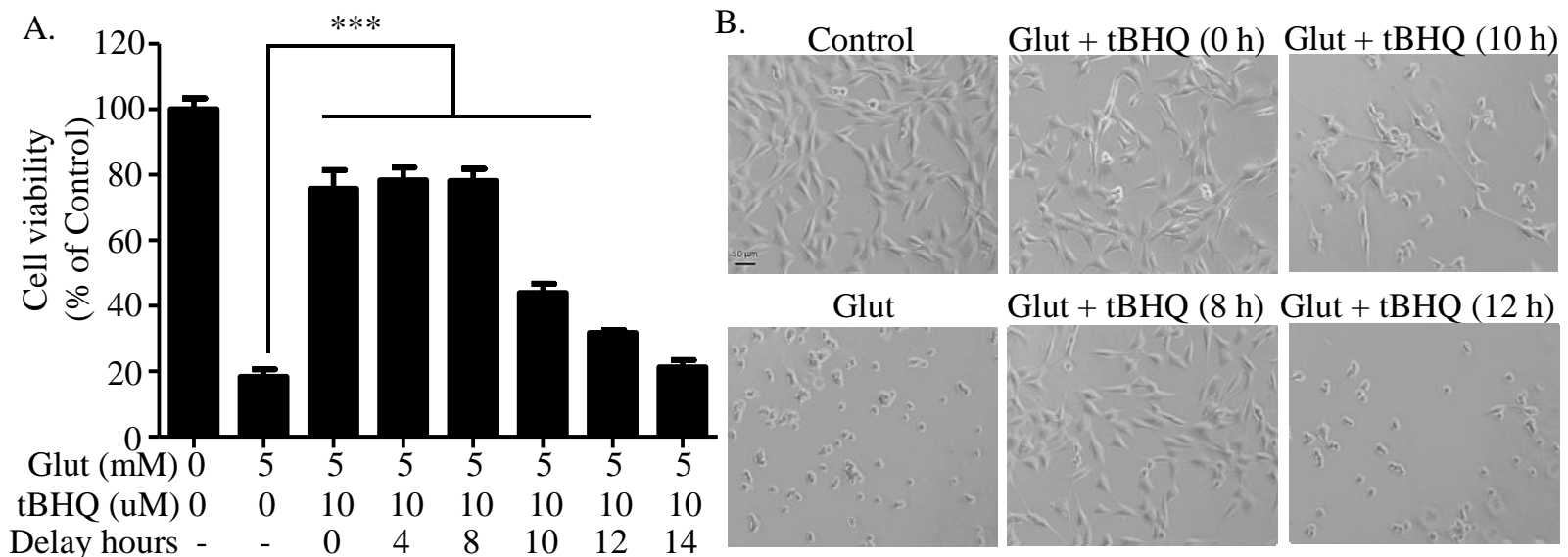

Figure $2.3 \mathrm{Up}$ to $8 \mathrm{hr}$ treatment delay, tBHQ prevents glutamate-induced cell death. (A) Cells were treated with glutamate at concentration of $5 \mathrm{mM}$ for $24 \mathrm{hr}$. tBHQ $(10 \mu \mathrm{M})$ treatment was applied at $0,4,8,10,12$, $14 \mathrm{hr}$ after glutamate. Cell viability was detected by Calcein AM assay $(\mathrm{n}=8)$ and $(\mathrm{B})$ morphological changes of cells were observed microscopically. Representative experiments were independently repeated three times. Results are reported as mean \pm SEM. $* * * \mathrm{P}<0.001$ compared with glutamate-treated cells (one-way ANOVA, Tukey's test). 


\section{tBHQ prevents glutamate-induced ROS and mitochondrial superoxide generation.}

Since ROS accumulation is a hallmark of glutamate-induced cell death in HT-22 cells (Tan et al., 1998), we determined whether tBHQ inhibited glutamate-induced intracellular ROS accumulation using an ROS-sensitive fluorescence indicator, $\mathrm{H}_{2}$ DCFDA. The accumulation of ROS was elevated by 2 -fold after a $10 \mathrm{hr}$ exposure to glutamate. Application of tBHQ at 0 and 6 hr after glutamate abrogated this ROS accumulation (Figure 2.4A). A previous study revealed that glutamate also induced an increase in superoxide level in the mitochondria (Fukui et al., 2012). We then measured the mitochondrial superoxide level using the mitochondrial-specific superoxide indicator MitoSOX. Using FACS analysis, we observed that glutamate induced a 2fold increase of mitochondrial superoxide production. Even with a $6 \mathrm{hr}$ exposure delay, tBHQ attenuated the accumulation of mitochondrial superoxide (Fig. 2.4B \& C).
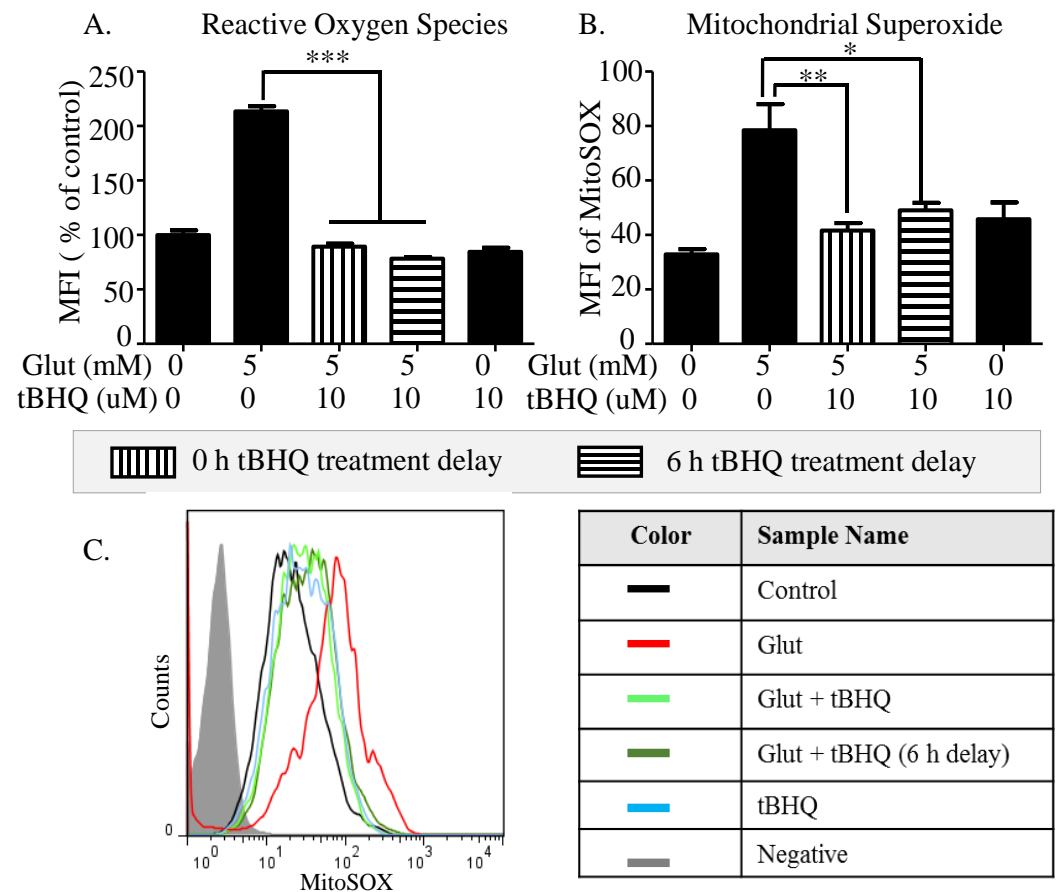

Figure 2.4. tBHQ prevents glutamate-induced ROS and mitochondrial superoxide in HT-22 cells. (A) HT-22 cells were treated with glutamate $(5 \mathrm{mM})$ for $10 \mathrm{hr}$. tBHQ $(10 \mu \mathrm{M})$ was applied at 0 or $6 \mathrm{hr}$ after glutamate exposure. ROS levels were detected by H2DCF and fluorescence was measured by plate reader $(\mathrm{n}=8)$. (B) tBHQ $(10 \mu \mathrm{M})$ was applied at 0 or $6 \mathrm{hr}$ after glutamate $(5 \mathrm{mM})$ exposure. Mitochondrial ROS was measured by mitoSOX after 11-hr treatment and quantified by FACS analysis $(\mathrm{n}=3)$. (C) Overlay of the FACS tracings for HT-22 cells staining with mitoSOX. All experiments were repeated three times and the results indicate the mean \pm SEM. $* \mathrm{P}<0.05, * * \mathrm{P}<0.01,{ }^{*} * * \mathrm{P}<0.001$ compared with glutamate-treated cells (one-way ANOVA, Tukey's test). 


\section{tBHQ prevents mitochondrial membrane potential disruption and mitochondrial calcium}

\section{overload induced by glutamate.}

It is well known that glutamate-induced oxidative damage causes the impairment of mitochondrial membrane potential and an increase of mitochondrial $\mathrm{Ca}^{2+}$ influx (Chen et al., 2003; Fukui et al., 2009). Thus, we evaluated the role of tBHQ in glutamate-compromised mitochondrial membrane potential using the NAO/TMRE fluorescence resonance energy transfer (FRET) assay, and we measured mitochondrial calcium levels using the fluorescent indicator Rhod-2 AM. Glutamate exposure induced a collapse of the mitochondrial intermembrane potential (Figure 2.5A) and a mitochondrial $\mathrm{Ca}^{2+}$ overload (Figure 2.5B \& C). Both simultaneous and delayed tBHQ exposures attenuated glutamate-induced mitochondrial membrane potential reduction and the increase in mitochondrial calcium levels. tBHQ alone did not have an appreciable effect on mitochondrial $\mathrm{Ca}^{2+}$ dynamic.

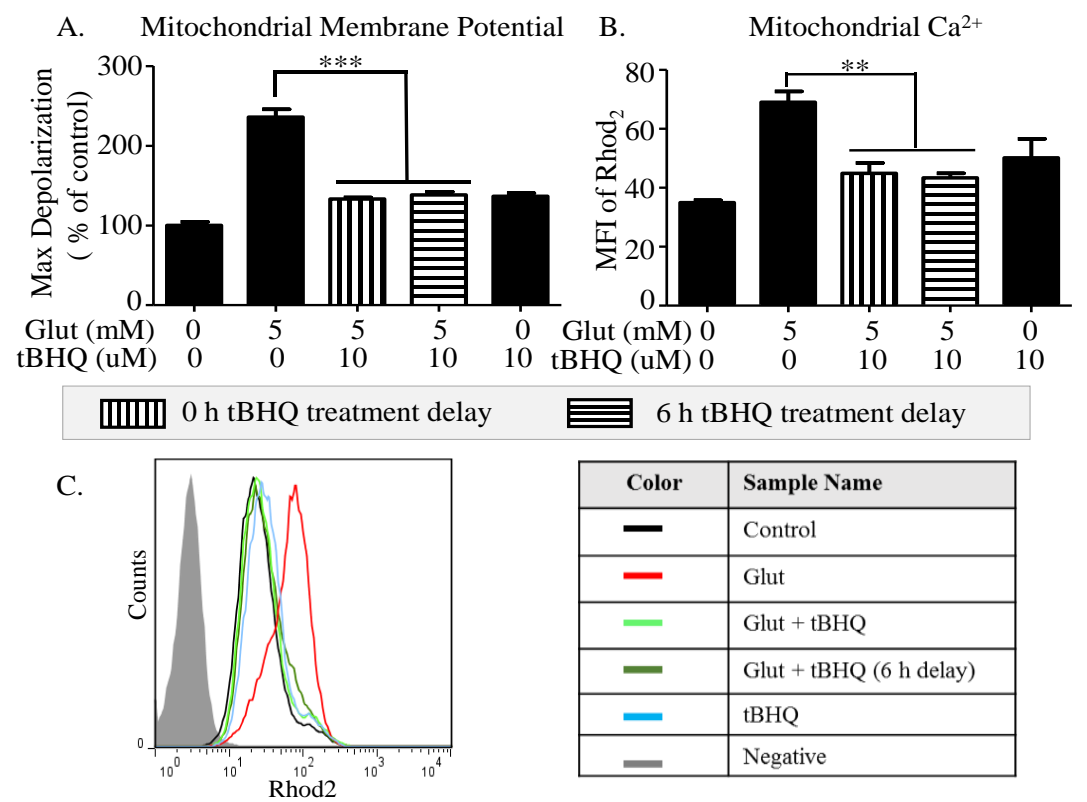

Figure 2.5. tBHQ prevents glutamate-induced mitochondrial membrane potential disruption and mitochondrial $\mathrm{Ca}^{2+}$ overload in $\mathrm{HT}$ 22 cells. (A) Cells were treated with $5 \mathrm{mM}$ glutamate. tBHQ $(10 \mu \mathrm{M})$ was applied simultaneously or $6 \mathrm{hr}$ after glutamate treatment. After 11-hr treatment with glutamate, mitochondrial membrane potential was measured by NAO/TMRE assay. Fluorescence of NAO was measured by a plate reader $(\mathrm{n}=8)$. (B) Cells were treated with glutamate $(5 \mathrm{mM})$ and tBHQ $(10 \mu \mathrm{M})$ was added at either 0 or $6 \mathrm{hr}$ after glutamate. Mitochondrial $\mathrm{Ca}^{2+}$ was measured by $\mathrm{Rhod}_{2}-\mathrm{AM}$ after 11-hr treatment and quantified by FACS analysis $(n=3)$. (C) Histogram overlay represents the Rhod2 levels in HT-22 cells. All experiments were repeated three times and the results indicate the mean \pm SEM. $* * \mathrm{P}<0.01, * * * \mathrm{P}<0.001$ compared with glutamate-treated cells (one-way ANOVA, Tukey's test). 


\section{tBHQ attenuated the exacerbation of mitochondrial respiration under glutamate toxicity.}

Mitochondrial respiration deficiency is a key index of mitochondrial failure (Lin \& Beal, 2006).

To determine the effect of glutamate and tBHQ exposure on mitochondrial respiration, we measured OCR using a Seahorse XFe96 analyzer (Figure 2.6A). Based on the OCR after application of stimuli, four parameters were calculated to evaluate mitochondrial respiration. Glutamate alone led to a $60 \%$ reduction in ATP production linked respiration, fully abolished maximal respiration and spare capacity; co-treatment with tBHQ ameliorated these effects of glutamate (Figure 2.6 B, C, D). Proton leak was not affected by glutamate or tBHQ (Figure 2.6E).
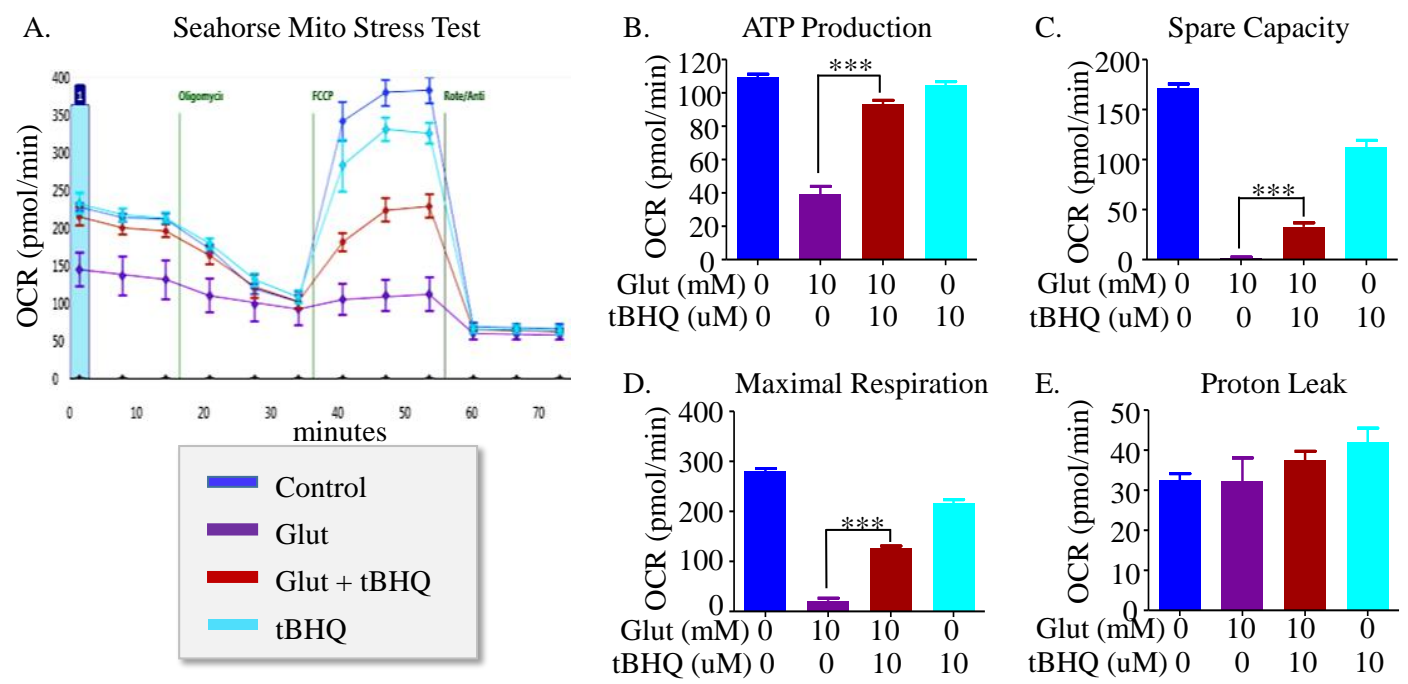

Figure 2.6. tBHQ prevents the impairment of mitochondrial metabolism induced by glutamate. After 12-hr treatment with $10 \mathrm{mM}$ glutamate and $10 \mu \mathrm{M} \mathrm{tBHQ}$, OCR was recorded by a Seahorse XFe96 flux analyzer $(n=8)$. (A) OCR recording at baseline and subsequent treatment of $1 \mu \mathrm{M}$ oligomycin, 0.5 $\mu \mathrm{M}$ FCCP, and a $1 \mu \mathrm{M}$ rotenone and antimycin mixture. ATP production (B), spare capacity (C), maximum respiration (D) and proton leak (E) were calculated. All experiments were repeated three times and the results indicate the mean \pm SEM. $* * * \mathrm{P}<0.001$ compared with glutamate-treated cells (one-way ANOVA, Tukey's test).

\section{tBHQ blocks mitochondria-mediated apoptosis under glutamate toxicity.}

Glutamate-induced oxidative stress triggers mitochondrial-mediated apoptosis by activating

Caspase 3/7 and AIF translocation to nucleus (Fukui et al., 2009; Landshamer et al., 2008). We explored the regulation of tBHQ on glutamate-induced mitochondrial-mediated apoptosis. 
Caspase 3/7 was not activated upon exposure of HT-22 cells to glutamate (Figure 2.7A), whereas the AIF level in the nuclear fraction was increased by almost 3 -fold after $16 \mathrm{hr}$ exposure to glutamate. tBHQ co-exposure inhibited glutamate-induced AIF translocation to the nucleus (Figure 2.7B). These findings were confirmed by immunocytochemistry. There was a clear translocation of AIF (Figure 2.7C, red) into the nucleus (Figure $2.7 \mathrm{C}$ blue) at $12 \mathrm{hr}$ after glutamate exposure; co-treatment with tBHQ prevented AIF translocation and preserved cell morphology.

\section{tBHQ is comparatively ineffective against electron transport chain (ETC) blockage- induced toxicity.}

In view of the ability of tBHQ to prevent mitochondrial dysfunction in response to glutamate, we determined if tBHQ protected cells from mitochondrial-specific toxins. Exposure to oligomycin $(20 \mu \mathrm{M})$, an ATP synthase inhibitor, increased cell death by approximately by $40 \%$, and this effect was partially rescued by tBHQ exposure (Figure 2.8A). FCCP, a protonophore, disrupts the mitochondrial proton gradient by transporting protons across the membrane. Exposure of cells to FCCP $(10 \mu \mathrm{M})$ alone reduced cell viability to $20 \%$ of control $24 \mathrm{hr}$ after exposure; coexposure with tBHQ exerted moderate protection (Figure 2.8B). Rotenone reduces oxidative phosphorylation by inhibition of mitochondrial complex I activity. Exposure of cells to Rotenone $(10 \mu \mathrm{M})$ induced $20 \%$ cell death, but tBHQ did not protect cells from rotenone-induced cytotoxicity in HT-22 cells (Figure 2.8C). Compared to the efficacy of tBHQ's protection against

glutamate-induced cytotoxicity, we conclude that tBHQ is comparatively ineffective against ETC blockage-induced toxicity in HT-22 cells. 
A.

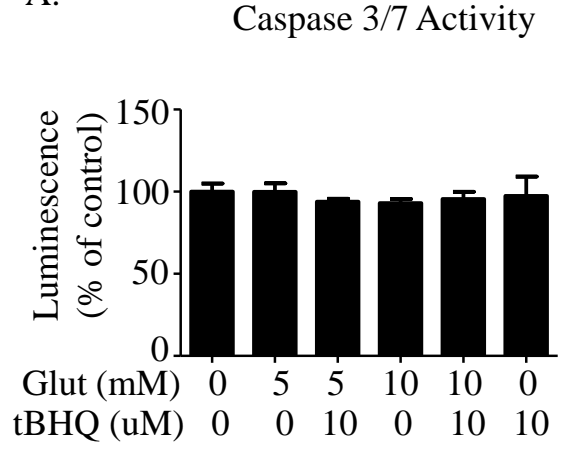

B. AIF

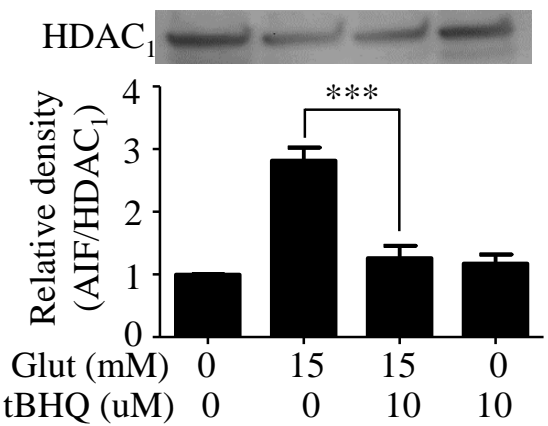

C.
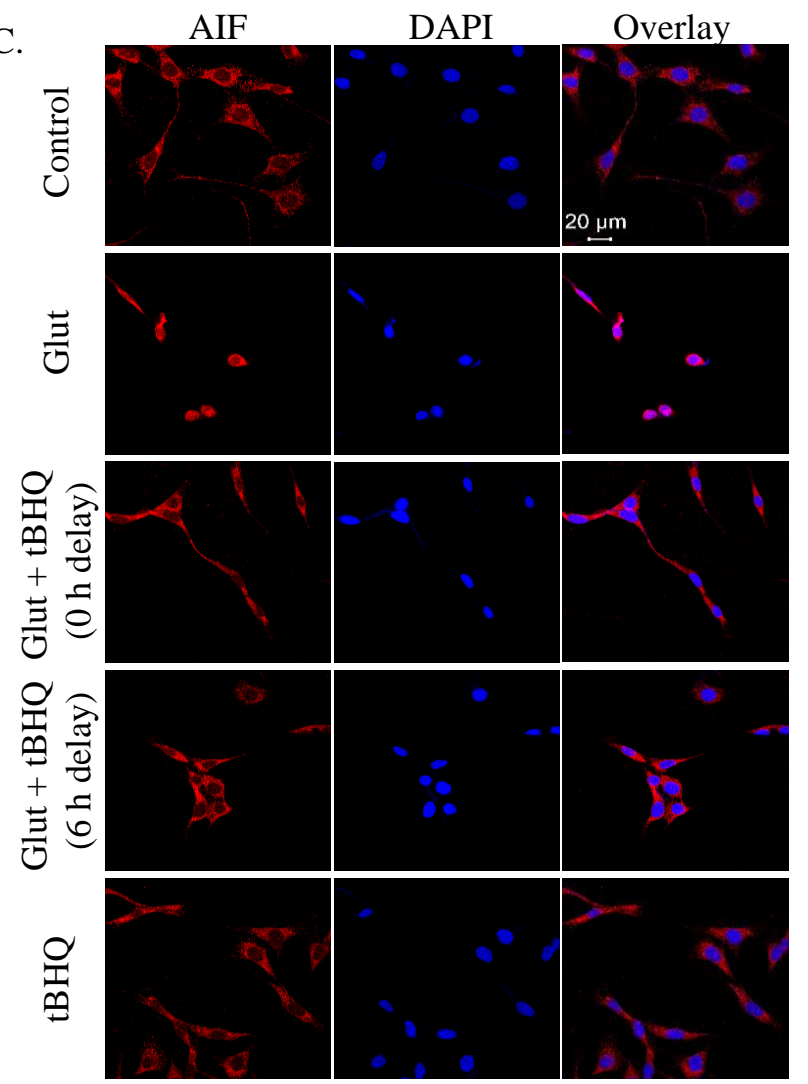

Figure 2.7. tBHQ inhibits glutamate-induced mitochondrial AIF-mediated apoptosis. (A) After 11-hr treatment of glutamate $(5$ and $10 \mathrm{mM})$ and tBHQ $(10 \mu \mathrm{M})$, caspase $3 / 7$ activities were measure ( $\mathrm{n}=3$ ). (B) After 16-hr treatment with $15 \mathrm{mM}$ glutamate and 10 $\mu \mathrm{M}$ tBHQ, AIF level in nuclear fraction was measured by western blot. Quantitation of AIF was normalized to $\mathrm{HDAC}_{1}$. Bars represent normalized relative densities plotted as mean \pm SEM calculated from 4 independent experiments. (C) Immunocytochemistry for AIF (red) and DAPI (blue). Images were captured at a 12-hr exposure time to $5 \mathrm{mM}$ glutamate and $10 \mu \mathrm{M}$ tBHQ by confocal microscopy. All experiments were repeated at least three times and the results indicate the mean \pm SEM. $* * * \mathrm{P}<0.001$ compared with glutamate-treated cells (one-way ANOVA, Tukey's test). 


\section{tBHQ causes a rapid up-regulation of $\mathrm{SOD}_{2}$ expression and a delayed up-regulation of HO-}

\section{1 expression.}

The neuroprotective treatment of tBHQ can be delayed up to $8 \mathrm{hr}$; the time before cells loss normal cell morphology, and we observed cell death after $11 \mathrm{hr}$ of glutamate exposure (Figure 2.1B). These data indicate that the protection of tBHQ is initiated within $3 \mathrm{hr}$ after application. Next, we investigated the underlying mechanisms accounting for the time-course of this protection. Since GSH depletion is the primary cause of glutamate-induced toxicity, we first measured the GSH level after tBHQ and glutamate exposure. Glutamate induced a profound reduction in GSH synthesis, which was not ameliorated by tBHQ. However, tBHQ alone increased intracellular GSH level by $20 \%$ (Figure 2.9A). tBHQ, a phenolic compound, has been reported to be a free radical scavenger (Figure 2.9B) (Alamed et al., 2009). We then determined if tBHQ served as an antioxidant by scavenging ROS. Within 30 min of exposure, tBHQ prevented $\mathrm{H}_{2} \mathrm{O}_{2}$-induced intracellular ROS accumulation (Figure 2.9C). These data indicate that tBHQ does not prevent the reduction of GSH level induced by glutamate, but does function as a free radical scavenger to eliminate glutamate-induced oxidative stress.
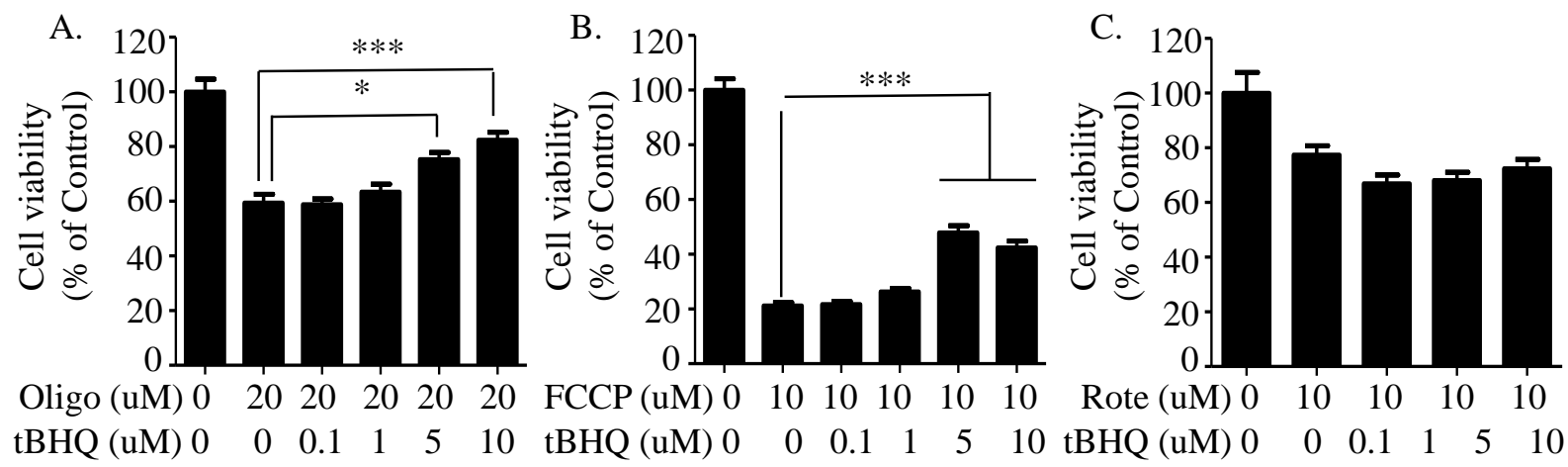

Figure 2.8. tBHQ is comparatively ineffective against mitochondrial ETC blockage-induced toxicity. HT22 cells were treated with $10 \mu \mathrm{M}$ oligomycin (A), $10 \mu \mathrm{M}$ FCCP (B), $10 \mu \mathrm{M}$ rotenone (C) and 1-10 $\mu \mathrm{M}$ tBHQ for $24 \mathrm{hr}$. Cell viability was measured by Calcein AM assay. Each experiment was repeated at least three time. Results are reported as mean \pm SEM. $* \mathrm{P}<0.05$, *** $\mathrm{P}<0.001$ compared with ETC stimuli (oligomycin, FCCP, rotenone) treatment only group (one-way ANOVA, Tukey's test). 
Further, we examined if the protection of tBHQ worked through its free radical scavenging activity. HT-22 cells were pretreated with tBHQ for $12 \mathrm{hr}$ and then cultures were incubated with glutamate in fresh medium without tBHQ. After $24 \mathrm{hr}$ exposure to treatments, cell viability was measured. As shown in Figure 2.9D, the protective effect was observed $24 \mathrm{hr}$ after removal of tBHQ. This indicates that the protection of tBHQ is not due to a radical scavenging effect for this chemical. Morphological changes after tBHQ and glutamate exposure were observed microscopically (Figure 2.9E).

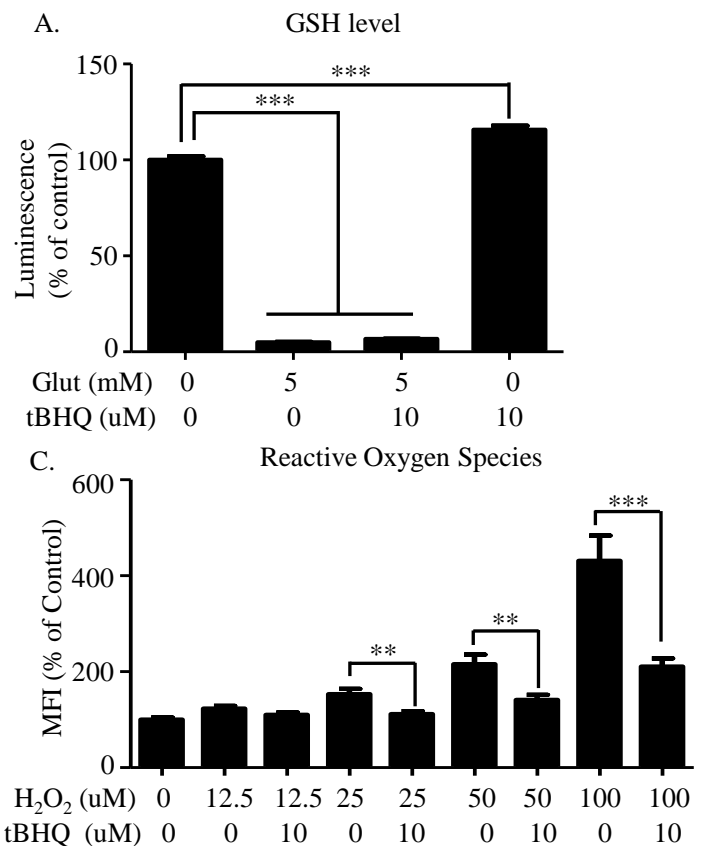

B.

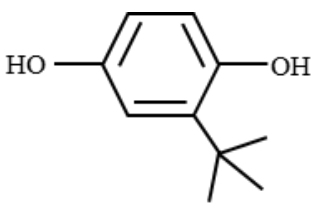

D.
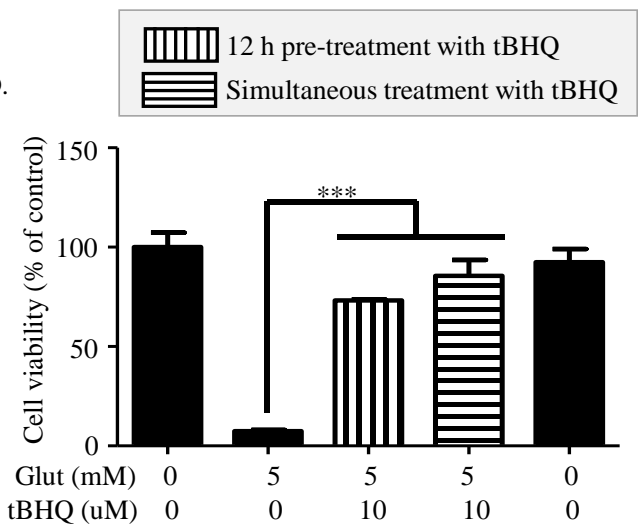

E.

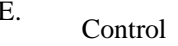

Glut

Glut + tBHQ (12h pre-treatment)

Glut + tBHQ

(Simultaneous)

tBHQ
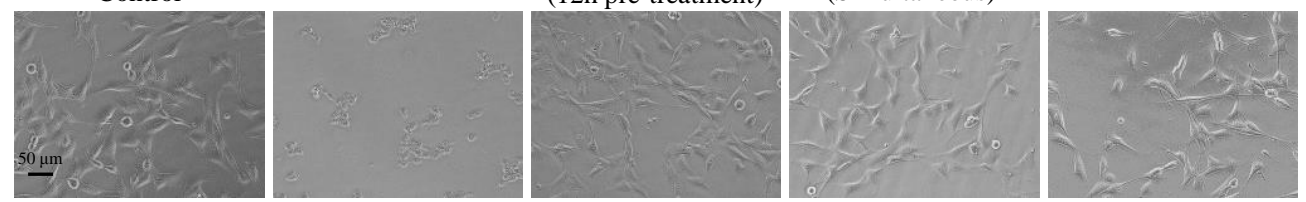

Figure 2.9. tBHQ fails to block glutamate-induced GHS depletion, but scavenges intracellular ROS. (A) GSH level was detected at $8 \mathrm{hr}$ after treatment with $5 \mathrm{mM}$ glutamate and $10 \mu \mathrm{M} \mathrm{tBHQ}(\mathrm{n}=5)$. (B) Chemical structure of tBHQ. (C) HT-22 cells were treated with $\mathrm{H}_{2} \mathrm{O}_{2}(12.5-100 \mu \mathrm{M})$ and tBHQ $(10 \mu \mathrm{M})$ from 30 min. ROS levels were detected by $\mathrm{H}_{2} \mathrm{DCF}$ and fluorescence was measured by plate reader (n=8). (D) HT-22 cells were pretreated with tBHQ for $12 \mathrm{hr}$ and then cultures were incubated in glutamate in fresh medium without tBHQ. After $24 \mathrm{hr}$ exposure of treatments, cell viability was measured by Calcein AM assay $(n=8)$. Simultaneous treatment of tBHQ was used as positive control. (E) Morphological changes of cells were observed microscopically. Results are reported as mean $\pm \mathrm{SEM}$. ** $\mathrm{P}<0.01$, *** $\mathrm{P}<0.001$ compared with glutamate treatment only group (one-way ANOVA, Tukey's test). 
Next, we investigated if activation of Nrf2 and its regulated gene expression by tBHQ contributes to its protection. There was a clear translocation of Nrf2 (Figure 2.10, red) into the nucleus (Figure 2.10, blue) at $1.5 \mathrm{hr}$ after tBHQ exposure; this co-localization was diminished with prolonged tBHQ exposure. HO-1 has been reported as an important target to prevent glutamate-induced oxidative damage in HT-22 cells (Rössler et al., 2004; Satoh et al., 2003). Therefore, we monitored the time-dependent change in HO-1 protein expression following tBHQ exposure. There was no significant change of HO-1 level within $3 \mathrm{hr}$ exposure of tBHQ, however a 30-fold increase of HO-1 expression was observed at $12 \mathrm{hr}$ after tBHQ treatment (Figure 2.11A). Previous studies have demonstrated that Nrf2-ARE signaling pathway regulates $\mathrm{SOD}_{2}$ expression (Dong et al., 2008; Piantadosi et al., 2008; Yan et al., 2010), and $\mathrm{SOD}_{2}$ plays a critical role in protecting HT-22 cells against glutamate-mediated cytotoxicity (Stocker et al., 1987). Our data showed a 2 -fold increase of $\mathrm{SOD}_{2}$ expression after $3 \mathrm{hr}$ of exposure to tBHQ (Figure 2.11B); while, $\mathrm{SOD}_{2}$ level returned to normal with prolonged tBHQ exposure (data not presented). As such, we asked if this rapid up-regulation of $\mathrm{SOD}_{2}$ expression is a key factor contributing to the protection offered by tBHQ.

\section{Delayed treatment of tBHQ fails to prevent glutamate-induced cell death in $\mathrm{SOD}_{2}$ knockdown HT-22 cells.}

To characterize the role of $\mathrm{SOD}_{2}$ in tBHQ-mediated protection, we transfected HT-22 cells with siRNA targeting $\mathrm{SOD}_{2}$. After 24- or 36-hr exposure to siNRA, a transfection efficiency of $>90 \%$ was achieved. $\mathrm{SOD}_{2}$ expression was reduced by $45 \%$ after $24-\mathrm{hr}$ transfection (Supplemental Figure 2.1). As shown in Figure 2.12A, $\mathrm{SOD}_{2}$ protein level was reduced by $65 \%$ at $36 \mathrm{hr}$ after transfection, the time we selected for the following study. We compared the protection efficacy of tBHQ in scrambled siRNA transfected and $\mathrm{SOD}_{2}$ knockdown HT-22 cells. After $18 \mathrm{hr}$ 
treatment of glutamate, cell morphological changes were observed (Figure 2.12B). In $\mathrm{SOD}_{2}$ knockdown HT-22 cells, simultaneous treatment of tBHQ was still able to protect cells from glutamate toxicity. However, silencing $\mathrm{SOD}_{2}$ attenuated the protective effect of delayed tBHQ exposure (Figure 2.12C).

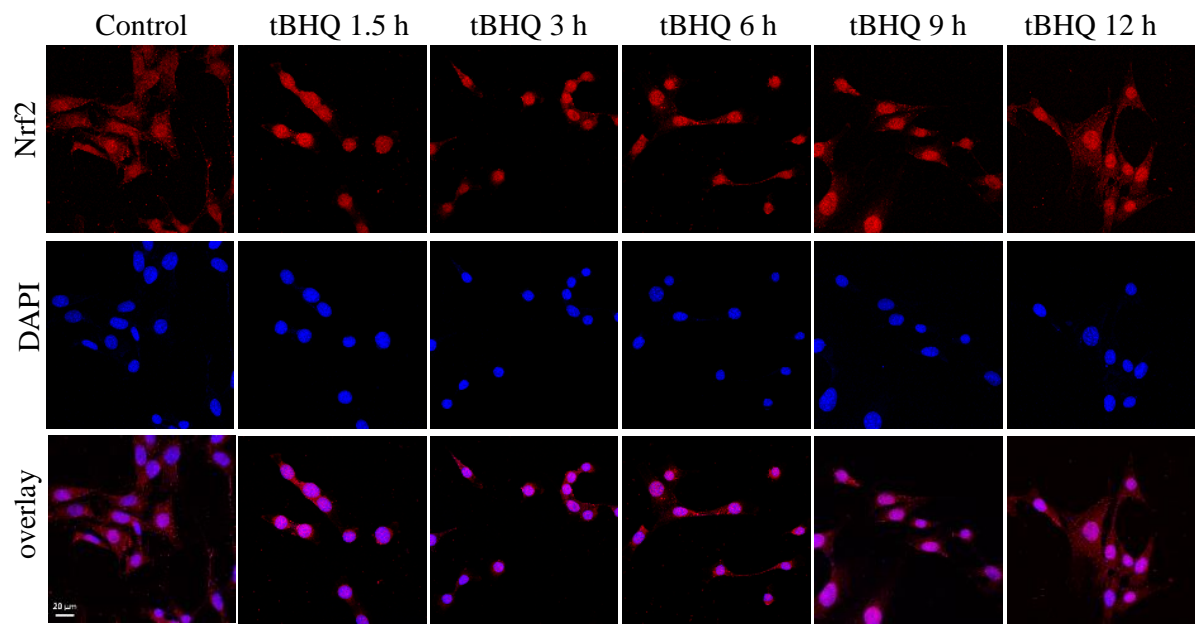

Figure 2.10. tBHQ induces a rapid activation of Nrf2-ARE signaling pathway. HT-22 cells were treated with $10 \mu \mathrm{M}$ tBHQ. Immunocytochemistry for Nrf2 (red) and DAPI (blue). Images were captured at 1.5, 3, 6, 9, $12 \mathrm{hr}$ exposure to tBHQ by confocal microscopy. Each experiment was repeated at least three time.
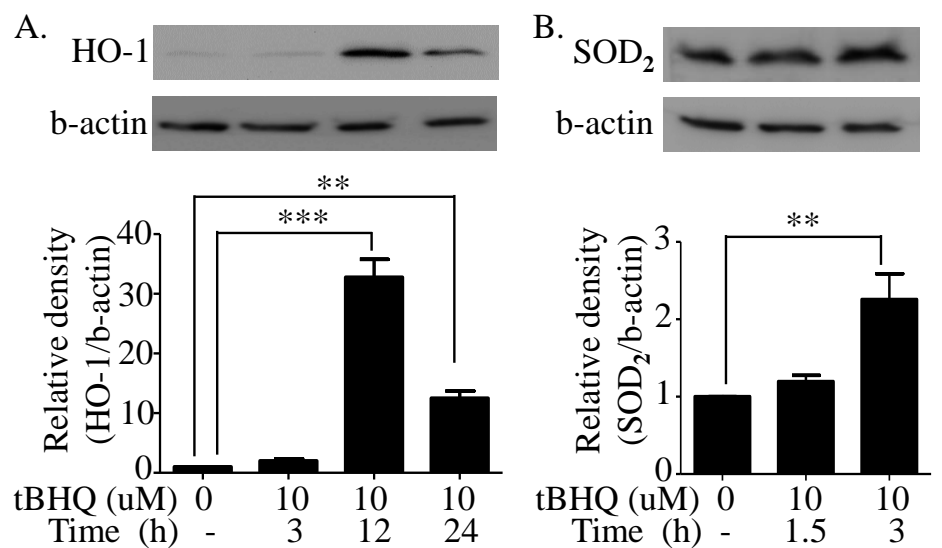

Figure 2.11. tBHQ induces a rapid increase of $\mathrm{SOD}_{2}$ expression following by a delayed up-regulation of HO-1 expression. HT-22 cells were treated with $10 \mu \mathrm{M}$ tBHQ. Samples were collected at 1.5, 3, 12, $24 \mathrm{hr}$ after tBHQ exposure. Cell extracts were subjected to immunoblot with antibodies specific for HO-1 (A) and $\mathrm{SOD}_{2}(\mathrm{~B})$. Quantitation of $\mathrm{HO}-1$ and $\mathrm{SOD}_{2}$ was normalized to $\beta$-actin. Bars represent normalized relative densities plotted as mean \pm SEM calculated from 4 independent blots. **P $<0.01$, $* * * \mathrm{P}<0.001$ compared with control group (one-way ANOVA, Tukey's test). 


\section{tBHQ reduces both glutamate and BSO mediated cytotoxicity in primary cortical neurons.}

Exposure of immature cortical neurons to glutamate or BSO has been previously shown to results in a time-dependent depletion of GSH (Li et al., 1997b). We exposed primary rat cortical neurons to either glutamate or BSO. A 24-hr exposure of 5mM glutamate caused the disruption of neurites and the shrinkage of cell bodies. With simultaneous exposure to tBHQ $(2.5-10 \mu \mathrm{M})$, glutamate-induced cell damage was significantly ameliorated. Glutamate induced a marked decrease in Calcein AM fluorescence, which was protected with tBHQ exposure (Figure 2.13A). Light microscopic analysis of cultures exposed to BSO $(500 \mu \mathrm{M})$ identified the disruption of neural networks and morphological changes consistent with Calcein AM data. Co-treatment of tBHQ (2.5-10 $\mu \mathrm{M})$ protected neurons from BSO-mediated cytotoxicity (Figure 2.13B). 

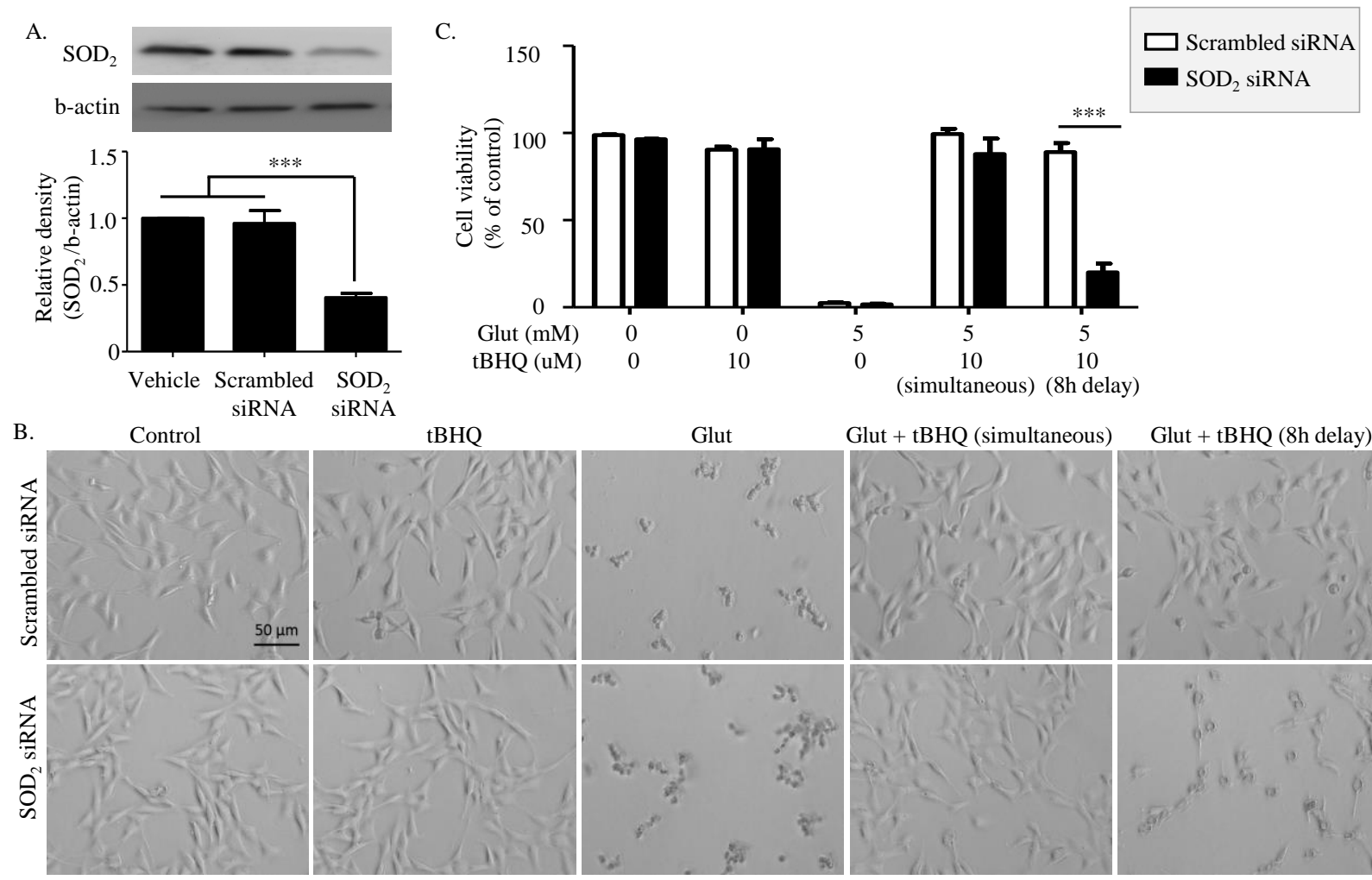

Glut + tBHQ (simultaneous)

Glut + tBHQ (8h delay)

Figure 2.12. Delay treatment of tBHQ fail to overcome glutamate-induced cell death in $\mathrm{SOD}_{2}$ knockdown HT-22 cell line. (A) HT-22 cells were transfected with scrambled and $\mathrm{SOD}_{2}$ siRNA for $36 \mathrm{hr}$. Transfection efficiency was measured by western blot with antibody specific for $\mathrm{SOD}_{2}$. $\beta$-actin was used to normalize loading. Bars represent normalized relative densities plotted as

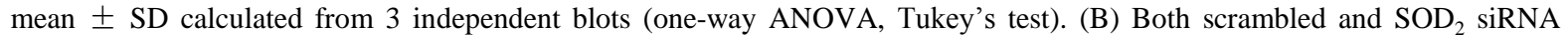
transfected HT-22 cells were treated with $5 \mathrm{mM}$ glutamate. tBHQ was applied either simultaneously or $8 \mathrm{hr}$ after glutamate exposure. Morphological changes of cells after respective treatments were observed by microscopically. (C) Based on the morphology, cells in each photomicrograph were counted and calculated to represent cell viability. Experiments were repeated three times independently. Results are reported as mean $\pm \mathrm{SEM}$. $* * * \mathrm{P}<0.001$ compared with glutamate treatment only group (two-way ANOVA, Bonferroni's test). 


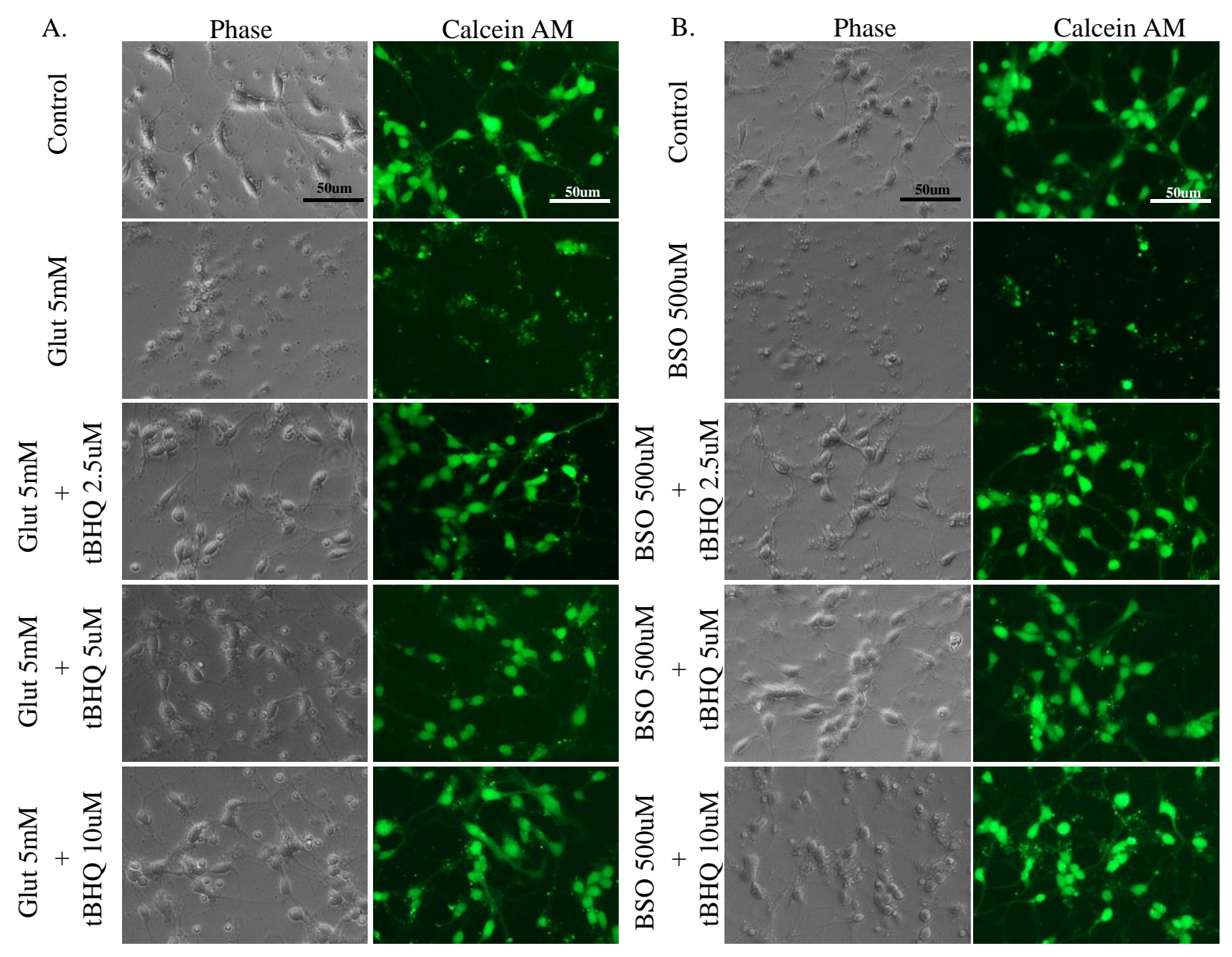

Figure 2.13. tBHQ reduces both glutamate and BSO mediated cell death in immature primary rat cortical neurons. One-day-old primary cultures prepared from embryonic day 17 rats were treated with glutamate $(5 \mathrm{mM})$, BSO $(500 \mathrm{uM})$ and tBHQ $(2.5-10 \mu \mathrm{M})$ for $24 \mathrm{hr}$. Phase contrast images and calcein AM staining fluorescence pictures were photographed. Representative experiments were independently repeated three times. 


\subsection{Discussion}

The present study demonstrates that tBHQ prevents cell death by GSH depletion-induced oxidative toxicity in both HT-22 cells and primary cortical neurons. In addition, this protection is observed with an 8-hr treatment delay of tBHQ through blocking glutamate-induced intracellular ROS accumulation and rescuing mitochondrial function in HT-22 cells. Glutamate activates mitochondria-mediated apoptosis, which is also inhibited by tBHQ. Further, tBHQ activates the expression of anti-oxidative enzymes, $\mathrm{SOD}_{2}$ and $\mathrm{HO}-1$, which contributes to its protective effect. This study is the first to demonstrate the role of tBHQ in preserving mitochondrial function during oxidative challenge.

Glutamate-induced excessive ROS accumulation leads to the loss of the proton gradient and disruption of the mitochondrial membrane potential. Our data demonstrate that tBHQ stabilizes mitochondrial membrane potential and maintains mitochondrial respiration under glutamate toxicity. The chemiosmotic hypothesis, identified by Peter Mitchell, describes the importance of mitochondrial membrane potential for mitochondrial ATP production (Mitchell, 1966). We speculate that tBHQ prevents mitochondrial membrane potential collapse by eliminating excessive ROS, which is positively correlated to improved mitochondrial metabolism. It is notable that $\mathrm{tBHQ}$ fully preserves ATP production linked respiration with a mild recovery of mitochondrial spare capacity (Figure 2.6C). This indicates that tBHQ blocks glutamate-induced energy crisis, but the amount of extra ATP, which is produced in case of a sudden increase in energy demand, is not fully recovered. It is well known that mitochondrial $\mathrm{Ca}^{2+}$ uptake regulates intracellular $\mathrm{Ca}^{2+}$ homeostasis (Rizzuto et al., 2012); mitochondrial $\mathrm{Ca}^{2+}$ overload induced by oxidative stress orchestrates execution of apoptosis (Mattson \& Chan, 2003; Orrenius et al., 2003; Ott et al., 2007). Previous studies suggest that the truncation of AIF by calpain is necessary for 
its release from mitochondria and triggering apoptotic cell death (Cregan et al., 2002; Susin et al., 1999). Calpains are a family of $\mathrm{Ca}^{2+}$-dependent cysteine proteases, which can be activated upon mitochondrial $\mathrm{Ca}^{2+}$ overload (Smith \& Schnellmann, 2012). tBHQ blocks glutamate-induced mitochondrial $\mathrm{Ca}^{2+}$ overload (Figure 2.5B and $\mathrm{C}$ ), which may contribute to its prevention of calpain activation. This provides an explanation of how tBHQ restrains AIF-mediated apoptosis under glutamate toxicity. Consistent with previous reports, no significant activation of caspase 3/7 was observed during glutamate-induced oxidative toxicity (Tan et al., 1998; van Leyen et al., 2005; Zhang \& Bhavnani, 2006). Caspase activation during the initiation of apoptosis requires ATP (Fukui et al., 2009; Hu et al., 1999; Li et al., 1997a). Fukui et al. (2010) reported that the lack of caspase 3/7 activation may results from rapid onset of mitochondrial dysfunction and energy depletion induced by glutamate.

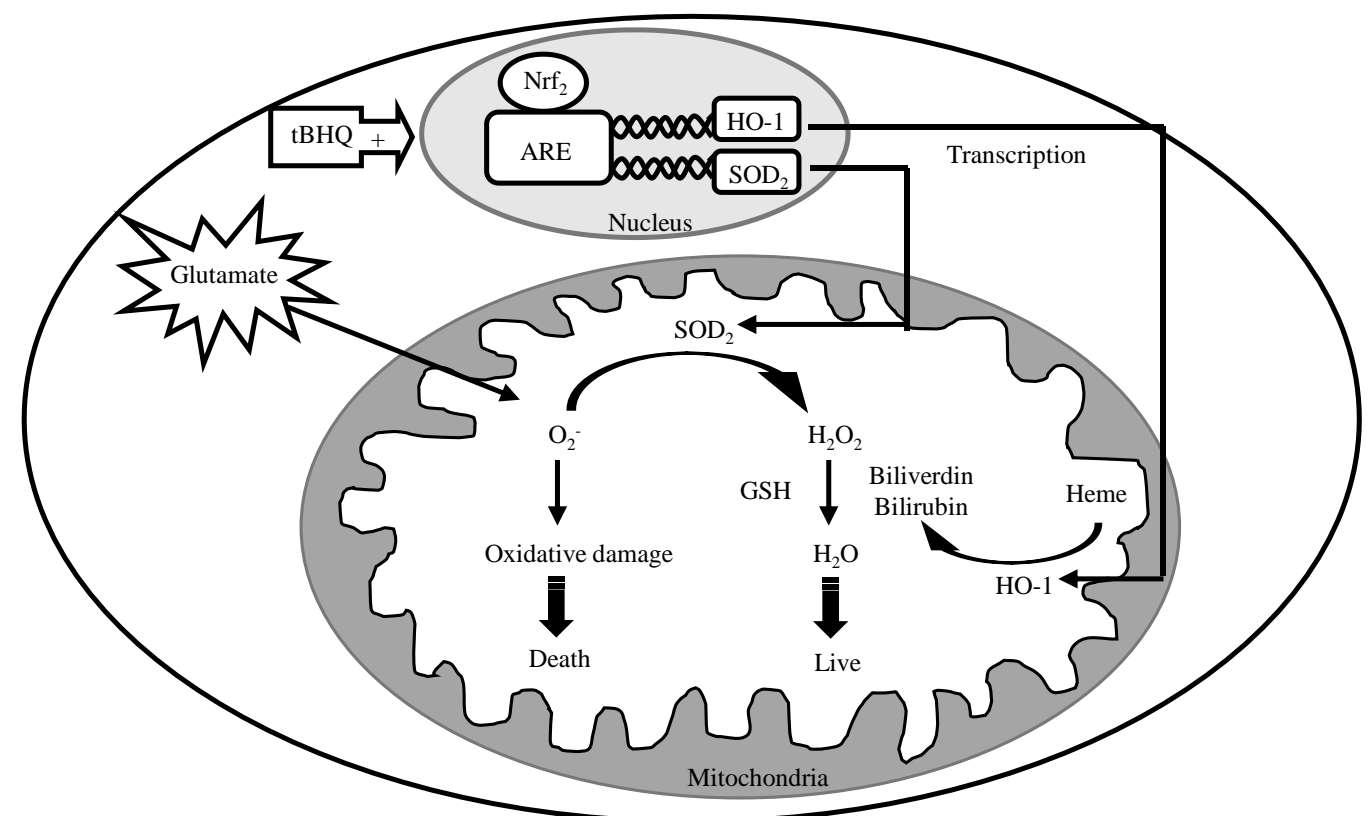

Figure 2.14. Diagram of the protective effect of tBHQ on mitochondrial against glutamate-induced oxidative stress. Through depletion of GSH synthesis, glutamate induces the oxidative damage to mitochondria in HT-22 cells. Mitochondrial $\mathrm{O}_{2} \cdot{ }^{-}$is eliminated by $\mathrm{SOD}_{2}$ and converted to $\mathrm{H}_{2} \mathrm{O}_{2}$. The detoxification of $\mathrm{H}_{2} \mathrm{O}_{2}$ requires the participation of biliverdin and bilirubin, ROS scavengers, which highly rely on HO-1 activity. tBHQ induces a rapid increase of SOD 2 expression and a delay up-regulation of HO-1 level. Sequential cooperation of $\mathrm{SOD}_{2}$ and HO-1 improve mitochondrial antioxidative ability and redox balance, which extricates cells from glutamate-induced oxidative stress. 
It has been shown that ROS accumulation adversely affects the mitochondrial ETC (Tan et al., 1998). Our observation that fully blocking glutamate-induced ROS generation by tBHQ (Figure 2.4) prompted us to investigate its effects on ETC function. As previously reported, oligomycin impedes the conversion of ADP to ATP, and induces a burst of cellular ROS levels (over 10-fold) in HT-22 cells (Liu \& Schubert, 2009). Similarly, inhibition of mitochondrial complex I activity by rotenone leads to a 3-fold increase in ROS, and cell death in HT-22 cells (Panee et al., 2007; Poteet et al., 2012). High concentration of FCCP causes a complete disruption of mitochondrial membrane potential, and triggers the apoptotic signaling cascade (Dispersyn et al., 1999). Briefly, ETC is associated with ROS accumulation and blockage of ETC leads to cell death. Our results reveal that tBHQ is comparatively ineffective against direct mitochondrial ETC inhibitors (Figure 2.8). These data argue that tBHQ indirectly protects mitochondria against glutamateinduced toxicity. However, Holmström et al. reported that Nrf2 directly regulates cellular energy metabolism through modulating the availability of substrates for mitochondrial respiration (Holmstrom et al., 2013).

Consistent with previous findings, we have observed that HT-22 cell death following $5 \mathrm{mM}$ glutamate exposure is delayed until $11 \mathrm{hr}$ and maximal by $16 \mathrm{hr}$ after exposure (Figure 2.1B) (Tobaben et al., 2011). With up to an 8-hr exposure delay, tBHQ prevented glutamate-induced cell death. This indicates that, within $3 \mathrm{hr}$ after application, tBHQ efficiently maintains mitochondrial function and further prevents cells damage. Up-regulation of HO-1 expression has been shown to prevent glutamate-induced oxidative toxicity in HT-22 cells (Chao et al., 2014; Rössler et al., 2004; Son et al., 2013). However, the temporal profile of expression of $\mathrm{SOD}_{2}$ and HO-1 shows that peak $\mathrm{SOD}_{2}$ expression occurs at $3 \mathrm{hr}$ but $\mathrm{HO}-1$ expression does not peak until $12 \mathrm{hr}$ following exposure to tBHQ (Figure 2.11). This indicates that elevation of HO-1 level is 
not the primary factor contributing to its acute protective effect. These data are similar to previous studies showing the time course of increased expression of $\mathrm{SOD}_{2}$ (Fukui et al., 2010) and HO-1 (Chao et al., 2014) in response to other polyphenols, suggesting that this temporal profile is a generalizable phenomenon. For simultaneous treatment of HT-22 cells with glutamate and $\mathrm{tBHQ}$, both $\mathrm{SOD}_{2}$ and $\mathrm{HO}-1$ expression were increased before cell death, which allow either or both to protect cells. However, only $\mathrm{SOD}_{2}$ expression was up-regulated by a delayed treatment with tBHQ and able to offer protection to cells. In $\mathrm{SOD}_{2}$ knockdown cells, simultaneous treatment of tBHQ was still protective to cells through an increase in HO-1 expression, which was peaked at about the time that HT-22 cells begin to die. However, with tBHQ exposure delay, absent a $\mathrm{SOD}_{2}$ response and given the long delay for the HO-1 response, cells are not protected (Figure 2.12). In summary, tBHQ ameliorates glutamate-mediated cytotoxicity by sequentially increasing $\mathrm{SOD}_{2}$ and $\mathrm{HO}-1$ expression. This coordinated activation of $\mathrm{HO}-1$ with $\mathrm{SOD}_{2}$ is consistent with their roles as anti-oxidative enzymes. As shown in Figure 2.14, $\mathrm{SOD}_{2}$ scavenges the highly cytotoxic mitochondrial superoxide $\left(\mathrm{O}_{2} \cdot^{-}\right)$and converts it to hydrogen peroxide $\left(\mathrm{H}_{2} \mathrm{O}_{2}\right)$. However, the detoxification of $\mathrm{H}_{2} \mathrm{O}_{2}$ requires biliverdin and bilirubin to serve as scavengers of the mitochondrial $\mathrm{H}_{2} \mathrm{O}_{2}$. The formation of bilirubin relies on catalysis of HO-1 during heme metabolism (Dore \& Snyder, 1999; Stocker et al., 1987). Therefore, we conclude that $\mathrm{tBHQ}$ activates the expression of anti-oxidative enzymes in a time-dependent sequence based on their physiological function. In our study, we also found that tBHQ serves as an antioxidant by scavenging ROS (Figure 2.9C). However, our results showed that the protection of tBHQ was abolished in $\mathrm{SOD}_{2}$ knockdown cells when tBHQ exposure was delayed for a time that prevented HO-1 expression (Figure 2.12). This indicates that free radical scavenging is not sufficient for tBHQ to rescue cells from glutamate toxicity. Overall, our study 
allows us to speculate that the protective effect of tBHQ is achieved by two mechanisms: a rapid up-regulation of $\mathrm{SOD}_{2}$ and a delayed activation of HO-1 expression (Figure 2.15).

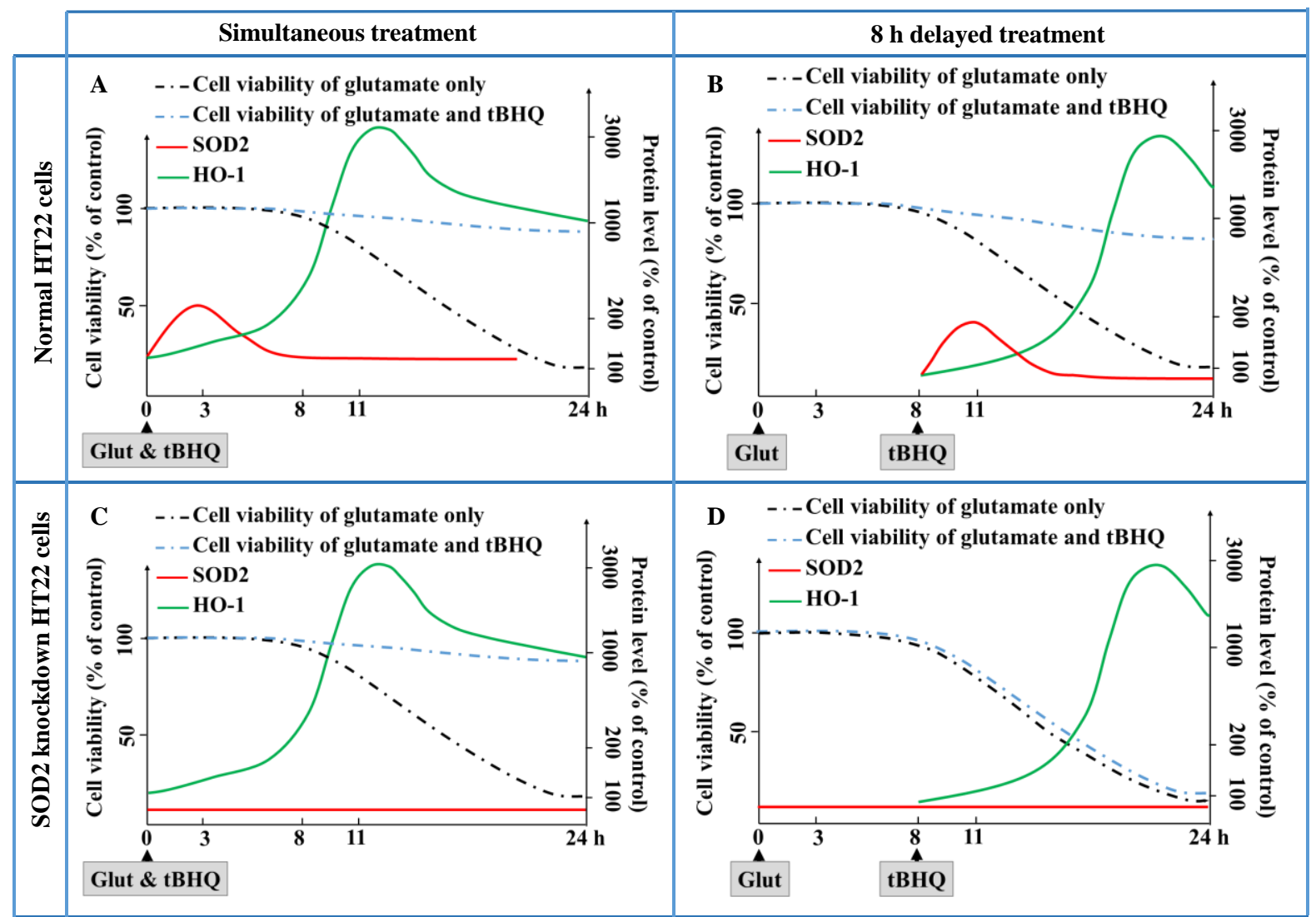

Figure 2.15 schematic depiction of cell viability and protein expression following glutamate and tBHQ exposure.

In our study, a major limitation is the method used to evaluate ROS generation. Even though DCF as a general indictor of the level of intracellular oxidative stress as it is routinely used for this indication (Fukui et al., 2010; Kang et al., 2014; Tobaben et al., 2011), DCF does not identify the species of reactive oxygen that is elevated. Similarly, MitoSOX is routinely used to assay superoxide (Fukui \& Zhu, 2010; Mukhopadhyay et al., 2007; Pfeiffer et al., 2014), and as it is taken up by mitochondria, it assays superoxide in this organelle (Robinson et al., 2008). However, the MitoSOX indicator does not identify if the superoxide originates in the mitochondria. As the vast majority of superoxide is produced in mitochondria as a result of 
electron leak during oxidative phosphorylation (Brand et al., 2004; Brand, 2010; Rössler et al., 2004), we assumed that the identified superoxide comes from mitochondria. The second limitation is that our study mainly focused on $\mathrm{SOD}_{2}$ and $\mathrm{HO}-1$, which was based on our review of the literature, and evidence that over expression of $\mathrm{SOD}_{2}$ or $\mathrm{HO}-1$ attenuated glutamateinduced cell death in HT-22 cells (Fukui \& Zhu, 2010; Rössler et al., 2004). However, it is well known that Nrf2 induces the expression of a wide range of enzymes involved in the maintenance of mitochondrial and cellular redox homeostasis (Bell \& Hardingham, 2011; Panee et al., 2007; Ray et al., 2012). Notably, we found that $6 \mathrm{hr}$ delay of exposure to tBHQ inhibits glutamateinduced ROS generation at $7.5 \mathrm{hr}$ after glutamate exposure (Supplemental Figure 2.2). This indicates that glutamate-induced ROS accumulation was attenuated by tBHQ even before $\mathrm{SOD}_{2}$ expression was elevated. Our results suggest that other antioxidative enzymes may mediate the protection of tBHQ. In addition, multiple pathways regulate the expression of $\mathrm{SOD}_{2}$ and HO-1 (Immenschuh \& Ramadori, 2000; Miao \& St. Clair, 2009). Therefore, Nrf2-ARE signaling pathway may not be the only factor activating the transcription of these enzymes in the current model, which needs to be addressed in future studies.

It is very important to note that tBHQ also protects against oxidative stress-induced death in primary cortical neurons. This experiment was done in an effort to confirm that the profound protective effect of tBHQ on oxidative stress-mediated cell damage was not specific to a transformed cell line. These significant data may provide a clinically-relevant argument for using tBHQ against acute neuron-compromising conditions. 

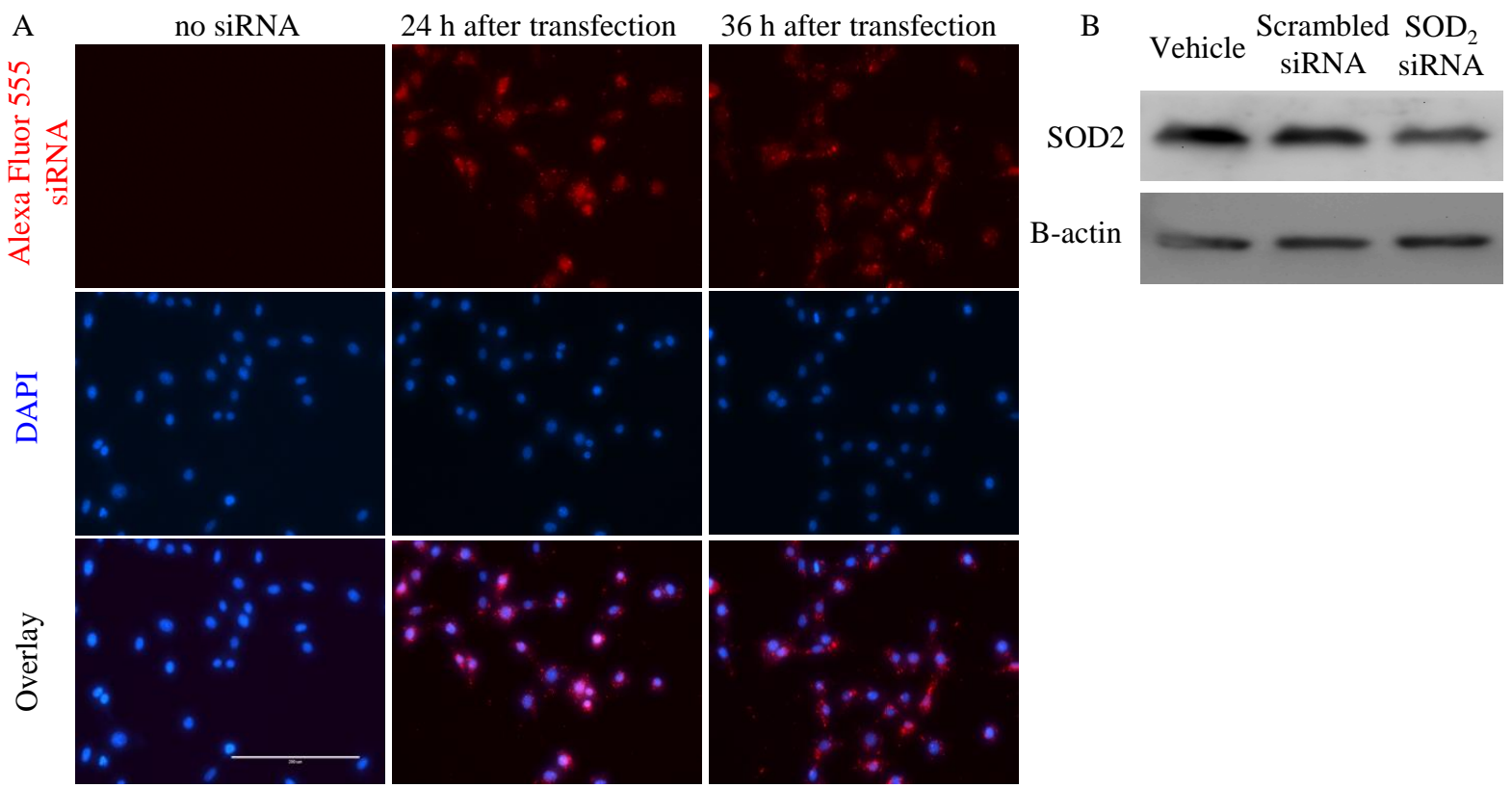

Supplemental Figure 2.1. Transfection efficiency testing in HT-22 cells. (A) Block-iT Alexa Fluor Red fluorescent control (Invitrogen) was used for determination of efficiency of siRNA transfection. HT-22 cells were transfected for 24-36 hr. Nuclei were counterstained with DAPI (blue). Block-iT Alexa Fluor Red fluorescent control (red) were observed and photographed using a fluorescence microscope. Scale bar=200uM (B) HT-22 cells were transfected with scrambled and SOD2 siRNA for $24 \mathrm{hr}$. SOD2 level was measured by western blot with antibody specific for SOD2. $\beta$ actin was used to normalize loading. 
A.

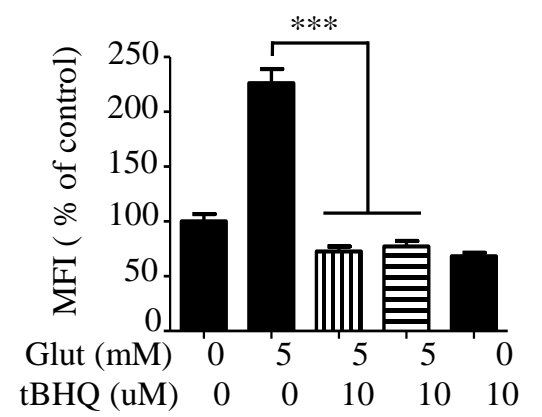

B.

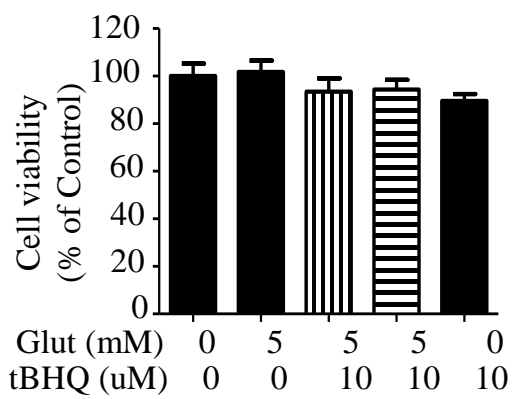

एسIII $0 \mathrm{~h} \mathrm{tBHQ}$ treatment delay

$6 \mathrm{~h}$ tBHQ treatment delay

Supplemental Figure 2.2. Within 1.5h, tBHQ reduces glutamate-induced ROS accumulation. HT-22 cells were treated with glutamate $(5 \mathrm{mM})$ for $7.5 \mathrm{hr}$. tBHQ $(10 \mu \mathrm{M})$ was applied at 0 and $6 \mathrm{hr}$ after glutamate exposure. (A) ROS levels were detected by $\mathrm{H}_{2} \mathrm{DCF}$ and fluorescence was measured by plate reader $(\mathrm{n}=8$ ). (B) Cell viability was detected by Calcein AM assay $(\mathrm{n}=8)$. Results are reported as mean \pm SEM. *** $\mathrm{P}<0.001$ compared with glutamate-treated cells (ANOVA, Tukey test). 


\title{
Chapter 3
}

\section{tBHQ Compromises Survival in Murine}

\author{
Experimental Stroke
}

Jiahong Sun, Heng Hu, Xuefang Ren and James W.

Simpkins

Sun J, Hu H, Ren X, Simpkins JW. Tert-butylhydroquinone Increases Brain

Edema and compromises Survival in Murine Experimental Stroke. Submitted to

Neurotoxicology and teratology (under review) 


\subsection{Abstract}

tert-butylhydroquinone (tBHQ), an Nrf2 signaling pathway inducer, that is a widely used food additive in the U.S., prevents oxidative stress-induced cytotoxicity in neurons. This study assesses the effects of tBHQ on ischemic stroke outcome in mice. We measured infarct volume and neurological deficits after tBHQ treatment in murine permanent middle cerebral artery occlusion (pMCAO) in vivo. tBHQ increased mortality and worsened stroke outcome. Further, we evaluated the regulation of $\mathrm{tBHQ}$ on mitochondrial function in cerebrovascular endothelial cells, which are critical to the blood-brain barrier (BBB) permeability. Mitochondrial function was suppressed by tBHQ treatment of cerebrovascular endothelial cells, and this suppression was potentiated by co-treatment with lipopolysaccharide (LPS), the bacterial mimic. tBHQ exposure induced brain edema in pMCAO, which might be due to a mitochondrial dysfunction-mediated blood-brain barrier disruption. 


\subsection{Introduction}

As reported by the World Health Organization, over 15 million people a year suffer from stroke worldwide (Weir \& Dennis, 1997). In the United States, stroke is the fifth leading cause of mortality and the leading cause of long-term disability (Roger et al., 2012). Ischemic stroke accounts for approximately $80-85 \%$ of all cases, which is caused by the disruption of cerebral blood flow and lack of oxygen and glucose to the affected area due to a clot. Currently, there are limited therapies approved for the treatment of acute ischemic stroke (Miller et al., 2011).

Brain injury following cerebral ischemia develops from a complex series of pathophysiological events that evolve in time and space (White et al., 2000). A considerable body of evidences suggests that excessive production of reactive oxygen species (ROS) is a fundamental contributor to brain damage in ischemic stroke (Manzanero et al., 2013). Many therapeutic strategies have targeted antioxidants to promote neuroprotection during ischemia (Gilgun-Sherki et al., 2002). However, to date, no antioxidative approaches have been approved in the United States. We should note that most of drug candidates tested in the clinical trials of stroke are free radical scavengers, which directly react with ROS. This strategy can rapidly eliminate ROS, but it fails to improve endogenous antioxidative status. Overall, the current antioxidative strategy for ischemic stroke therapy is not optimal.

The nuclear factor E2-related factor 2 (Nrf2)-antioxidant response element (ARE) signaling pathway controls a battery of antioxidative gene expression. Activation of Nrf2-ARE signaling pathway improves intracellular antioxidant capacity, which is critical for the detoxification and elimination of oxygen-derived free radicals. Under normal condition, Nrf2 binding with Kelchlike ECH-associated protein 1 (Keap1), a sensor of intracellular redox status, is inactivated (Itoh 
et al., 1999). Upon the stimulation of oxidative stress, Nrf2 dissociates with Keap1, translocates into the nucleus and further activates the transcription of ARE-driven genes (Apopa et al., 2008). ARE-driven genes are involved in a battery of antioxidant and phase II enzymes production (Jaiswal, 2004). One well-characterized Nrf2 inducer, tert-butylhydroquinone (tBHQ), is approved for human use as a food additive in the US (National Toxicology Program, 1997). Our previous study has shown that tBHQ exert a protection against oxidative stress-induced cytotoxicity in neurons though preserving mitochondrial function (Sun et al., 2015). A published study reported that pre-stroke administration of tBHQ significantly improves sensorimotor and histological outcomes after transient middle cerebral artery occlusion (tMCAO) (Shih et al., 2005).

We investigated the effect of tBHQ on a murine permanent middle cerebral artery occlusion (pMCAO) model, which induces a much more severe ischemic damage. Surprisingly, tBHQ induced a significant increase of mortality and failed to protect stroke outcomes compared to control. Further, we found that tBHQ inhibited mitochondrial function of cerebrovascular endothelial cells, which are critical to the blood-brain barrier (BBB) permeability (Doll et al., 2015). BBB disruption can lead to edema, which further aggravates the ischemic process. Our results demonstrated that tBHQ significantly increased brain volume and induced edema in pMCAO mice model. These data suggest that $\mathrm{tBHQ}$ exposure lead to mitochondrial suppressionmediated BB disruption, which exacerbates acute stroke outcomes. 


\subsection{Materials and Methods}

\section{Animals and experimental treatment}

All procedures were conducted according to the criteria approved by the Institutional Animal Care and Use Committees at the West Virginia University (WVU). C57/BL6J male mice (3-4 months old, 25-30 g; Jackson Laboratories) were used for all studies. tBHQ (Sigma, Saint Louis, MO) solution was prepared at $0.116,0.668$ and $6.68 \mathrm{mg} / \mathrm{ml}$ in vehicle (1\% DMSO in saline). Intraperitoneal injection of tBHQ $(0.582,3.34$ or $33.4 \mathrm{mg} / \mathrm{kg})$ was performed every $12 \mathrm{~h}$, starting at $24 \mathrm{~h}$ before pMCAO. An equal volume of saline was administered to control mice. To assign pretreatments of mice, we numbered the animals and applied a simple randomization by using excel-generated random numbers. The experimenters were blinded to the pretreatments and data analysis.

Permanent middle carotid artery occlusion: All surgical anesthesia was induced with 4-5\% isoflurane until the animal showed no response to a toe pinch and was maintained with $1-2 \%$ isoflurane via face-mask in $\mathrm{O}_{2}$-enriched air. We performed focal cerebral ischemia for $24 \mathrm{hr}$ by occlusion of the right middle cerebral artery with a 6.0 monofilament suture (Doccol, Sharon, MA). We used laser Doppler flowmetry (Moor Instruments, United Kingdom) to detect regional cerebral blood flow and confirmed a successful occlusion (>70\% decrease in flow). Rectal body temperature was maintained at $37 \pm 0.5^{\circ} \mathrm{C}$ during surgery.

Neurological Deficits: Neurological deficit was determined daily before and after tMCAO according to a 0- to 5-point scale neurological score system as published (Doll et al., 2015). Criteria of neurological assessment is shown in Table 3.1. 


\begin{tabular}{|c|c|}
\hline Score & Performance \\
\hline 0 & No deficit \\
\hline 1 & Failure to extend contralateral forepaw fully \\
\hline 2 & Circling to the contralateral \\
\hline 3 & Failing to the contralateral \\
\hline 4 & No spontaneous walking with a depresses level of consciousness \\
\hline 5 & Dead \\
\hline
\end{tabular}

Table 3.1 Criteria of neurological assessments

\section{Criteria for the Successful Animal Experiments}

The following criteria for successful pMCAO were observed for all animals. (1) Regional cerebral blood flow decreased $>70 \%$ during occlusion as detected by laser Doppler flowmetry. (2) Surgery time was never over 30 minutes. (3) Neurological deficits was observed 3 hours after MCAO (neurological score 0). (4) Infarction in the MCA territory (striatum) on 2,3,5triphenyltetrazolium chloride (TTC) staining was seen. (5) There was no subarachnoid hemorrhage on postmortem examination. (6) There was no substantial ambient temperature change in the animal facility. Animals that died before the planned time of assessments were postmortem examined for subarachnoid hemorrhage, and the mortality was recorded.

\section{Analysis of Infarct Volume and Brain Edema}

Mice were euthanized with isofluorane. We removed the brains and cut 2-mm coronal sections with a mouse brain matrix. We stained the sections with 2\% TTC (Sigma, Saint Louis, MO) in phosphate buffer solution at $37^{\circ} \mathrm{C}$ for 30 minutes then fixed the tissue in $10 \%$ formalin phosphate buffer for digital photograph. We analyzed the digitized image of each brain section using a computerized image analysis software (ImageJ, National Institutes of Health) in a blinded 
manner. The infarction volume was expressed as a percentage of contralateral cortex, striatum, and total hemisphere. Ipsilateral, contralateral and total brain volumes were used to evaluate brain edema. The ratio of ipsilateral brain volume to contralateral brain volume was calculated as edema index.

\section{Cell Culture}

The bEnd.3 cell line (CRL-2299 from ATCC, Manassas, VA) was originally derived from mouse brain cortex endothelial cells and confirmed by the observed major phenotypic features of the BBB (Doll et al., 2015). Passages 25 to 30 were used in the study. The bEnd.3 cells were routinely grown in high glucose Dulbecco modified Eagle medium (ATCC) supplemented with $10 \%$ FCS and $1 \%$ penicillin/streptomycin (Hyclone, South Logan, UT) at $37^{\circ} \mathrm{C}$ in $5 \% \mathrm{CO}_{2}$ humid atmosphere.

\section{Oxygen Consumption}

Oxygen consumption rate was measured at $37^{\circ} \mathrm{C}$ using an XF96e extracellular analyzer (Seahorse Bioscience, North Billerica, MA) according to the manufacturer's instructions. Briefly, the bEnd.3 cells were seeded into Seahorse Bioscience XF96e cell culture plates (16 000 cells/well) in $80-\mu \mathrm{L}$ medium and allowed to adhere and grow overnight. After respective exposures, the media was exchanged $1 \mathrm{hr}$ prior to the assay with $\mathrm{XF}$ assay medium (Seahorse Bioscience, North Billerica, MA). Oligomycin $(1 \mu \mu \mathrm{M})$, carbonilcyanide $p$ triflouromethoxyphenylhydrazone (FCCP, $0.5 \mu \mathrm{M})$ and antimycin $(1 \mu \mathrm{M})$ and rotenone $(1 \mu \mathrm{M})$ (Sigma) were diluted into XF 96 media and loaded into the accompanying cartridge. Injections of the components into the wells occurred at the time points specified. Oxygen consumption rate (OCR) was monitored using a Seahorse Bioscience XF 96 Extracellular Flux Analyzer. To 
calculate basal respiration, the measurement prior to oligomycin addition was subtracted from OCR measurement after rotenone and antimycin injection. ATP production was measured using the third OCR measurement prior to addition of oligomycin subtracted from OCR after oligomycin injection. Maximal respiration was calculated using the maximal OCR after FCCP injection subtracted from OCR after rotenone and antimycin injection. To calculate spare capacity, the maximal OCR after FCCP injection was subtracted from the measurement prior to addition of oligomycin.

Statistical analysis: The data were shown as means \pm SD. Statistical analyses were performed using one-way ANOVA with Tukey's post hoc test or Chi-Square test for multiple comparisons. GraphPad PRISM 5.0 was used for statistical analyses. 


\subsection{Results}

\section{Pre-ischemic exposure to tBHQ failed to protect mice from pMCAO and significantly increased mortality.}

As shown in Figure 3.1, we performed three i.p. injections of tBHQ with a $12 \mathrm{hr}$ interval starting at $24 \mathrm{hr}$ before pMCAO. Following a $24 \mathrm{hr}$ of pMCAO, neurological score and brain infarct size were evaluated. Three dosages of tBHQ $(0.582,3.34$ and $33.4 \mathrm{mg} / \mathrm{kg})$ were included in this study.

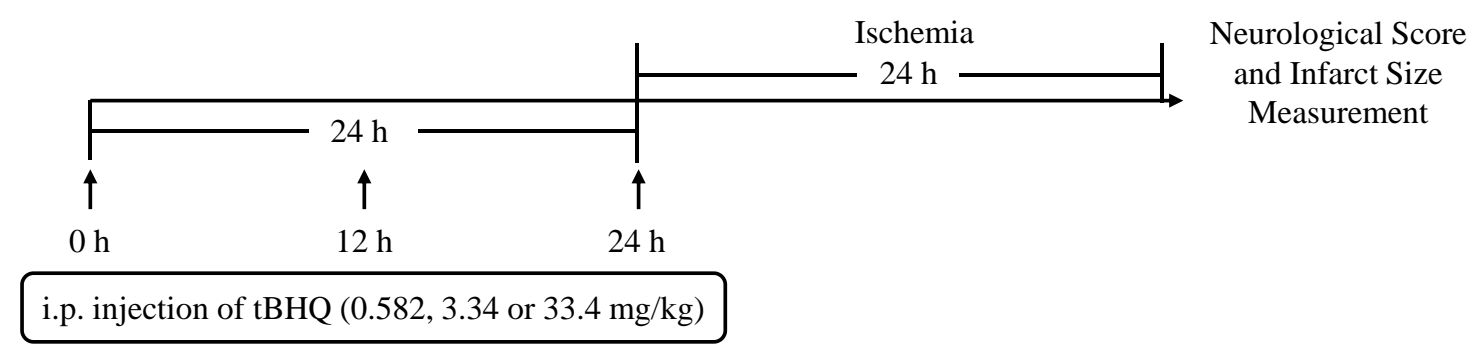

Figure 3.1 A schematic diagram summarizing the injection and stroke timeline. The short arrows represent time points of tBHQ injection.

Based on the dosage published in an animal study (Shih et al., 2005), ten mice were injected with tBHQ at dose of $33.4 \mathrm{mg} / \mathrm{kg}$. Two mice died before pMCAO surgery and four mouse died during ischemic stroke (Figure 3.2A). According to our previous in vitro study, this dosage induced cytotoxicity in neurons (Sun et al., 2015). Therefore, we reduced dosage to $3.34 \mathrm{mg} / \mathrm{kg}$, which was a protective concentration against oxidative toxicity in the neuronal cell line (Sun et al., 2015). However, mortality remained high. Further, we lowered the dose to $0.582 \mathrm{mg} / \mathrm{kg}$, which has been shown to be protective in primary cortical neurons (Sun et al., 2015). However, mortality of tBHQ treatment group was still higher than vehicle (Figure 3.2A). For the neurological assessment, all tBHQ treatment group demonstrated a severer damage of motor function compared to vehicle group (Figure 3.2B). Overall, these data indicates that pre-ischemic treatment with tBHQ significantly increases mortality of pMCAO in mice and worsens 
neurological score. After a $24 \mathrm{hr}$ of occlusion, we measured brain infarction by TTC staining. Representative stained coronal sections used to analyze brain infarction of mice. As shown in Figure 3.3, there was no significant difference of the infarct sizes in tBHQ treatment group compared to vehicle.

A

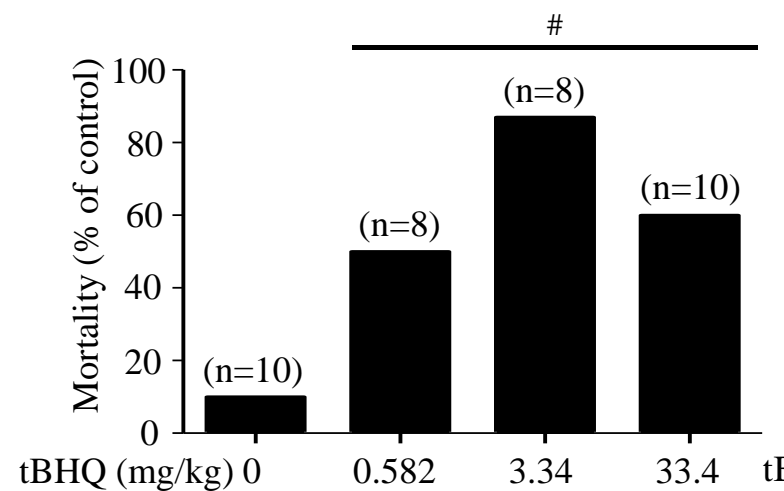

B.

Neurological Score

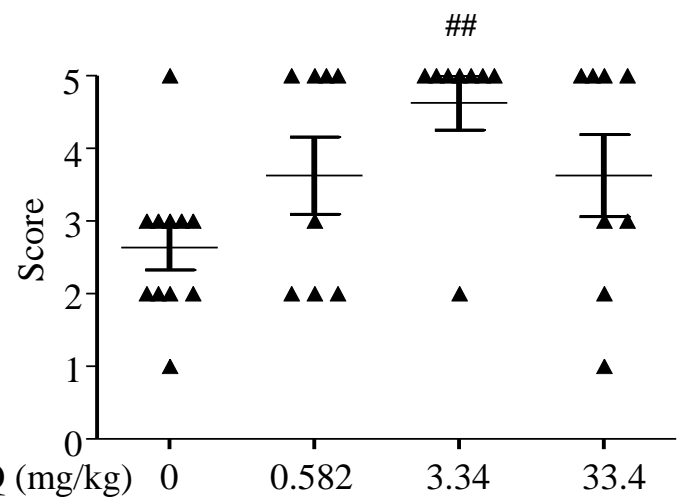

Figure 3.2. Pre-ischemic treatment with $\mathrm{tBHQ}$ increases mortality and does not improved neurological score in pMCAO mice model. (A) schematic diagram summarizing the injection and stroke timeline. The short arrows represent time points of tBHQ injection. (B). Mortality after $24 \mathrm{hr}$ pMCAO. Vehicle, $\mathrm{n}=11$, tBHQ $0.582 \mathrm{mg} / \mathrm{kg}, \mathrm{n}=8$, tBHQ $3.34 \mathrm{mg} / \mathrm{kg}, \mathrm{n}=8$, tBHQ $33.4 \mathrm{mg} / \mathrm{kg}, \mathrm{n}=10$. (C). Neurological score after pMCAO. Data are expressed as mean \pm SD. Vehicle, $\mathrm{n}=11$, tBHQ 0.582 $\mathrm{mg} / \mathrm{kg}, \mathrm{n}=8$, tBHQ $3.34 \mathrm{mg} / \mathrm{kg}, \mathrm{n}=8$, tBHQ $33.4 \mathrm{mg} / \mathrm{kg}, \mathrm{n}=8$. One-way ANOVA followed by post hoc Tukey test and ChiSquare test were used for multiple group comparison. ${ }^{\#} \mathrm{P}<0.05,{ }^{\#} \mathrm{P}<0.01$ compared to vehicle.

\section{tBHQ suppressed mitochondrial respiration of brain cortex endothelial cells.}

Even though tBHQ has been reported to be protective against oxidative stress-induced cell death in neurons, our data demonstrated that tBHQ induce a toxicity in murine pMCAO model. Other than neuronal cell death, cerebrovascular system also participates in ischemic brain injury during stroke. Our published study reported that inhibition of mitochondrial function disrupt the BBB and further worsened stroke outcomes (Doll et al., 2015). Next, we evaluated the effect of tBHQ on mitochondrial function in a brain cortex endothelial cell line, bEnd.3 cells. After a $24 \mathrm{hr}$ exposure to tBHQ (5-40 uM), a bioenergetic assay was used to examine cellular energetic 
oxygen consumption rate (Figure 3.4A). As shown in Figure 3.4B and C, basal oxygen consumption rate and ATP production were reduced at high concentration of tBHQ treatment groups (20 and $40 \mathrm{uM}$ ). Beginning at the concentration of $10 \mathrm{uM}$, tBHQ induced a dosedependent suppression on maximal respiration and spare capacity (Figure 3.4D and E). We noted that an exposure of $40 \mathrm{uM}$ tBHQ almost fully abolished mitochondrial spare capacity and reduced maximal respiration to $30 \%$ of control.

A
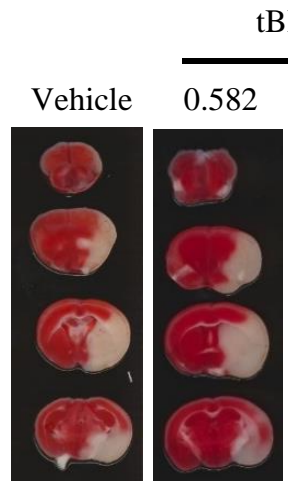

$\mathrm{C}$

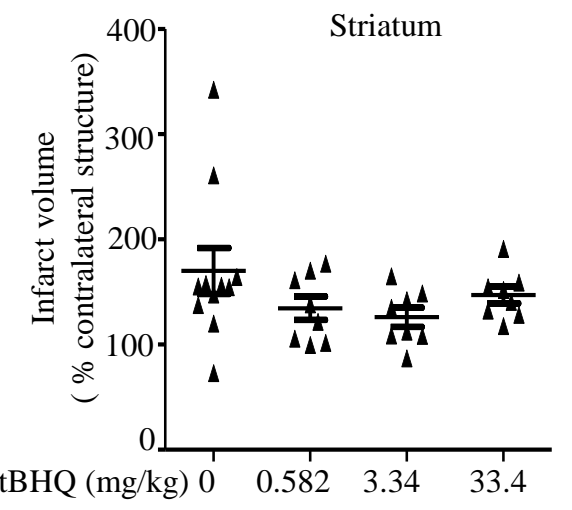

B

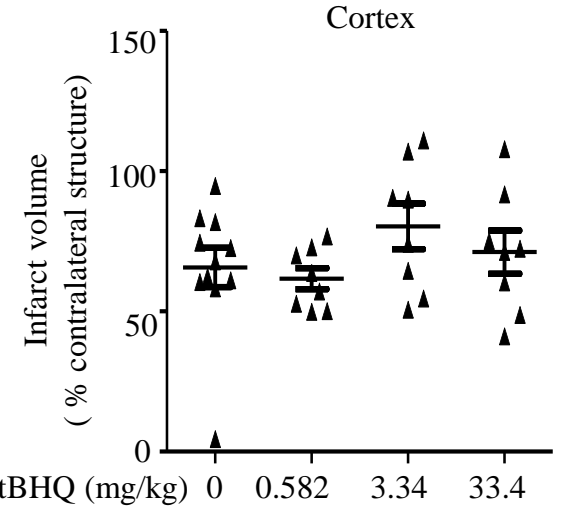

$\mathrm{D}$

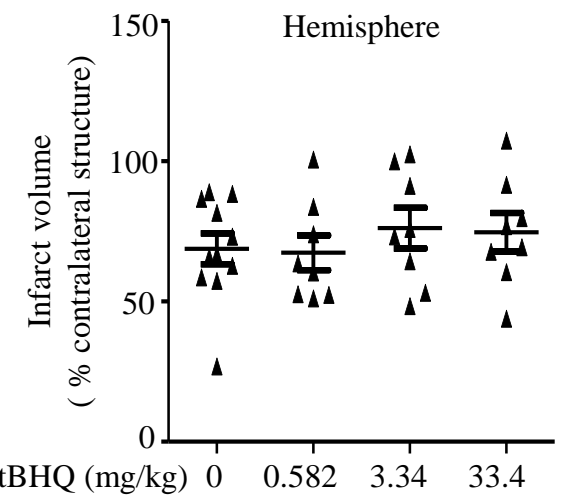

Figure 3.3. Pre-ischemic treatment of tBHQ had no effect on infarct size compared to vehicle group. (A). Infarct volumes were measured at $24 \mathrm{hr}$ after ischemia induction. Representative triphenyltetrazolium chloride-stained coronal sections used to analyze infarction of mice treated with vehicle vs tBHQ. (B). Mice treated with tBHQ had a similar infarct volume when compared to vehicle group in cortex, striatum, and total hemisphere. Vehicle, $\mathrm{n}=11$, tBHQ $0.582 \mathrm{mg} / \mathrm{kg}, \mathrm{n}=8$, tBHQ $3.34 \mathrm{mg} / \mathrm{kg}, \mathrm{n}=8$, tBHQ $33.4 \mathrm{mg} / \mathrm{kg}, \mathrm{n}=8$. Mean $\pm \mathrm{SD}$; One-way ANOVA followed by post hoc Tukey test was used for multiple group comparison. 

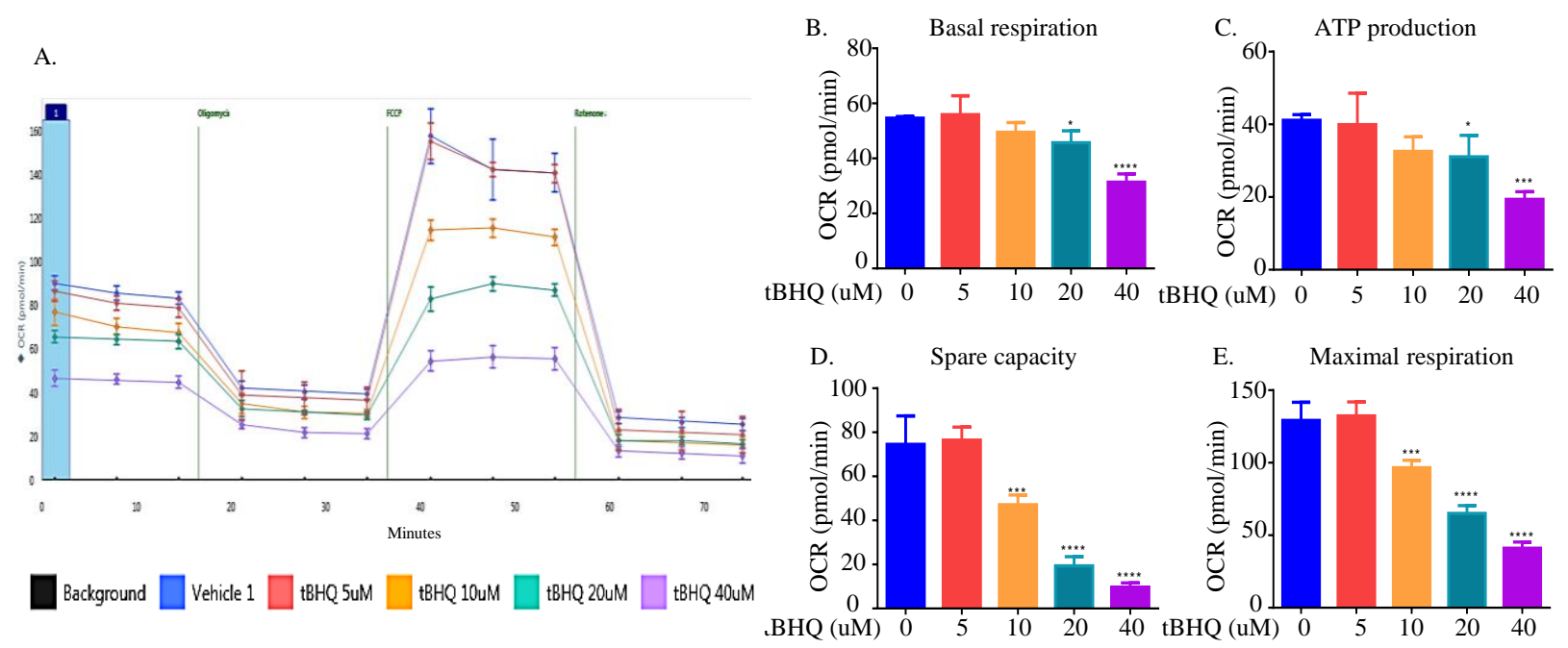

Figure 3.4. tBHQ suppressed mitochondrial respiration in bEnd.3 cell line. After 24-hr treatment with various concentration of tBHQ, OCR was recorded by a Seahorse XFe96 flux analyzer $(n=8)$. (A) OCR recording at baseline and subsequent treatment of $1 \mu \mathrm{M}$ oligomycin, $0.5 \mu \mathrm{M}$ FCCP, and a $1 \mu \mathrm{M}$ rotenone and antimycin mixture. Basal respiration (B), ATP production (C), spare capacity (D) and maximum respiration (E) were calculated. All experiments were repeated three times and the results indicate the mean $\pm \mathrm{SEM}$. $* \mathrm{P}<0.05$, $* * * \mathrm{P}<0.001$, $* * * * \mathrm{P}<0.00001$ compared to control. (one-way ANOVA, Tukey's test).

\section{tBHQ exacerbated LPS-induced mitochondrial dysfunction.}

Lipopolysaccharide (LPS), a bacterial infection mimic, leads to the mitochondrial dysfunctioninduced BBB disruption and further worsen stroke outcomes (Doll et al., 2015). To mimic our in vivo study, we evaluated mitochondrial respiration after co-treatment of tBHQ and LPS challenge for $24 \mathrm{hr}$ (Figure 3.5A). LPS (1 ug/ml) alone resulted in a decrease in maximal respiration and spare capacity without a significant change of basal respiration and ATP production (Figure 3.5B, C, D and E). Surprisingly, co-treatment with tBHQ induced a more significant inhibition of mitochondrial function, including basal respiration and ATP production. At concentration of $5 \mathrm{uM}$, tBHQ treatment alone did not inhibit mitochondrial respiration (Figure 3.4); while, a substantial mitochondrial inhibited was observed in the presence of LPS (Figure 3.5). Overall, we conclude that tBHQ inhibit mitochondrial respiration in cerebrovascular endothelial cells, and this inhibition is potentiated by LPS challenge. 

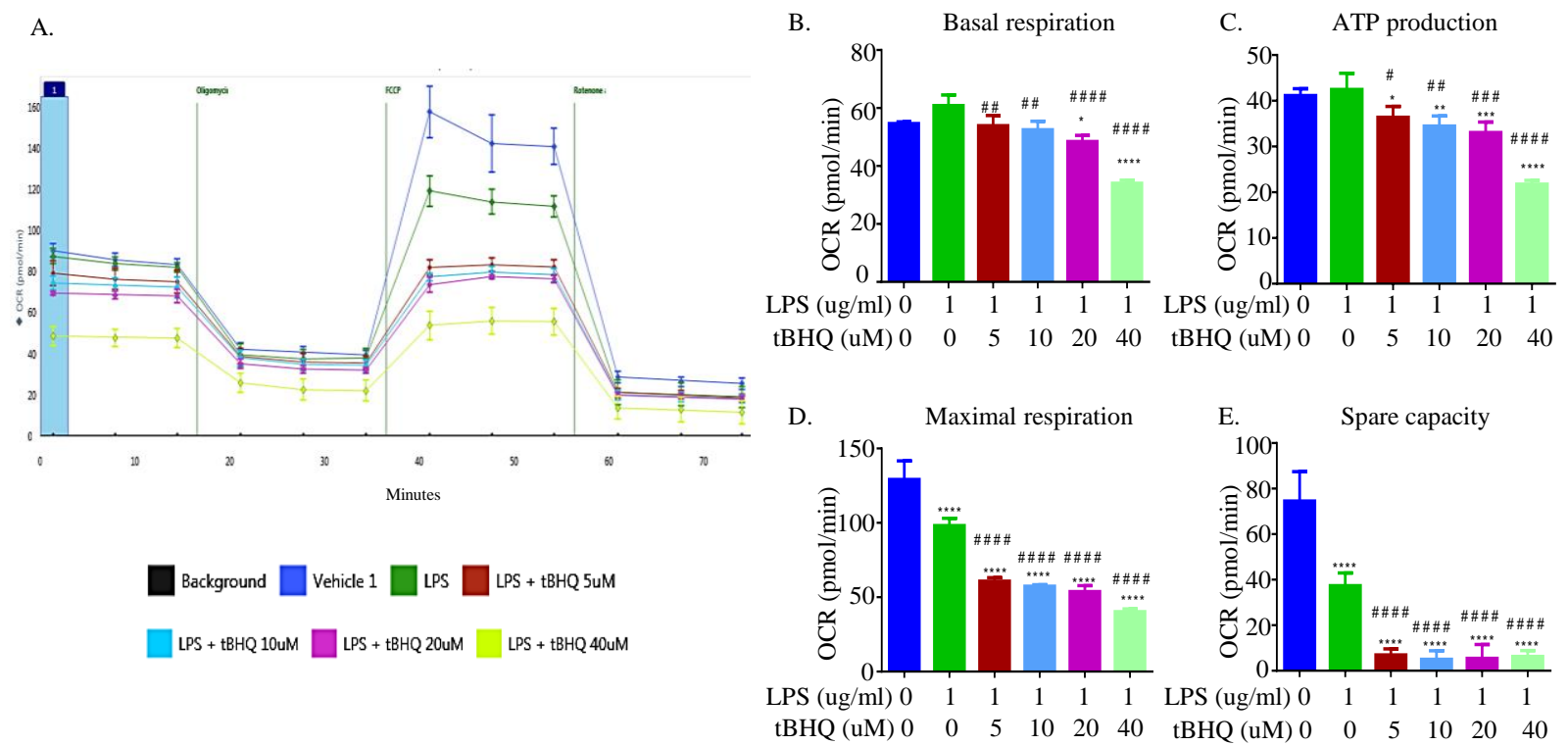

Figure 3.5. tBHQ exacerbated LPS-induced mitochondrial inhibition in bEnd.3 cell line. (A) Bioenergetics functional assay exposed to LPS and various concentration of tBHQ compared with vehicle control for $24 \mathrm{hr}$. Basal respiration (B), ATP production (C), maximal respiration (D), and spare capacity (D) were calculated from the assay and presented. Mean \pm $\mathrm{SD} ; \mathrm{n}=4$ per group; One-way ANOVA followed by post hoc Tukey test was used for data analysis. ${ }^{*} \mathrm{P}<0.05,{ }^{* *} \mathrm{P}<0.01$,

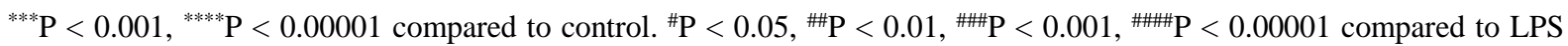
treatment.

\section{tBHQ increased brain volume and induce brain edema in pMCAO mice model.}

Disruption of the BBB contributes to the formation of edema, which further impairs survival. To investigate if tBHQ induce mitochondrial suppression-mediated BBB damage, we evaluated brain volume and edema after tBHQ exposure in pMCAO mice model. tBHQ exposure induced a significant increase in ipsilateral and total brain volume (Figure 3.6A and C), while there was no significant change in the contralateral brain volume (Figure 3.6B). Brain edeme index was increased in the $3.34 \mathrm{mg} / \mathrm{kg}$ tBHQ treatment group (Figure 3.7). Overall, our data indicates that tBHQ exposure leads to brain edema, which might be caused by mitochondrial dysfunctioninduced BBB disruption. 
A.

Ipsilateral

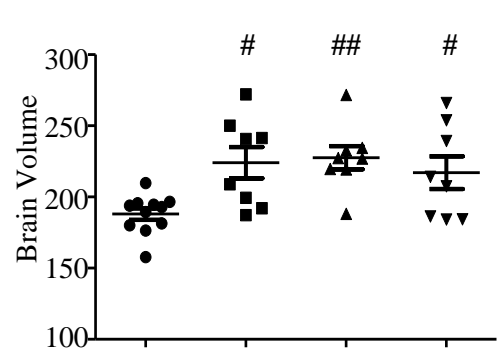

B.

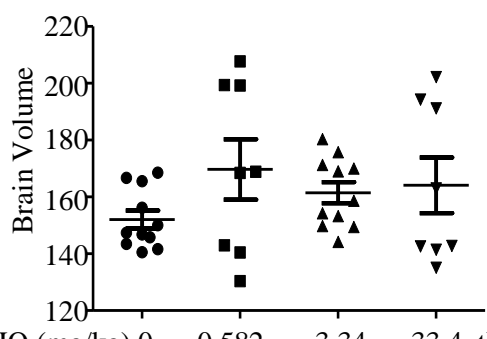

C.

Total

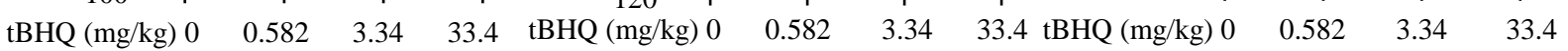

Figure 3.6. Pre-ischemic treatment of tBHQ increased brain volume compared to vehicle group. Ipsilateral (A), contralateral (B) and total (C) brain volumes were measured at $24 \mathrm{hr}$ after ischemia induction. Representative coronal sections used to analyze brain volume of mice treated with vehicle vs $\mathrm{tBHQ}$. Mice treated with $\mathrm{BBHQ}$ had an increased brain volume when compared to vehicle group in ipsilateral and total brain. Vehicle, $\mathrm{n}=11$, tBHQ $0.582 \mathrm{mg} / \mathrm{kg}, \mathrm{n}=8$, tBHQ $3.34 \mathrm{mg} / \mathrm{kg}, \mathrm{n}=8$, tBHQ $33.4 \mathrm{mg} / \mathrm{kg}, \mathrm{n}=8$. Mean $\pm \mathrm{SD}$; One-way ANOVA followed by post hoc Tukey test was used for multiple group comparison. ${ }^{\#} \mathrm{P}<0.05$, ${ }^{\#} \mathrm{P}<0.01$ compared to vehicle.

Brain edema

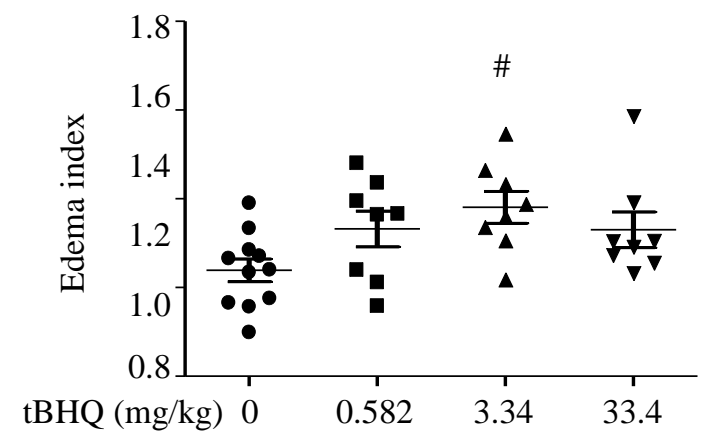

Figure 3.7. Pre-ischemic treatment of tBHQ increased edema index compared to vehicle group. Based on the ipsilateral and contralateral brain volume, edema index was calculated. Mice treated with tBHQ $(33.4 \mathrm{mg} / \mathrm{kg})$ had an increased edema index when compared to vehicle group. Vehicle, $\mathrm{n}=11$, tBHQ $0.582 \mathrm{mg} / \mathrm{kg}, \mathrm{n}=8$, tBHQ $3.34 \mathrm{mg} / \mathrm{kg}, \mathrm{n}=8$, tBHQ $33.4 \mathrm{mg} / \mathrm{kg}, \mathrm{n}=8$. Mean $\pm \mathrm{SD}$; One-way ANOVA followed by post hoc Tukey test was used for multiple group comparison. ${ }^{\#} \mathrm{P}<0.05$ compared to vehicle. 


\section{Discussions}

The present study demonstrates that pre-ischemic exposure to tBHQ significantly increases mortality from pMCAO in mice. tBHQ profoundly compromises mitochondrial respiration of brain cortex endothelial cells, which lead to brain edema. The present study is the first to report an adverse effect of tBHQ-enchanced mortality from pMCAO.

An increase in oxygen-derived free radicals generation has been observed during cerebral ischemia. In focal cerebral ischemia, the production of ROS mainly occurs in the special ischemic brain regions where the local oxygen tension is partially preserved by residual collateral flow, such as in the ischemic penumbra (Olmez \& Ozyurt, 2012). Free radicals play a key role in the pathophysiologic cascade leading to ischemic tissue damage (Chen et al., 2011; Niizuma et al., 2009). One published study reported that administration of tBHQ before stroke improves sensorimotor and histological outcome in transient ischemic mouse model (Shih et al., 2005), while, our study demonstrated a significant toxicity of tBHQ in pMCAO model. It is important to note that the formation of oxygen-free radicals in the acute phase of pMCAO is different with that occurring in tMCAO. A burst-like pattern of ROS accumulation is generated after reperfusion, while a steady accumulation of ROS is induced during permanent occlusion (Peters et al., 1998). Our previous data showed that tBHQ induce a rapid activation of Nrf2-ARE signaling pathway. However, activation of Nrf2-ARE signaling pathway was diminished with prolonged exposure of tBHQ (Sun et al., 2015). A persistent accumulation of ROS during permanent occlusion may exceed the effective time window of tBHQ. This provides a potential explanation why tBHQ exerts a quite different effect in pMCAO versus tMCAO model. Since the patterns of ROS generation are diversiform depending on ischemic conditions, a universal intervention of antioxidants may be too simplistic. Therefore, the complexity of 
pathophysiological events that involved in ischemic brain injury need to be considered for antioxidative strategy design.

Free radicals are typically generated during ATP production in mitochondria. As the primary site of ROS generation, the steady state concentration of ROS in the mitochondria is much higher than other subcellular component. This makes mitochondria a vulnerable target of oxidative damage. ROS can induce the modification of subunits in the mitochondrial electron transport chain, which results in an increased propensity to generate free radicals. Further, it overwhelms the mitochondria's ability to protect itself from endogenous oxidative stress, which triggers mitochondrial-mediated cell apoptosis. Therefore, oxidative stress-induced mitochondrial dysfunction is one of the major pathogenic mechanisms of neurodegeneration (Melov, 2000). Other than neuronal cells, mitochondrial dysfunction is also known to induce a detrimental effect on the cerebrovascular system. Our recent work demonstrates that a compromised mitochondrial function in cerebrovascular endothelial cells robustly disrupts BBB both in vitro and in vivo, which further exacerbates stroke outcomes (Doll et al., 2015). BBB is a highly specialized vascular interface that maintains homeostasis in brain by separating the blood compartment from the central nervous system. Disruption of BBB not only disrupts the normal central nervous system entry route of critical nutrients, but also allows entry of unwanted toxins into brain (Rubin \& Staddon, 1999). Disruption or dysfunction of the BBB has been shown to cause brain damage during ischemic stroke (Schoknecht et al., 2015). It is apparent that mitochondrial dysfunction lead to damage in both neuronal cells and non-neuronal cells during ischemia.

Although the protective effects of tBHQ on neurons was reported in our previous study (Sun et al., 2015), the present study demonstrates an adverse effect of tBHQ on cerebrovascular system. 
Mitochondrial dysfunction is increasingly recognized as an accomplice in ischemic stroke (Sims \& Anderson, 2002). tBHQ significantly suppresses mitochondrial function of brain endothelial cells (Figure 3.4). Our previous study showed that LPS disrupted BBB and exacerbated stroke outcomes due to the compromised mitochondrial function of cerebrovascular endothelial cells (Doll et al., 2015). In the presence of LPS, tBHQ induces a more potent inhibition of mitochondrial function (Figure 3.5). This indicates that tBHQ-induced mitochondrial suppression can be potentiated in the present of other mitochondrial toxins.

BBB disruption leads to influx of toxic substances, inflammation and vasogenic edema after stroke. Brain edema aggravates the ischemic process by its volumetric effect, through a compression of microcirculation, an increase of intracranial pressure, and a dislocation of parts of the brain (Yang \& Rosenberg, 2011). The disruption of BBB is detectable in animals after 4.5-6 hr of pMCAO, while the hemispheric lesion volume increases progressively during permanent cerebral ischemia (Kastrup et al., 1999). This indicates that increase in BBB permeability occurs in a relatively early phase of ischemic stroke and contributes to the further brain damage. Although tBHQ is known to increase the expression of many antioxidative enzymes, a rapid impairment of $\mathrm{BBB}$ function induced by $\mathrm{tBHQ}$ during ischemia might override its antioxidative activity.

tBHQ is a United States Food and Drug Administration-approved food additive which is commonly used to preserve unsaturated vegetables oil and animal fats. As such, it is consumed daily by most Americans and is considered safe for consumption (Evaluation of certain food additives and contaminants. forty-ninth report of the joint FAO/WHO expert committee on food additives.1999; National Toxicology Program, 1997). The maximal content of a food containing the additive is $0.02 \%$ of the oil or fat content. This exposure would be equivalent on average to 
$0.4 \mathrm{mg} / \mathrm{kg}$ (body weight) for an adult (European Food Safety Authority, 2004). The half-life of elimination of tBHQ in human is about 20-24 hours (Astill et al, 1967). This indicates higher concentrations of tBHQ might accumulate after repeated consumption of food containing tBHQ. Since tBHQ can be consumed daily, it might exert a harmful effect on cerebrovascular system and lead to BBB disruption when stroke occurs during an infection. Overall, our study raises a safety concern for $\mathrm{tBHQ}$ as a food additive or a potential therapeutic treatment for stroke. 


\section{Chapter 4}

\section{Discussions and Conclusions}




\subsection{Discussions}

Ischemic stroke, one of the leading causes of mortality and disability, remains a serious and significant global health problem. Despite the substantial efforts on both scientific research and clinical trials, there is still only one Food and Drug Administration approved treatment for stroke, tPA, which has a limited time window for administration and increases the risk for subsequent hemorrhage. Oxidative stress, as an important pathological factor in ischemic stroke, makes free radical scavengers a useful potential therapeutic strategy. Numerous antioxidative compounds have been shown to be of benefit in animal models of ischemic stroke. However, these promising candidates have lacked significant protective activity for brain tissue and cerebral blood vessels in clinical trials and many of those with protective activity have had poor bioavailability or safety problems (Kikuchi et al., 2014). Almost all the clinical trials of antioxidative protectants have failed to improve stroke outcomes; also, the development of neurovascular protectants to treat ischemic stroke has been beset by disappointments. Since the mediators involved in ischemic cascade are many, and the reasons for these unsuccessful attempts of clinical translation are complicated and still not fully understood, the development of clinical therapy for ischemic stroke has been slow.

\section{Antioxidative defense system}

Antioxidants are a diverse group of compounds that act in several ways to reduce oxidative stress including directly eliminating ROS, inhibiting ROS formation and binding metal ions needed for catalysis of ROS generation (Uttara et al., 2009). The antioxidant system can be classified into two major groups: antioxidative enzymes and small molecular antioxidants. The small molecular 
antioxidants group can be further classified into directly acting antioxidants, such as scavengers and chain breaking antioxidants, and indirectly acting antioxidants, such as chelating agents (Gilgun-Sherki et al., 2002). The former are extremely important in defending against ROS. Most of them, including ascorbic and lipoic acids, polyphenols, and carotenoids, are derived from dietary sources (Shohami et al., 1997). Vitamin E is a fat-soluble vitamin known to be one of the most potent antioxidants. It breaks the propagation of the free radical chain reaction in the lipids of biological membranes. Vitamin $\mathrm{C}$ is a water-soluble antioxidant that is found throughout the body as the ascorbate anion. It inhibits peroxidation of membrane phospholipids and acts as a scavenger of free radicals (Rice, 2000). Epidemiological studies examined the correlation between antioxidative vitamin consumption and stroke incidence and mortality and found that increased antioxidative vitamin intake reduced the risk of stroke (Keli et al., 1996). The cell itself synthesizes a minority of small molecules antioxidants, such as GSH, NAD(P)H, ubiquinol and bilirubin. GSH has major intracellular antioxidant activity, mainly due to the thiol group within the molecule. It plays a critical role in detoxification of peroxides and electrophilic toxins (Meister and Anderson, 1983).

Endogenous antioxidants directly react with free radicals by donating protons, and thereby losing their reducing equivalent. These antioxidants can be reduced and further recycled for redox reactions under the catalysis of antioxidative enzymes, such as GSH reductase. Therefore, antioxidative enzymes involved in antioxidant synthesis and reduction are also important for intracellular redox hemostasis. On the other hand, some enzymes can directly eliminate ROS without requiring the participation of antioxidants. Superoxide is one of the major ROS produced from a variety of sources. SOD, as the primary antioxidative defense, can directly convert superoxide to hydrogen peroxide. 
During the past decades, the traditional concept of antioxidant has been updated. Estrogens have been shown to be potent inhibitors of lipid peroxidation, which support its neuroprotective role (Green and Simpkins, 2000). Overall, we conclude that an intracellular antioxidative defense system is composed of a plethora of components. Simply targeting one antioxidant might have only short-term protection, but it is impossible to restore intracellular antioxidative balance. During ischemic stroke, accumulation of oxidative damage finally overwhelms the limited intracellular antioxidative capacity, which results in the damage being too extensive to reverse. A narrow target on antioxidative system might be a pitfall of current pre-clinical studies and clinical trials. Novel therapeutic options for the acute treatment of ischemic stroke are needed.

The importance of Nrf2-ARE signaling pathway

The Nrf2 transcription factor responds to diverse oxidative and electrophilic environmental stresses by circumventing repression by Keap1, translocating to the nucleus, and activating cytoprotective genes. The profile of gene-expression changes mediated by the Nrf2 pathway has been well documented. More than 500 genes, involving in cell proliferation and oxidative detoxification, are under the regulation of Nrf2. A plethora of Nrf2-regulated genes are important to detoxify oxidants and electrophiles and remove damaged macromolecules. Members of the GSH system, such as glutathione reductase and glutathione peroxidase, are direct transcriptional targets of Nrf2 (Malhotra et al., 2010). Activation of Nrf2-ARE signaling pathway has been shown to promote the generation of NADPH and expression of many antioxidative enzymes that regulated the synthesis of other antioxidants (Wu et al., 2011). Hence, by targeting the Nrf2-ARE signaling pathway, we might be able to promote a global circuitry of endogenous antioxidant expression. 
My dissertation focused on one antioxidant approved for human consumption, $\mathrm{tBHQ}$, which is also an inducer of Nrf2-ARE signaling pathway. As an antioxidant, tBHQ can boost intracellular antioxidative capacity immediately after administration, which directly reacts with ROS and prevents oxidative damage. Activation of Nrf2-ARE signaling pathway results in an increase in a wide range of intracellular antioxidant and antioxidative enzyme levels. This can fundamentally reestablish intracellular redox hemostasis. The dual antioxidative activities make tBHQ as a valuable candidate for the treatment of oxidative stress-induced neurodegeneration. Although the protective activities of tBHQ have been reported in many neurodegenerative conditions, the underlying mechanisms have not been elucidated. In the first part of my dissertation, I investigated the protective mechanism of tBHQ on oxidative stress-induced cell death. As the major target of ROS, mitochondrial function is an important determinant of ischemic neuronal death and survival (Niizuma et al., 2009). Therefore, we focused on the role of Nrf2-ARE signaling pathway in effecting mitochondrial function. Our studies elucidated that tBHQ improves mitochondrial antioxidative capacity by up-regulating the expression of SOD2 and HO-1, which further prevent oxidative stress-induced mitochondrial dysfunction and cell death. This promising neuroprotective activities further promoted me to investigate the effect of tBHQ on ischemic stroke.

The paradox of in vitro protection and in vivo toxicity

Stroke is widely considered to have an oxidative stress component originating directly from the biochemistry of the ischemia, and later from secondary events such as excitotoxicity and neuroinflammation (Alexandrova et al., 2003). The mechanisms of ROS generation during ischemia are different from that in ischemia-reperfusion. In the early stages of ischemia, oxygen 
tension drops prior to the depletion of glucose, which leads to an effective blockade of mitochondrial respiration (Liu et al., 2004). This favors the glycolytic pathway as the means of anaerobic ATP production. The consequence is an accumulation of lactic acid resulting in acidosis, which promotes pro-oxidant and detrimental changes in neurons (Manzanero et al., 2013). Upon reperfusion, a sudden supplement of oxygen reacts with the accumulated reducing equivalents, which rapidly promotes incomplete reduction of molecular oxygen yielding free radicals and peroxides. This causes the distinct patterns of ROS accumulation in different ischemic stroke models: a steady increase in ROS production in pMCAO model and a burst-like pattern of enhanced ROS production in tMCAO model (Peters et al., 1998). Since our in vitro study demonstrated a profound protection of tBHQ against oxidative stress-induced toxicity in neurons, we further investigated the effect of tBHQ in an ischemic stroke animal model. In our in vitro study, instead of an immediate cytotoxicity, glutamate induces a time-dependent depletion of GSH synthesis, which leads to a steady accumulation of ROS. The programmed cell death is initiated until the irreversible oxidative damage is induced. Therefore, we investigated the effect of tBHQ in pMCAO model, whose temporal profile of ROS generation is similar with our in vitro model. However, in addition to oxidative stress, many other mechanisms are also involved in the brain damage during ischemia, which might not be targeted by tBHQ exposure. Permanent occlusion induces a more severe brain injury and functional deficit compared to transient occlusion. Using a stroke animal model that induces a severe ischemic injury represents an important part of a strategy aiming to prevent the translational failure in future therapeutic development. Hence, if tBHQ exerts protective effects on permanent occlusion model, it would provide a strong support for applying tBHQ into clinical trials. However, our studies elucidated 
that $\mathrm{tBHQ}$ induces a significant toxicity in pMCAO mice model and exerts a detrimental effect on cerebrovascular system.

In the chapter 2, we demonstrated a significant protection of tBHQ against oxidative stressinduced neuronal cell death. However, the major limitation of this study is that only one cell type has been used to investigate the protection of tBHQ. Other than neurons, glia represent the most numerous group of brain cells, and their roles in providing structural, metabolic and trophic support to neurons are well established (Bezzi and Volterra, 2001). It is known that astrocytes, oligodendrocytes, as well as microglial cells, play significant roles in the demise of brain tissue after cerebral ischemia, in addition to protecting brain function and enhancing survival and regeneration under these conditions (Nedergaard and Dirnagl, 2005). The effect of tBHQ on glial cells during oxidative stress challenge is not investigated in my study. The protection of tBHQ observed in neurons might not apply to other cell types in the brain. Most forms of cerebral ischemia are initiated by a vascular problem. In contrast, tBHQ significantly inhibited mitochondrial respiration in brain endothelial cells, which can lead to the disruption of BBB in the animal models. This unfavorable effect on cerebrovascular system might explain why tBHQ induces toxicity in pMCAO mice model. Our studies demonstrate that the observations from in vitro studies are not always consistent with the results from animal studies. A drug candidate may exert beneficial effects on certain cell types or organs, but this does not indicate that these drug candidates can exert the beneficial effect on the whole organism.

Since each type of cell has specific physiological characteristics and function, the sensitivity and response of cells to the same insult or toxin might be different based on their cell type. We observed a significant cell death in neuronal cells after an exposure of $5 \mathrm{mM}$ glutamate. However, up to a concentration of $500 \mathrm{mM}$ glutamate challenge, there is no significant damage in brain 
cortex endothelial cells (data not presented). Similarly, even though a slight decrease in mitochondrial respiration is induced by tBHQ in neuronal cells, tBHQ still exerted a profound protection against oxidative stress-induced neuronal cell death. We speculate that preventing the accumulation of ROS by tBHQ is enough to rescue neurons from glutamate-induced oxidative damage in neurons. On the other hand, tBHQ suppresses mitochondrial respiration in endothelial cells. Since it is now known that mitochondria are key players in BBB permeability, inhibition of mitochondrial function in brain endothelial cells can lead to the disruption of BBB and worsen stroke outcomes (Doll et al., 2015). Therefore, the detrimental effect on cerebrovascular effect might masks the beneficial effect of tBHQ on neurons, which results in the toxicity of tBHQ in pMCAO model.

Neuroprotection is defined as 'any strategy' that antagonizes, interrupts, or slows the sequence of injurious biochemical and molecular events that would eventuate in irreversible ischemic injury (Sutherland et al., 2012). Most strategies for neuroprotection target neurons rather than the cerebral vasculature. The contradiction between our in vitro and in vivo studies advances our understanding about the complexity of biological systems. Instead of solely focusing on one pathological target, pre-clinical studies should provide a more comprehensive investigation of other non-specific effects, which is important to improve the pre-clinical criteria of drug screening.

From bench to bedside: preclinical limitation and translational challenges

In the past decades, varieties of therapeutic strategies for focal cerebral ischemia have been developed. Despite promising preclinical results and successful safety assessments in many cases, 
not a single approach has shown the efficacy in clinical trials. A fundamental challenge in neuroprotectant clinical trial design is the heterogeneity of stroke. Ischemic stroke is a syndrome due to multiple etiologies (Muir et al., 2002). Broad categories of brain infarction include lacunar (subcortical), cardioembolic, large vessel atherosclerotic (extracranial and intracranial), and cryptogenic (approximately $25 \%$ of infarcts) (Furlan et al., 2012). Each ischemic stroke category has a different natural history reflecting multiple clinical, vascular, and physiological variables, which may respond differently to a given therapeutic intervention. The majority of stroke clinical trials, especially neuroprotectants, have included all types of infarction in multiple anatomic locations with multiple sites of occlusion (or more commonly, sites of occlusion unknown). All these factors increase the difficulty for neuroprotectant clinical trial design and data interpretation.

There is a common understanding that suboptimal design of preclinical experiments and improper animal models may at least partially account for this dilemma. Current experimental animal models for ischemic stroke are limited and do not reflect several clinical ischemic conditions. Even though the protection of drug candidate is reported in certain ischemic stroke animal models, it does not mean that this protection is universal. However, it is unrealistic for pre-clinical studies to investigate the effect of one drug candidate on all experimental animal models due to the limitation of time and funding support. There is a high chance that the outcomes after certain neuroprotectant treatment might be distinct in different ischemic animal models. One published study demonstrated that pre-ischemic treatment of tBHQ significantly ameliorates brain damage and functional deficits in ischemic-reperfusion conditions. However, our study revealed that the outcomes after tBHQ exposure are totally opposite in the permanent 
occlusion condition. Consequently, a more thorough and rigorous standard for preclinical research is demanded by translational stroke researchers and clinicians.

Pathophysiological heterogeneity is of particular relevance to neuroprotective strategy. During ischemia, pathological evens are time-dependently initiated. This indicates that treatments might be time-sensitive based on their therapeutic targets. One limitation of our in vivo study is that only one drug administration strategy has been tested. Even though this strategy is designed after a cautious calculation based on our in vitro results, the pharmacokinetic profile under this administration strategy might not perfectly match with the pattern of ROS accumulation during permanent occlusion, which can diminish and even quench the actual efficacy of treatment.

The discrepancy on administration time of potential protective drugs between pre-clinical studies and clinical trials also may be a contributor to translational failure. In the clinical condition, intervention for stroke can be only applied after the onset of symptoms. Since ischemic stroke induces an acute brain injury, the narrow therapeutic window is a substantial challenge for stroke treatment. However, most of pre-clinical studies focus on the pre-ischemic treatment strategy, which is thought to maximize the efficacy of drug candidates. Even though the protective effects are induced by these neuroprotectants, little clinical relevance can be provided, especially for clinical trial design. In our study, we only tested the prevention treatment of tBHQ in stroke and observed a significant toxicity induced by $\mathrm{tBHQ}$, which impeded further investigation on intervention treatment of tBHQ. However, when correlated with other pre-clinical studies, the importance of administration strategy design needs to be brought up for a serious consideration. In order to obtain sufficient information regarding the therapeutic time window, dosage, and duration of therapy and safety, a recommendation is to test a therapeutic candidate in an experimental condition that can better reflects ischemic stroke in humans. 
As with most in vivo studies, our study has some common limitations, which results in an optimistic overestimation of treatment effect. In the preclinical studies, animal data are usually collected in healthy laboratory rodents with the same age, in which a standardized amount of cerebral infarction is induced by a reproducible intervention. In contrast, genetics and health conditions in stroke patients are very heterogeneous. Patients are mostly elderly with comorbidity. Aging is associated with significant structural and functional changes in the brain, which affects outcome and the ability to recover after an ischemic event. It is well known that elderly patients tend to have worse stroke outcomes than younger patients. Moreover, experimental animal models can not perfectly represent pathological situation in humans. It has been reported that animal models of stroke mimic at best less than $25 \%$ of all strokes, with the rodent model of MCAO model probably reflecting the Total Anterior Circulation Stroke Syndrome in humans (Small and Buchan, 2000). In most preclinical studies, efficacy of neuroprotective agents was detected by reduction of histological infarction volume. However, in clinical trials, neuroprotective efficacy is evaluated by neurological outcomes. Infarction volume does not always correlate with neurological function because a small lesion in a critical brain area can cause a profound functional deficit. Conversely, large lesions in a relatively silent area may induce little detectable function loss. Discrepancy in the outcome measures in scientific research is also an obstacle for clinical translation. Overall, the implementation of essential quality standards in experimental stroke research, without a doubt, need to be improved.

Future attention of research on antioxidative therapy for stroke

Currently, antioxidative strategies can be divided into three groups: (1) suppressing the generation of ROS, (2) directly scavenging free radicals, (3) increase of free radical degradation 
by using agents mimicking the antioxidative enzymatic activities or up-regulating endogenous antioxidative enzyme levels. Antioxidant therapies have been shown to be protective in preclinical studies, but rarely this protection is applicable for human intervention studies, which diminishes enthusiasm to pursue antioxidant neuroprotectants in the clinic. Multiple factors cause the translational failure of antioxidant studies. Even though considerable effort has been devoted to develop a clinical relevant animal model, there is a substantial difference between pre-clinical research and the clinical situation. This is partially attributed to an incomplete understanding of pathological processes. Focusing on the mechanism of ischemic damage, including oxidative stress, in clinical conditions can provide guidance for scientific research design, which is important for the improvement of experimental animal models. Besides, a full elucidation of pathological mechanisms promote the discovery of potential therapeutic targets and inspires novel approaches for stroke treatment.

Each antioxidative strategy focuses on different aspects of oxidative stress-induced injury during stroke. A combination of these antioxidative neuroprotectants may have synergistic effects against ischemic injury. Other than oxidative damage, many neuroprotective agents target other pathological cascades during neurodegeneration. The concept of combining antioxidants with other neuroprotective therapies has not been extensively explored in either pre-clinical studies or human clinical trials. Since ischemic neuroprotection needs to be achieved within a narrow timewindow, a combined therapeutic strategy might accomplish a potent and fast-acting protection by targeting multiple pathological pathways. Therefore, a combination of neuroprotectants should be evaluated clinically.

In our in vivo study, a profound toxicity was induced by tBHQ exposure in permanent occlusion animal models. Our results also indicate that tBHQ exerts a detrimental effect on cerebrovascular 
system. This raises a serious safety concern for tBHQ as food additive for human consumption and diminishes the potential application of tBHQ for stroke treatment. However, whether the toxicity of tBHQ was caused by activating the Nrf2-ARE signaling pathway was not elucidated in my dissertation and this concept merits further study. Based on the current in vivo study, we should not exclude the Nrf2-ARE signaling pathway as a therapeutic target.

Safety concern of tBHQ for human consumption

Antioxidants are present in foods at low concentrations compared to that of an oxidizable substrate, and delay or prevent the oxidation of the substrate. Food manufacturers have used food-grade antioxidants to prevent quality deterioration of products and to maintain their nutritional value. tBHQ is one of the most widely used antioxidants in food, which was commercially approved in nine countries, including the United States (Shahidi et al., 2000). Currently, tBHQ is prohibited as food additive in several countries, including Japan and European Union. The Joint FAO/WHO Expert Committee on Food Additives evaluated and established a group acceptable daily intake of $0-0.5 \mathrm{mg} / \mathrm{kg}$ body weight for human for tBHQ alone or in combination with other antioxidants (Evaluation of certain food additives and contaminants. forty-ninth report of the joint FAO/WHO expert committee on food additives.1999; National Toxicology Program, 1997). The total antioxidant content of the food can not exceed $0.02 \%$ of the oil or fat content (21 CFR 172.185).

Potential human exposure to tBHQ through diet is estimated by considering that all fats consumed would contain tBHQ at $200 \mathrm{mg} / \mathrm{kg}$ in fat or oil. The average proportion of total energy intake from fat is $44 \%$, which is equal to a $112 \mathrm{~g}$ daily fat intake (European Food Safety 
Authority, 2004). Assuming all the fats contain tBHQ, the daily tBHQ consumption amount is 22.4 mg. Considering a $60 \mathrm{~kg}$ body weight, this exposure is equivalent to $0.4 \mathrm{mg} / \mathrm{kg}$. Exposure in infants and children is even higher since energy from fat in their diet is higher than that of adults. tBHQ exposure in an infant would be $1.3 \mathrm{mg} / \mathrm{kg}$ body weight if infant formulae contains tBHQ. Potential exposure of tBHQ in a 10 years old child is up to $0.75 \mathrm{mg} / \mathrm{kg}$ body weight. In our study, the lowest dosage of tBHQ that induced toxicity in a pMCAO model is $0.582 \mathrm{mg} / \mathrm{kg}$. We should note is that the route of administration in our animal study is different with that for human consumption. Therefore, the interpretation about toxic dosage should be taken with caution. However, for the metabolism of tBHQ in humans, one study reported that excretion seems to be essentially complete after $2-4$ days. It takes 22 hours for a half-reduction of the plasma concentration (Astill et al, 1967). This indicates a higher concentration of tBHQ accumulated after repeated consumption of food containing tBHQ, which could induce a toxic effect on cerebrovascular system. In addition, this damage might be exacerbated when other comorbid factors are present. Overall the safety of tBHQ as the food additive for human consumption needs to be re-evaluated.

\subsection{Conclusions}

My dissertation systemically investigated the potential clinical application of tBHQ, a wellknown Nrf2-ARE signaling pathway inducer, for ischemic stroke treatment. Our study mechanistically demonstrated the protection of tBHQ against oxidative stress-induced cytotoxicity in neurons. tBHQ increased mitochondrial antioxidative capacity by sequentially elevating the expression of SOD2 and HO-1, which are critical for preserving mitochondrial function under oxidative stress challenge. However, we observed a paradoxical results from our 
in vivo study in that tBHQ increased mortality and worsened stroke outcomes in a pMCAO model. Further, we found that tBHQ significantly suppressed mitochondrial respiration in cerebrovascular endothelial cells, which might result in the disruption of BBB. This adverse effect on the cerebrovascular system might contribute to the toxicity of tBHQ in pMCAO model, which brings up a safety concern of tBHQ for human consumption. This paradox between in vitro protection and in vivo toxicity suggest that an exhaustive evaluation in pre-clinical studies is necessary to justify the quantification of drug candidates for clinical trials. 


\section{References}

A randomized trial of tirilazad mesylate in patients with acute stroke (RANTTAS). the RANTTAS investigators.1996. Stroke 27, 1453-1458.

Abdel-Wahab, M. H., 2005. Potential neuroprotective effect of t-butylhydroquinone against neurotoxicity-induced by 1-methyl-4-(2'-methylphenyl)-1,2,3,6-tetrahydropyridine (2'methyl-MPTP) in mice. J Biochem Mol Toxicol 19, 32-41.

Adam-Vizi, V., Chinopoulos, C., 2006. Bioenergetics and the formation of mitochondrial reactive oxygen species. Trends Pharmacol Sci 27, 639-645.

Akhter, H., Katre, A., Li, L., Liu, X., Liu, R. M., 2011. Therapeutic potential and antiamyloidosis mechanisms of tert-butylhydroquinone for alzheimer's disease. J Alzheimers Dis $26,767-778$.

Al Ahmad, A., Gassmann, M., Ogunshola, O. O., 2012. Involvement of oxidative stress in hypoxia-induced blood-brain barrier breakdown. Microvasc Res 84, 222-225.

Alamed, J., Chaiyasit, W., McClements, D. J., Decker, E. A., 2009. Relationships between free radical scavenging and antioxidant activity in foods. J Agric Food Chem 57, 2969-2976.

Alfieri, A., Srivastava, S., Siow, R. C. M., Cash, D., Modo, M., Duchen, M. R., Fraser, P. A., Williams, S. C. R., Mann, G. E., 2013. Sulforaphane preconditioning of the Nrf2/HO-1 defense pathway protects the cerebral vasculature against blood-brain barrier disruption and neurological deficits in stroke. Free Radical Biology and Medicine 65, 1012-1022. 
Allen, C. L., Bayraktutan, U., 2009. Oxidative stress and its role in the pathogenesis of ischaemic stroke. Int J Stroke 4, 461-470.

Alexandrova, M. L., Bochev, P. G., Markova, V. I., Bechev, B. G., Popova, M. A., Danovska, M. P., Simeonova, V. K., 2003. Oxidative stress in the chronic phase after stroke. Redox Rep 8, 169-176.

Amemiya, S., Kamiya, T., Nito, C., Inaba, T., Kato, K., Ueda, M., Shimazaki, K., Katayama, Y., 2005. Anti-apoptotic and neuroprotective effects of edaravone following transient focal ischemia in rats. Eur J Pharmacol 516, 125-130.

American Heart Association, 2012. About stroke. In

Andersen, J. K., 2004. Oxidative stress in neurodegeneration: Cause or consequence? Nat Med 10 Suppl, S18-25.

Apopa, P. L., He, X., Ma, Q., 2008. Phosphorylation of Nrf2 in the transcription activation domain by casein kinase 2 (CK2) is critical for the nuclear translocation and transcription activation function of Nrf2 in IMR-32 neuroblastoma cells. J Biochem Mol Toxicol 22, 6376.

Aronowski, J., Strong, R., Grotta, J. C., 1996. Treatment of experimental focal ischemia in rats with lubeluzole. Neuropharmacology 35, 689-693.

Astill, B.D., Cantor, E.E., Ely, T.S., Jones, W.H. and Uskavitch, R.J. 1967. The Oral ingestion of t-butylhydroquinone (TBHQ) by humans; clinical observations and metabolic fate. 
Unpublished report from the Laboratory of Industrial Medicine, Eastman Kodak. (As cited by WHO 1998).

Bandera, E., Botteri, M., Minelli, C., Sutton, A., Abrams, K. R., Latronico, N., 2006. Cerebral blood flow threshold of ischemic penumbra and infarct core in acute ischemic stroke: A systematic review. Stroke 37, 1334-1339.

Banks, W. A., Erickson, M. A., 2010. The blood-brain barrier and immune function and dysfunction. Neurobiol Dis 37, 26-32.

Barber, P. A., Zhang, J., Demchuk, A. M., Hill, M. D., Buchan, A. M., 2001. Why are stroke patients excluded from TPA therapy? an analysis of patient eligibility. Neurology 56, 10151020.

Barnham, K. J., Masters, C. L., Bush, A. I., 2004. Neurodegenerative diseases and oxidative stress. Nat Rev Drug Discov 3, 205-214.

Bell, K. F., Hardingham, G. E., 2011. CNS peroxiredoxins and their regulation in health and disease. Antioxid Redox Signal 14, 1467-1477.

Bezzi, P., Volterra, A., 2001. A neuron-glia signalling network in the active brain. Curr Opin Neurobiol 11, 387-394.

Brand, M. D., 2010. The sites and topology of mitochondrial superoxide production. Exp Gerontol 45, 466-472. 
Brand, M. D., Affourtit, C., Esteves, T. C., Green, K., Lambert, A. J., Miwa, S., Pakay, J. L., Parker, N., 2004. Mitochondrial superoxide: Production, biological effects, and activation of uncoupling proteins. Free Radical Biology and Medicine 37, 755-767.

Cadenas, E., Davies, K. J. A., 2000. Mitochondrial free radical generation, oxidative stress, and aging. Free Radical Biology and Medicine 29, 222-230.

Calkins, M. J., Johnson, D. A., Townsend, J. A., Vargas, M. R., Dowell, J. A., Williamson, T. P., Kraft, A. D., Lee, J. M., Li, J., Johnson, J. A., 2009. The Nrf2/ARE pathway as a potential therapeutic target in neurodegenerative disease. Antioxid Redox Signal 11, 497-508.

Chao, X. J., Chen, Z. W., Liu, A. M. et al., 2014. Effect of tacrine-3-caffeic acid, A novel multifunctional anti-alzheimer's dimer, against oxidative-stress-induced cell death in HT22 hippocampal neurons: Involvement of Nrf2/HO-1 pathway. CNS Neurosci Ther 20, 840-850.

Chen, H., Yoshioka, H., Kim, G. S., Jung, J. E., Okami, N., Sakata, H., Maier, C. M., Narasimhan, P., Goeders, C. E., Chan, P. H., 2011. Oxidative stress in ischemic brain damage: Mechanisms of cell death and potential molecular targets for neuroprotection. Antioxid Redox Signal 14, 1505-1517.

Chen, Q., Chai, Y. C., Mazumder, S., Jiang, C., Macklis, R. M., Chisolm, G. M., Almasan, A., 2003. The late increase in intracellular free radical oxygen species during apoptosis is associated with cytochrome c release, caspase activation, and mitochondrial dysfunction. Cell Death Differ 10, 323-334. 
Choi, D. W., 1994. Chapter 6 glutamate receptors and the induction of excitotoxic neuronal death. Prog Brain Res 100, 47-51.

Coyle, J. T., Puttfarcken, P., 1993. Oxidative stress, glutamate, and neurodegenerative disorders. Science 262, 689-695.

Cregan, S. P., Fortin, A., MacLaurin, J. G. et al., 2002. Apoptosis-inducing factor is involved in the regulation of caspase-independent neuronal cell death. J Cell Biol 158, 507-517.

Devasagayam, T. P., Tilak, J. C., Boloor, K. K., Sane, K. S., Ghaskadbi, S. S., Lele, R. D., 2004. Free radicals and antioxidants in human health: Current status and future prospects. J Assoc Physicians India 52, 794-804.

Diener, H. C., Cortens, M., Ford, G., Grotta, J., Hacke, W., Kaste, M., Koudstaal, P. J., Wessel, T., 2000. Lubeluzole in acute ischemic stroke treatment: A double-blind study with an 8hour inclusion window comparing a 10-mg daily dose of lubeluzole with placebo. Stroke 31, 2543-2551.

Dirnagl, U., Iadecola, C., Moskowitz, M. A., 1999. Pathobiology of ischaemic stroke: An integrated view. Trends Neurosci 22, 391-397.

Dispersyn, G., Nuydens, R., Connors, R., Borgers, M., Geerts, H., 1999. Bcl-2 protects against FCCP-induced apoptosis and mitochondrial membrane potential depolarization in PC12 cells. Biochimica Et Biophysica Acta (BBA) - General Subjects 1428, 357-371.

Doll, D. N., Hu, H., Sun, J., Lewis, S. E., Simpkins, J. W., Ren, X., 2015. Mitochondrial crisis in cerebrovascular endothelial cells opens the blood-brain barrier. Stroke 46, 1681-1689. 
Dong, J., Sulik, K. K., Chen, S. Y., 2008. Nrf2-mediated transcriptional induction of antioxidant response in mouse embryos exposed to ethanol in vivo: Implications for the prevention of fetal alcohol spectrum disorders. Antioxid Redox Signal 10, 2023-2033.

Dore, S., Snyder, S. H., 1999. Neuroprotective action of bilirubin against oxidative stress in primary hippocampal cultures. Ann N Y Acad Sci 890, 167-172.

Du, J., Gebicki, J. M., 2004. Proteins are major initial cell targets of hydroxyl free radicals. Int J Biochem Cell Biol 36, 2334-2343.

Dumont, E., Monari, A., 2015. Understanding DNA under oxidative stress and sensitization: The role of molecular modeling. Front Chem 3, 43.

Edaravone Acute Infarction Study Group, 2003. Effect of a novel free radical scavenger, edaravone (MCI-186), on acute brain infarction. randomized, placebo-controlled, doubleblind study at multicenters. Cerebrovasc Dis 15, 222-229.

Eftekharzadeh, B., Maghsoudi, N., Khodagholi, F., 2010. Stabilization of transcription factor Nrf2 by tBHQ prevents oxidative stress-induced amyloid $\beta$ formation in NT2N neurons. Biochimie 92, 245-253.

Emerit, J., Edeas, M., Bricaire, F., 2004. Neurodegenerative diseases and oxidative stress. Biomedicine \& Pharmacotherapy 58, 39-46.

European Food Safety Authority. Opinion of the Scientific Panel on food additives, flavourings, processing aids and materials in contact with food (AFC) on a request from the Commission related to tertiary Butylhydroquinone (TBHQ). 12 July 2004. 
Evaluation of certain food additives and contaminants. forty-ninth report of the joint FAO/WHO expert committee on food additives.1999. World Health Organ Tech Rep Ser 884, i-viii, 196.

Finkel, T., 2003. Oxidant signals and oxidative stress. Curr Opin Cell Biol 15, 247-254.

Floyd, R. A., Hensley, K., 2002. Oxidative stress in brain aging: Implications for therapeutics of neurodegenerative diseases. Neurobiol Aging 23, 795-807.

Freeman, L. R., Keller, J. N., 2012. Oxidative stress and cerebral endothelial cells: Regulation of the blood-brain-barrier and antioxidant based interventions. Biochimica Et Biophysica Acta (BBA) - Molecular Basis of Disease 1822, 822-829.

Fukui, M., Choi, H. J., Zhu, B. T., 2012. Rapid generation of mitochondrial superoxide induces mitochondrion-dependent but caspase-independent cell death in hippocampal neuronal cells that morphologically resembles necroptosis. Toxicol Appl Pharmacol 262, 156-166.

Fukui, M., Choi, H. J., Zhu, B. T., 2010. Mechanism for the protective effect of resveratrol against oxidative stress-induced neuronal death. Free Radical Biology and Medicine 49, 800-813.

Fukui, M., Song, J., Choi, J., Choi, H. J., Zhu, B. T., 2009. Mechanism of glutamate-induced neurotoxicity in HT22 mouse hippocampal cells. Eur J Pharmacol 617, 1-11.

Fukui, M., Zhu, B. T., 2010. Mitochondrial superoxide dismutase SOD2, but not cytosolic SOD1, plays a critical role in protection against glutamate-induced oxidative stress and cell death in HT22 neuronal cells. Free Radical Biology and Medicine 48, 821-830. 
Furlan, A. J., 2012. Challenges in acute ischemic stroke clinical trials. Curr Cardiol Rep 14, 761766.

Gandolfo, C., Sandercock, P., Conti, M., 2002. Lubeluzole for acute ischaemic stroke. Cochrane Database Syst Rev (1), CD001924.

Gilgun-Sherki, Y., Rosenbaum, Z., Melamed, E., Offen, D., 2002. Antioxidant therapy in acute central nervous system injury: Current state. Pharmacol Rev 54, 271-284.

Ginsberg, M. D., 2008. Neuroprotection for ischemic stroke: Past, present and future. Neuropharmacology 55, 363-389.

Graham, S. H., Chen, J., 2001. Programmed cell death in cerebral ischemia. J Cereb Blood Flow Metab 21, 99-109.

Green, P. S., Simpkins, J. W., 2000. Neuroprotective effects of estrogens: Potential mechanisms of action. International Journal of Developmental Neuroscience 18, 347-358.

Gutteridge, J. M., 1995. Lipid peroxidation and antioxidants as biomarkers of tissue damage. Clin Chem 41, 1819-1828.

Halestrap, A. P., McStay, G. P., Clarke, S. J., 2002. The permeability transition pore complex: Another view. Biochimie 84, 153-166.

Haley, E. C.,Jr, 1998. High-dose tirilazad for acute stroke (RANTTAS II). RANTTAS II investigators. Stroke 29, 1256-1257. 
Hara, H., Ohta, M., Ohta, K., Kuno, S., Adachi, T., 2003. Increase of antioxidative potential by tert-butylhydroquinone protects against cell death associated with 6-hydroxydopamineinduced oxidative stress in neuroblastoma SH-SY5Y cells. Mol Brain Res 119, 125-131.

Haseldonckx, M., Van Reempts, J., Van de Ven, M., Wouters, L., Borgers, M., 1997. Protection with lubeluzole against delayed ischemic brain damage in rats. A quantitative histopathologic study. Stroke 28, 428-432.

Holmstrom, K. M., Baird, L., Zhang, Y., Hargreaves, I., Chalasani, A., Land, J. M., Stanyer, L., Yamamoto, M., Dinkova-Kostova, A. T., Abramov, A. Y., 2013. Nrf2 impacts cellular bioenergetics by controlling substrate availability for mitochondrial respiration. Biol Open 2, 761-770.

Hu, Y., Benedict, M. A., Ding, L., Nunez, G., 1999. Role of cytochrome c and dATP/ATP hydrolysis in apaf-1-mediated caspase-9 activation and apoptosis. EMBO J 18, 3586-3595.

Huang, H. C., Nguyen, T., Pickett, C. B., 2002. Phosphorylation of Nrf2 at ser-40 by protein kinase C regulates antioxidant response element-mediated transcription. J Biol Chem 277, $42769-42774$.

Imai, H., Masayasu, H., Dewar, D., Graham, D. I., Macrae, I. M., 2001. Ebselen protects both gray and white matter in a rodent model of focal cerebral ischemia. Stroke 32, 2149-2154.

Imlay, J. A., 2003. Pathways of oxidative damage. Annu Rev Microbiol 57, 395-418.

Immenschuh, S., Ramadori, G., 2000. Gene regulation of heme oxygenase-1 as a therapeutic target. Biochem Pharmacol 60, 1121-1128. 
Internet Stroke Center, 2007. Stroke Trials Registry.

Itoh, K., Wakabayashi, N., Katoh, Y., Ishii, T., Igarashi, K., Engel, J. D., Yamamoto, M., 1999. Keap1 represses nuclear activation of antioxidant responsive elements by Nrf2 through binding to the amino-terminal Neh2 domain. Genes Dev 13, 76-86.

Itoh, K., Tong, K. I., Yamamoto, M., 2004. Molecular mechanism activating nrf2-keap1 pathway in regulation of adaptive response to electrophiles. Free Radical Biology and Medicine 36, 1208-1213.

Jacobson, M. D., 1996. Reactive oxygen species and programmed cell death. Trends Biochem Sci 21, 83-86.

Jaiswal, A. K., 2004. Nrf2 signaling in coordinated activation of antioxidant gene expression. Free Radical Biology and Medicine 36, 1199-1207.

Janardhan, V., Qureshi, A. I., 2004. Mechanisms of ischemic brain injury. Curr Cardiol Rep 6, $117-123$.

Jin, W., Kong, J., Wang, H., Wu, J., Lu, T., Jiang, J., Ni, H., Liang, W., 2011. Protective effect of tert-butylhydroquinone on cerebral inflammatory response following traumatic brain injury in mice. Injury 42, 714-718.

Jin, W., Ni, H., Dai, Y., Wang, H., Lu, T., Wu, J., Jiang, J., Liang, W., 2010. Effects of tertbutylhydroquinone on intestinal inflammatory response and apoptosis following traumatic brain injury in mice. Mediators Inflamm 2010, 502564. 
Johnson, J. A., Johnson, D. A., Kraft, A. D., Calkins, M. J., Jakel, R. J., Vargas, M. R., Chen, P. C., 2008. The Nrf2-ARE pathway: An indicator and modulator of oxidative stress in neurodegeneration. Ann N Y Acad Sci 1147, 61-69.

Kahles, T., Luedike, P., Endres, M., Galla, H. J., Steinmetz, H., Busse, R., Neumann-Haefelin, T., Brandes, R. P., 2007. NADPH oxidase plays a central role in blood-brain barrier damage in experimental stroke. Stroke 38, 3000-3006.

Kamat, C. D., Gadal, S., Mhatre, M., Williamson, K. S., Pye, Q. N., Hensley, K., 2008. Antioxidants in central nervous system diseases: Preclinical promise and translational challenges. J Alzheimers Dis 15, 473-493.

Kang, Y., Tiziani, S., Park, G., Kaul, M., Paternostro, G., 2014. Cellular protection using Flt3 and PI3Kalpha inhibitors demonstrates multiple mechanisms of oxidative glutamate toxicity. Nat Commun 5, 3672.

Kastrup, A., Engelhorn, T., Beaulieu, C., de Crespigny, A., Moseley, M. E., 1999. Dynamics of cerebral injury, perfusion, and blood-brain barrier changes after temporary and permanent middle cerebral artery occlusion in the rat. J Neurol Sci 166, 91-99.

Kaufmann, A. M., Firlik, A. D., Fukui, M. B., Wechsler, L. R., Jungries, C. A., Yonas, H., 1999. Ischemic core and penumbra in human stroke. Stroke 30, 93-99.

Keli, S. O., Hertog, M. G., Feskens, E. J., Kromhout, D., 1996. Dietary flavonoids, antioxidant vitamins, and incidence of stroke: The zutphen study. Arch Intern Med 156, 637-642. 
Kikuchi K, Tanaka E, Murai Y and Tancharoen S (2014) Clinical trials in acute ischemic stroke. CNS Drugs 28:929-938.

Kudin, A. P., Bimpong-Buta, N. Y., Vielhaber, S., Elger, C. E., Kunz, W. S., 2004. Characterization of superoxide-producing sites in isolated brain mitochondria. J Biol Chem $279,4127-4135$.

Kuroda, S., Tsuchidate, R., Smith, M. L., Maples, K. R., Siesjo, B. K., 1999. Neuroprotective effects of a novel nitrone, NXY-059, after transient focal cerebral ischemia in the rat. J Cereb Blood Flow Metab 19, 778-787.

Landshamer, S., Hoehn, M., Barth, N. et al., 2008. Bid-induced release of AIF from mitochondria causes immediate neuronal cell death. Cell Death Differ 15, 1553-1563.

Lee, J. M., Zipfel, G. J., Choi, D. W., 1999. The changing landscape of ischaemic brain injury mechanisms. Nature 399, A7-14.

Lees, K. R., Zivin, J. A., Ashwood, T. et al., 2006. NXY-059 for acute ischemic stroke. N Engl J Med 354, 588-600.

Lemasters, J. J., Nieminen, A., Qian, T. et al., 1998. The mitochondrial permeability transition in cell death: A common mechanism in necrosis, apoptosis and autophagy. Biochimica Et Biophysica Acta (BBA) - Bioenergetics 1366, 177-196.

Lemasters, J. J., Theruvath, T. P., Zhong, Z., Nieminen, A., 2009. Mitochondrial calcium and the permeability transition in cell death. Biochimica Et Biophysica Acta (BBA) - Bioenergetics $1787,1395-1401$. 
Lesage, A. S., Peeters, L., Leysen, J. E., 1996. Lubeluzole, a novel long-term neuroprotectant, inhibits the glutamate-activated nitric oxide synthase pathway. J Pharmacol Exp Ther 279, 759-766.

Levi, M. S., Brimble, M. A., 2004. A review of neuroprotective agents. Curr Med Chem 11, 2383-2397.

Li, H., Wu, S., Wang, Z., Lin, W., Zhang, C., Huang, B., 2012. Neuroprotective effects of tertbutylhydroquinone on paraquat-induced dopaminergic cell degeneration in C57BL/6 mice and in PC12 cells. Arch Toxicol 86, 1729-1740.

Li, P., Nijhawan, D., Budihardjo, I., Srinivasula, S. M., Ahmad, M., Alnemri, E. S., Wang, X., 1997a. Cytochrome c and dATP-dependent formation of apaf-1/caspase-9 complex initiates an apoptotic protease cascade. Cell 91, 479-489.

Li, Y., Maher, P., Schubert, D., 1997b. A role for 12-lipoxygenase in nerve cell death caused by glutathione depletion. Neuron 19, 453-463.

Lin, M. T., Beal, M. F., 2006. Mitochondrial dysfunction and oxidative stress in neurodegenerative diseases. Nature 443, 787-795.

Liu, S., Shi, H., Liu, W., Furuichi, T., Timmins, G. S., Liu, K. J., 2004. Interstitial pO2 in ischemic penumbra and core are differentially affected following transient focal cerebral ischemia in rats. J Cereb Blood Flow Metab 24, 343-349.

Liu, Y., Fiskum, G., Schubert, D., 2002. Generation of reactive oxygen species by the mitochondrial electron transport chain. J Neurochem 80, 780-787. 
Liu, Y., Schubert, D. R., 2009. The specificity of neuroprotection by antioxidants. J Biomed Sci 16, 98-0127-16-98.

Lu, X., Wang, H., Xu, J., Ding, K., Li, T., 2014. Pretreatment with tert-butylhydroquinone attenuates cerebral oxidative stress in mice after traumatic brain injury. J Surg Res 188, 206212.

Malhotra, D., Portales-Casamar, E., Singh, A. et al., 2010. Global mapping of binding sites for Nrf2 identifies novel targets in cell survival response through ChIP-seq profiling and network analysis. Nucleic Acids Res 38, 5718-5734.

Manzanero, S., Santro, T., Arumugam, T. V., 2013. Neuronal oxidative stress in acute ischemic stroke: Sources and contribution to cell injury. Neurochem Int 62, 712-718.

Margaill, I., Plotkine, M., Lerouet, D., 2005. Antioxidant strategies in the treatment of stroke. Free Radical Biology and Medicine 39, 429-443.

Marshall, J. W., Duffin, K. J., Green, A. R., Ridley, R. M., 2001. NXY-059, a free radical-trapping agent, substantially lessens the functional disability resulting from cerebral ischemia in a primate species. Stroke 32, 190-198.

Mattson, M. P., Chan, S. L., 2003. Calcium orchestrates apoptosis. Nat Cell Biol 5, 1041-1043.

McCord, J. M., 2000. The evolution of free radicals and oxidative stress. Am J Med 108, 652659.

Meister, A., Anderson, M. E., 1983. Glutathione. Annu Rev Biochem 52, 711-760. 
Melov, S., 2000. Mitochondrial oxidative stress. physiologic consequences and potential for a role in aging. Ann N Y Acad Sci 908, 219-225.

Miao, L., St. Clair, D. K., 2009. Regulation of superoxide dismutase genes: Implications in disease. Free Radical Biology and Medicine 47, 344-356.

Miller, D. J., Simpson, J. R., Silver, B., 2011. Safety of thrombolysis in acute ischemic stroke: A review of complications, risk factors, and newer technologies. Neurohospitalist 1, 138-147.

Mitchell, P., 1966. Chemiosmotic coupling in oxidative and photosynthetic phosphorylation. Biol Rev Camb Philos Soc 41, 445-502.

Moosmann, B., Behl, C., 2002. Antioxidants as treatment for neurodegenerative disorders. Expert Opin Investig Drugs 11, 1407-1435.

Muir, K. W., 2002. Heterogeneity of stroke pathophysiology and neuroprotective clinical trial design. Stroke 33, 1545-1550.

Mukhopadhyay, P., Rajesh, M., Hasko, G., Hawkins, B. J., Madesh, M., Pacher, P., 2007. Simultaneous detection of apoptosis and mitochondrial superoxide production in live cells by flow cytometry and confocal microscopy. Nat Protoc 2, 2295-2301.

National Toxicology Program, 1997. NTP toxicology and carcinogenesis studies of tbutylhydroquinone (CAS no. 1948-33-0) in F344/N rats and B6C3F(1) mice (feed studies). Natl Toxicol Program Tech Rep Ser 459, 1-326.

Nedergaard, M., Dirnagl, U., 2005. Role of glial cells in cerebral ischemia. Glia 50, 281-286. 
Nicholls, D. G., 2004. Mitochondrial membrane potential and aging. Aging Cell 3, 35-40.

Niizuma, K., Endo, H., Chan, P. H., 2009. Oxidative stress and mitochondrial dysfunction as determinants of ischemic neuronal death and survival. J Neurochem 109 Suppl 1, 133-138.

Nouhi, F., Tusi, S. K., Abdi, A., Khodagholi, F., 2011. Dietary supplementation with tBHQ, an Nrf2 stabilizer molecule, confers neuroprotection against apoptosis in amyloid beta-injected rat. Neurochem Res 36, 870-878.

Ogawa, A., Yoshimoto, T., Kikuchi, H., Sano, K., Saito, I., Yamaguchi, T., Yasuhara, H., 1999. Ebselen in acute middle cerebral artery occlusion: A placebo-controlled, double-blind clinical trial. Cerebrovasc Dis 9, 112-118.

Olanow, C. W., 1993. A radical hypothesis for neurodegeneration. Trends Neurosci 16, 439-444.

Olmez, I., Ozyurt, H., 2012. Reactive oxygen species and ischemic cerebrovascular disease. Neurochem Int 60, 208-212.

Orrenius, S., Zhivotovsky, B., Nicotera, P., 2003. Regulation of cell death: The calciumapoptosis link. Nat Rev Mol Cell Biol 4, 552-565.

Ott, M., Gogvadze, V., Orrenius, S., Zhivotovsky, B., 2007. Mitochondria, oxidative stress and cell death. Apoptosis 12, 913-922.

Panee, J., Liu, W., Nakamura, K., Berry, M. J., 2007. The responses of HT22 cells to the blockade of mitochondrial complexes and potential protective effect of selenium supplementation. Int J Biol Sci 3, 335-341. 
Pardridge, W. M., Connor, J. D., Crawford, I. L., 1975. Permeability changes in the blood-brain barrier: Causes and consequences. CRC Crit Rev Toxicol 3, 159-199.

Peters, O., Back, T., Lindauer, U., Busch, C., Megow, D., Dreier, J., Dirnagl, U., 1998. Increased formation of reactive oxygen species after permanent and reversible middle cerebral artery occlusion in the rat. J Cereb Blood Flow Metab 18, 196-205.

Pfeiffer, A., Jaeckel, M., Lewerenz, J. et al., 2014. Mitochondrial function and energy metabolism in neuronal HT22 cells resistant to oxidative stress. Br J Pharmacol 171, 2147 2158.

Piantadosi, C. A., Carraway, M. S., Babiker, A., Suliman, H. B., 2008. Heme oxygenase-1 regulates cardiac mitochondrial biogenesis via Nrf2-mediated transcriptional control of nuclear respiratory factor-1. Circ Res 103, 1232-1240.

Poteet, E., Winters, A., Yan, L. J., Shufelt, K., Green, K. N., Simpkins, J. W., Wen, Y., Yang, S. H., 2012. Neuroprotective actions of methylene blue and its derivatives. PLoS One 7, e48279.

Raichle, M. E., 2010. Two views of brain function. Trends Cogn Sci (Regul Ed ) 14, 180-190.

Ray, P. D., Huang, B., Tsuji, Y., 2012. Reactive oxygen species (ROS) homeostasis and redox regulation in cellular signaling. Cell Signal 24, 981-990.

Rice, M. E., 2000. Ascorbate regulation and its neuroprotective role in the brain. Trends Neurosci 23, 209-216. 
Richter, C., Kass, G. E. N., 1991. Oxidative stress in mitochondria: Its relationship to cellular $\mathrm{Ca} 2+$ homeostasis, cell death, proliferation, and differentiation. Chem Biol Interact 77, 1-23.

Rizzuto, R., De Stefani, D., Raffaello, A., Mammucari, C., 2012. Mitochondria as sensors and regulators of calcium signalling. Nat Rev Mol Cell Biol 13, 566-578.

Robinson, K. M., Janes, M. S., Beckman, J. S., 2008. The selective detection of mitochondrial superoxide by live cell imaging. Nat Protoc 3, 941-947.

Roger, V. L., Go, A. S., Lloyd-Jones, D. M. et al., 2012. Executive summary: Heart disease and stroke statistics--2012 update: A report from the american heart association. Circulation 125, 188-197.

Rössler, O. G., Bauer, I., Chung, H., Thiel, G., 2004. Glutamate-induced cell death of immortalized murine hippocampal neurons: Neuroprotective activity of heme oxygenase-1, heat shock protein 70, and sodium selenite. Neurosci Lett 362, 253-257.

Rubin, L. L., Staddon, J. M., 1999. The cell biology of the blood-brain barrier. Annu Rev Neurosci 22, 11-28.

Satoh, T., Baba, M., Nakatsuka, D., Ishikawa, Y., Aburatani, H., Furuta, K., Ishikawa, T., Hatanaka, H., Suzuki, M., Watanabe, Y., 2003. Role of heme oxygenase-1 protein in the neuroprotective effects of cyclopentenone prostaglandin derivatives under oxidative stress. Eur J Neurosci 17, 2249-2255. 
Satoh, T., Okamoto, S. I., Cui, J., Watanabe, Y., Furuta, K., Suzuki, M., Tohyama, K., Lipton, S. A., 2006. Activation of the Keap1/Nrf2 pathway for neuroprotection by electrophilic [correction of electrophillic] phase II inducers. Proc Natl Acad Sci U S A 103, 768-773.

Saykally, J. N., Rachmany, L., Hatic, H., Shaer, A., Rubovitch, V., Pick, C. G., Citron, B. A., 2012. The nuclear factor erythroid 2-like 2 activator, tert-butylhydroquinone, improves cognitive performance in mice after mild traumatic brain injury. Neuroscience 223, 305-314.

Schoknecht, K., David, Y., Heinemann, U., 2015. The blood-brain barrier-Gatekeeper to neuronal homeostasis: Clinical implications in the setting of stroke. Semin Cell Dev Biol 38, $35-42$.

Sena, E., Wheble, P., Sandercock, P., Macleod, M., 2007. Systematic review and meta-analysis of the efficacy of tirilazad in experimental stroke. Stroke 38, 388-394.

Serebruany, V. L., 2006. Hypokalemia, cardiac failure, and reporting NXY-059 safety for acute stroke. J Cardiovasc Pharmacol Ther 11, 229-231.

Shahidi F., 2000. Antioxidants in food and food antioxidants. Nahrung 44:158-163.

Shih, A. Y., Li, P., Murphy, T. H., 2005. A small-molecule-inducible Nrf2-mediated antioxidant response provides effective prophylaxis against cerebral ischemia in vivo. J Neurosci 25 , 10321-10335.

Shohami, E., Beit-Yannai, E., Horowitz, M., Kohen, R., 1997. Oxidative stress in closed-head injury: Brain antioxidant capacity as an indicator of functional outcome. J Cereb Blood Flow Metab 17, 1007-1019. 
Shuaib, A., Lees, K. R., Lyden, P. et al., 2007. NXY-059 for the treatment of acute ischemic stroke. N Engl J Med 357, 562-571.

Small, D. L., Buchan, A. M., 2000. Animal models. Br Med Bull 56, 307-317.

Sims, N. R., Anderson, M. F., 2002. Mitochondrial contributions to tissue damage in stroke. Neurochem Int 40, 511-526.

Smith, E. E., Abdullah, A. R., Petkovska, I., Rosenthal, E., Koroshetz, W. J., Schwamm, L. H., 2005. Poor outcomes in patients who do not receive intravenous tissue plasminogen activator because of mild or improving ischemic stroke. Stroke 36, 2497-2499.

Smith, M. A., Schnellmann, R. G., 2012. Calpains, mitochondria, and apoptosis. Cardiovasc Res $96,32-37$.

Son, Y., Byun, S. J., Pae, H. O., 2013. Involvement of heme oxygenase-1 expression in neuroprotection by piceatannol, a natural analog and a metabolite of resveratrol, against glutamate-mediated oxidative injury in HT22 neuronal cells. Amino Acids 45, 393-401.

Starkov, A. A., 2008. The role of mitochondria in reactive oxygen species metabolism and signaling. Ann N Y Acad Sci 1147, 37-52.

Stocker, R., Yamamoto, Y., McDonagh, A. F., Glazer, A. N., Ames, B. N., 1987. Bilirubin is an antioxidant of possible physiological importance. Science 235, 1043-1046.

Su, K., Bourdette, D., Forte, M., 2013. Mitochondrial dysfunction and neurodegeneration in multiple sclerosis. Front Physiol 4, 169. 
Sun, J., Ren, X., Simpkins, J. W., 2015. Sequential upregulation of superoxide dismutase 2 and heme oxygenase 1 by tert-butylhydroquinone protects mitochondria during oxidative stress. Mol Pharmacol 88, 437-449.

Susin, S. A., Lorenzo, H. K., Zamzami, N. et al., 1999. Molecular characterization of mitochondrial apoptosis-inducing factor. Nature 397, 441-446.

Sutherland, B. A., Minnerup, J., Balami, J. S., Arba, F., Buchan, A. M., Kleinschnitz, C., 2012. Neuroprotection for ischaemic stroke: Translation from the bench to the bedside. Int $\mathbf{J}$ Stroke 7, 407-418.

Takasago, T., Peters, E. E., Graham, D. I., Masayasu, H., Macrae, I. M., 1997. Neuroprotective efficacy of ebselen, an anti-oxidant with anti-inflammatory actions, in a rodent model of permanent middle cerebral artery occlusion. Br J Pharmacol 122, 1251-1256.

Tan, S., Sagara, Y., Liu, Y., Maher, P., Schubert, D., 1998. The regulation of reactive oxygen species production during programmed cell death. J Cell Biol 141, 1423-1432.

Tirilazad mesylate in acute ischemic stroke: A systematic review. tirilazad international steering committee.2000. Stroke 31, 2257-2265.

Tobaben, S., Grohm, J., Seiler, A., Conrad, M., Plesnila, N., Culmsee, C., 2011. Bid-mediated mitochondrial damage is a key mechanism in glutamate-induced oxidative stress and AIFdependent cell death in immortalized HT-22 hippocampal neurons. Cell Death Differ 18, 282-292. 
Toyoda, K., Fujii, K., Kamouchi, M., Nakane, H., Arihiro, S., Okada, Y., Ibayashi, S., Iida, M., 2004. Free radical scavenger, edaravone, in stroke with internal carotid artery occlusion. J Neurol Sci 221, 11-17.

Turrens, J. F., 2003. Mitochondrial formation of reactive oxygen species. J Physiol 552, 335-344.

Valko, M., Leibfritz, D., Moncol, J., Cronin, M. T. D., Mazur, M., Telser, J., 2007. Free radicals and antioxidants in normal physiological functions and human disease. Int $\mathrm{J}$ Biochem Cell Biol 39, 44-84.

van der Worp, H. B., Kappelle, L. J., Algra, A., Bar, P. R., Orgogozo, J. M., Ringelstein, E. B., Bath, P. M., van Gijn, J., TESS Investigators, TESS II Investigators, 2002. The effect of tirilazad mesylate on infarct volume of patients with acute ischemic stroke. Neurology 58, $133-135$.

van Esch, G. J., 1986. Toxicology of tert-butylhydroquinone (TBHQ). Food and Chemical Toxicology 24, 1063-1065.

van Leyen, K., Siddiq, A., Ratan, R. R., Lo, E. H., 2005. Proteasome inhibition protects HT22 neuronal cells from oxidative glutamate toxicity. J Neurochem 92, 824-830.

Uttara, B., Singh, A. V., Zamboni, P., Mahajan, R. T., 2009. Oxidative stress and neurodegenerative diseases: A review of upstream and downstream antioxidant therapeutic options. Curr Neuropharmacol 7, 65-74. 
Wang, X., Tsuji, K., Lee, S. R., Ning, M., Furie, K. L., Buchan, A. M., Lo, E. H., 2004. Mechanisms of hemorrhagic transformation after tissue plasminogen activator reperfusion therapy for ischemic stroke. Stroke 35, 2726-2730.

Watanabe, T., Yuki, S., Egawa, M., Nishi, H., 1994. Protective effects of MCI-186 on cerebral ischemia: Possible involvement of free radical scavenging and antioxidant actions. $\mathbf{J}$ Pharmacol Exp Ther 268, 1597-1604.

Weir, N. U., Dennis, M. S., 1997. Meeting the challenge of stroke. Scott Med J 42, 145-147.

White, B. C., Sullivan, J. M., DeGracia, D. J., O’Neil, B. J., Neumar, R. W., Grossman, L. I., Rafols, J. A., Krause, G. S., 2000. Brain ischemia and reperfusion: Molecular mechanisms of neuronal injury. J Neurol Sci 179, 1-33.

Wu, K. C., Cui, J. Y., Klaassen, C. D., 2011. Beneficial role of Nrf2 in regulating NADPH generation and consumption. Toxicol Sci 123, 590-600.

Yamaguchi, T., Sano, K., Takakura, K., Saito, I., Shinohara, Y., Asano, T., Yasuhara, H., 1998. Ebselen in acute ischemic stroke: A placebo-controlled, double-blind clinical trial. ebselen study group. Stroke 29, 12-17.

Yan, D., Dong, J., Sulik, K. K., Chen, S., 2010. Induction of the Nrf2-driven antioxidant response by tert-butylhydroquinone prevents ethanol-induced apoptosis in cranial neural crest cells. Biochem Pharmacol 80, 144-149.

Yang, Y., Rosenberg, G. A., 2011. Blood-brain barrier breakdown in acute and chronic cerebrovascular disease. Stroke 42, 3323-3328. 
Yang, Y., Herrup, K., 2007. Cell division in the CNS: Protective response or lethal event in postmitotic neurons? Biochimica Et Biophysica Acta (BBA) - Molecular Basis of Disease 1772, 457-466.

Yu, R., Tan, T. H., Kong, A. N., 1997. Butylated hydroxyanisole and its metabolite tertbutylhydroquinone differentially regulate mitogen-activated protein kinases. the role of oxidative stress in the activation of mitogen-activated protein kinases by phenolic antioxidants. J Biol Chem 272, 28962-28970.

Zhang, N., Komine-Kobayashi, M., Tanaka, R., Liu, M., Mizuno, Y., Urabe, T., 2005. Edaravone reduces early accumulation of oxidative products and sequential inflammatory responses after transient focal ischemia in mice brain. Stroke 36, 2220-2225.

Zhang, Y., Bhavnani, B. R., 2006. Glutamate-induced apoptosis in neuronal cells is mediated via caspase-dependent and independent mechanisms involving calpain and caspase-3 proteases as well as apoptosis inducing factor (AIF) and this process is inhibited by equine estrogens. BMC Neurosci 7, 49. 